(Aus der medizinischen Klinik der Universität Heidelberg.)

\title{
Über \\ die „osmotischen Eigenschaften“ der Nieren ${ }^{1)}$.
}

Von

\section{Dr. Richard Siebeck,}

Assistent der Klinik.

(Mit 2 Textfiguren.)

\section{Einleitung.}

Durch die Nieren werden Wasser und im Blut gelöste Stoffe, vor allem Salze ausgeschieden. Die Nierenzellen nehmen dauernd Salze aus dem Blute auf und scheiden sie in die Harnkanälchen aus. Die Bedingungen der Salzaufnahme und -abgabe haben daher eine grosse Bedeutung für das Verständnis der Nierenfunktion. Ausserdem erscheint es interessant, den Mechanismus dieser Vorgänge gerade an solchen Zellen zu untersuchen, die während des Lebens dauernd Salze aufnehmen und abgeben.

Ich möchte hier nun kurz besprechen, was ganz allgemein über Stoffaufuahme und -abgabe von Zellen bekannt ist, und wie die Erscheinungen gedeutet werden ${ }^{2}$ ). Denn nur auf dieser Grundlage können spezifische Eigenschaften der Nierenzellen untersucht werden.

Aus zahlreichen Untersuchungen ${ }^{3}$ ), vor allem von 0 verton,

1) Die Resultate der Arbeit wurden teilweise auf dem 29. Kongress für innere Medizin 1912 vorgetragen.

2) Es soll hier nur gezeigt werden, von welchen Grundlagen ich ausging. Es ist natürlich keine erschöpfende, kritische Darstellung beabsichtigt.

3) 1. Untersuchungen an Muskeln: Nasse, Pflüger's Arch. Bd. 2 S. 97. 1869. Jacques Loeb; Pflüger's Arch. Bd. 56 S. 270. 1894; Bd. 69 S. 1. 1898; Bd. 71 S. 457. 1898. E. Cooke, Journ. of Physiol. vol. 23 p. 137. 1898. Vor allem Overton, Pflüger's Arch. Bd. 92 S. 115 u. 346. 1902; Bd. 105 S. 176. 1904. - 2. Untersuchungen an roten Blutkörperchen: Hamburger, Arch. f. (Anat. u.) Physiol. 1886 S. 476, 1887 S. 31 . Overton, 
ist bekannt, dass unversehrte Zellen verschiedenster Art aus dem Pflanzen- und Tierreiche in isotonischen Lösungen ganz verschiedener St offe, wie z. B. Kochsalz, Natriumsulfat, Lithiumbromid, Traubenzucker usw., im Wassergleichgewicht sind, in verdünnteren Lösungen aber Wasser aufnehmen und in konzentrierteren Wasser abgeben. Dies Verhalten erinnert unmittelbar an das eines osmotischen Systems und führt so zu der Vorstellung, dass eine Phase in der Zelle einer verdünnten wäsşerigen Lösung entsprechende Eigenschaften hat, und dass diese Phase durch eine andere, für gewisse gelöste Stoffe undurchlässige Plase begrenzt wird.

Overton fasste die Ergebnisse seiner Untersuchungen und der Untersuchungen anderer Autoren in dem Satze zusammen, dass in "osmotischen Versuchen" vor allem anorganische Neutralsalze, Zucker, Aminosäuren u. a. nicht in le b e n d e Zellen eindringen, während Stoffe, die sich in organischen Lösungsmitteln wie einwertigen Alkoholen höheren Molekulargewichts, Äther, Benzol und fetten Ölen, leicht lösen, „lipoidlösliche“ Stoffe, leicht von Zellen aufgenommen werden. Zur Erklärung dieser eigentümlichen Durchlässigkeitsverhältnisse stellt 0 verton im Auschluss an die Nernstsche Erklärung der Permeabilität einer Membran die Theorie auf, dass die Grenzschicht der Zellen, die sogenannte Plasmahaut, durch Stoffe von ähnlichem Lösungsvermögeu wie jene organischen Lösungsmittel imprägniert sei. Vor allem denkt er dabei an Lecithin und Cholosterin.

Die Overton'sche "Lipoidtheorie" hat sich ohne Zweifel für viele Untersuchungen als nützlich erwiesen. Andererseits lässt sie zahlreiche wichtige Erscheinungen unerklärt. Vor allem ist nicht ohne weiteres zu verstehen, dass Wasser ausserordentlich leicht von Zellen aufgenommen und abgegeben wird. Overton sucht die

Vierteljahrsschr. d. naturforsch. Gesellsch. in Zürich. 40. Jahrg. S. 1. 1895. Gryns, Pflüger's Arch. Bd. 63 S. 86. 1896. Hedin, Skandinav. Arch. f. Physiol. Bd. 2 S. 134 u. 360. 1891; Pflüger's Arch. Bd. 68 S. 229. 1897; Bd. 70 S. 525 . - 3. Untersuchungen über Hautepithelien der Amphibien: Overton, Verhandl. der phys.-med. Gesellsch. N. F. Bd. 36 S. 277. Würzburg 1904. Zusammenfassende Darstellungen: Overton, Üher den Mechanismus der Resorption und Sekretion in Nagel's Handb. d. Physiol. Bd. 2 und Höber, Physik. Chemie dər Zelle und Gewebe, 3. Aufl., 1911, Kap. 6, 7 und 18. 
Permeabilität für Wasser durch die "Quellbarkeit" der Zelllipoide zu. erklären, aber dadurch entstehen neue Schwierigkeiten; denn nach $\mathrm{Nath}$ a $\operatorname{son}^{1}$ ) scheint das spezifische Lösungsvermögen der Lipoide durch Quellung wesentlich verändert zu werden.

Ausserdem spielt bei physiologischen Vorgängen gerade die Aufnahme lipoidunlöslicher Stoffe (Salze, Zucker, Aminosäuren usw.) eine grosse Rolle. Overton hat daher von der rein "passiven“ Durchlässigkeit, für die allein sein Gesetz gelte, eine „aktive" unterschieden, bei der das Protoplasma in irgendeiner Weise aktiv beteiligt sei. Freilich ist damit keine Erklärung dieser Vorgänge gegeben.

Dass die Lipoidtheorie die wichtigsten physiologischen Vorgänge unerklärt liesse, das wurde nun auch stets gegen die Overtonschen Anschauungen angefübrt.

Vor allem hat Jacques $L_{0 e b^{2}}$ ) seinen Untersuchungen die Annahme zugrunde gelegt, dass Salze in die Zellen und aus denselben frei diffundieren. $\mathrm{Zu}$ dieser Annahme ist $\mathrm{Jacques} \mathrm{Loeb}$ wohl in erster Linie durch die Beobachtung gekommen, dass die Entwicklungsvorgänge im Seeigelei durch umspülende Salzlösungen beeiuflusst werden. Seit aber Warburg ${ }^{3}$ ) gezeigt hat, dass Ionen, ohne in die Eizelle einzudringen, nur von der Oberfäche aus auf die Eutwicklungsvorgänge einwirken können, kann aus diesen Erscheinungen nicht mehr auf eine Durchlässigkeit der Zellen für Salze geschlossen werden.

Nimmt man aber an, die Zellen würden Salze ohne Widerstand aufnehmen und abgeben, so lässt sich zunächst nicht verstehen, dass der Wassergehalt der Zellen vom osmotischen Drucke der umgebenden Lösung abhängig ist. Jacques L o eb erklärt nun diese osmotischen Erscheinungen mit $\mathrm{Ha} \mathrm{mburger}{ }^{4}$ ) durch die Annahme, dass Wasser viel rascher in die und aus den Zellen diffundiere als Salze. Es wird damit wenigstens ein gewisses Diffusionshindernis für Salze angenommen.

Ferner ist bekannt, dass die Zellen tierischer Gewebe einen

1) Nathan s o n, Jahrb. f. wissensch. Bot. Bd. 39 S. 607. 1904.

2) Eine Zusammenfassung der Arbeiten Jacques Loeb's findet sich in seinem Artikel „Über physiologische Ionenwirkungen" in Oppenheimer's Handb. der Biochem. Bd. 2 H. 1 S. 105. 1910. (Litt.)

3) Warburg, Zeitschr. f. physiol. Chemie Bd. 66 S. 305.1910.

4) H amburger, Osmotischer Druck und Ionenlehre. Wiesbaden 1902. 
anderen Salzgehalt haben als das sie umspülęude Serum. U ran $0^{1}$ ) und $\mathrm{Fahr}{ }^{2}$ ) baben z. B. in äusserst sorgfältigen Versuchen gezeigt, dass Muskelzellen kein oder fast kein Natrium enthalten, während im Serum der Gehalt an Natrium den an anderen Kationen doch überwiegt. Um diese Tatsache ohne Annahme einer gewissen Salzundurchlässigkeit der Zellen zu erklären, wurde besonders von Jacques Loeb, Pa u li, Ha m burger und anderen ${ }^{3}$ ) die Hypothese aufgestellt, dass die Salze in den Zellen nicht in "freiem Zustande" enthalten, sondern in Form schwer dissoziabler organischer Verbindungen (sogenannter „Ionenproteide") festgelegt wären.

Es muss aber ausdrücklich betont werden, dass die Existenz solcher Ionenproteide ganz unbewiesen ist. Über den Zustand der Salze im Innern der Zellen ist freilich überhaupt nichts bekaunt ${ }^{4}$ ). Man weiss eben nur, dass die Zellen mit verschiedenen Lösungen von gauz bestimmtem osmotischen Drucke im Wassergleichgewicht sind.

Es wurde nun auch versucht, das Wassergleichgewicht der Zellen unabhängig rom osmotischen Druck der umgebenden Lösung zu erklären. Besonders nachdrücklich hat M. H. Fischer ${ }^{5}$ ) aus der Schule Jacques Loeb's die Anschaung vertreten, dass für das Wassergleichgewicht der Zellen nur (oder ganz überwiegend) der Zustand der Kolloide massgebend sei. Wasseraufnahme und -abgabe beruhen auf Quellung und Entquellung der Kolloide in den Zellen. Diese Anschauung sucht M. H. Fischer durch Versuche zu beweisen, in denen Muskeln nach ähnlichen Regeln quellen, wie Fibrin oder Gelatine. In diesen Versuchen kann aber von intakten Organen nicht die Rede $\operatorname{sein}^{6}$ ). In den angewandten Lösungen, wie

1) Urano, Zeitschr. f. Biol. Bd. 50 S. 212. 1908, und Bd. 51 S. 483.1908.

2) Fahr, Zeitschr. f. Biol. Bd. 52 S. 72. 1909.

3) Vgl. darüber Brailsford Robertson, Ergebn. der Physiol. Bd. 10 S. 216. 1910. (Litt.) - Jacques Loeb, l. c. und Vorlesungen über Dynamik der Lebenserscheinungen. Leipzig 1906. - Pauli, Kolloidzeitschr. Bd. 3 S. 2. 1908; Hofmeister's Beitr. Bd. 10 S. 53. 1907; Biochem. Zeitschr. Bd. 18 S. 340. 1909, u. Bd. 24 S. 239. 1910; Pflüger's Arch. Bd. 136 S. 483.1910. Ferner auch Hamburger, Osmotischer Druck und Innenlehre.

4) Die Versuche Höber's (Pflüger's Arch. Bd. 133 S. 237. 1910; ferner Zentralbl. f. Physiol. Bd. 24 S. 801 u. 830. 1910), die "innere Leitfähigkeit" von Zellen zu bestimmen, geben bis jetzt nur grobe Ausschläge,

5) M. H. Fischer, Pflüger's Arch. Bd. 124 S. 69. 1908; ferner: Das Ödem. Dresden 1910.

6) Fischer spricht selbst davon, dass sich die Muskeln zuweilen auflösen. 
1/110 n. Salzsäure und dergleichen, werden Muskeln in kurzer Zeit abgetötet, und Overton hat seit Jahren auf Grund zablreicher Erfahrungen ausdrücklich betont, dass sich die „osmotischen Eigenschaften" der Zellen mit ihrem Absterben rasch ändern. Die Versuche M. H. Fischer's sind also für die Erklärung der Wasseraufnahme durch intakte Zellen nicht zu verwerten ${ }^{1}$ ). So ist denn auch in letzter Zeit aus dem Institut von Jacques Loeb eine Arbeit von Be utu er ${ }^{2}$ ) erschienen, die die osmotischer Vorstellungen, wie sie gerade $O$ verton stets vertreten hat, vollkommen rechtfertigt.

Dass aus einer umspülenden Lösung verschiedene Stoffe sehr verschieden rasch von den Zellen aufgenommen werden, ergibt sich zweifellos aus sehr vielen Beobachtungen. Overton uahm nun, wie erwähnt, an, dass die Stoffe um so leichter in Zellen eindringen, je mehr die Löslichkeit in Lipoiden die in Wasser überwiege (je grösser der Teilungskoeffizieut $\left[\frac{\text { Oel }}{\mathrm{W}} \overline{\text { asser }}\right]$ sei). Ausser den osmotischen Versuchen fübrte Overton Beobachtungen an, die dafür sprachen, dass solche Farbstoffe vital färben, also in lebende Zellen eindringen, die "lipoidlöslich" sind. Bei einer eingehenderen Untersuchung haben sich allerdings zahlreiche Ausnahmen von dieser Regel ergeben ${ }^{3}$ ).

J. $\mathrm{Tr}_{a} \mathrm{ube}^{4}$ ) konnte nun zeigen, dass alle die Stoffe, die nach Overton leicht in Zellen eindringen, die Oberflächenspannung des Wassers erniedrigen; die Stoffe, die nicht in Zellen einzudringen vermögen, dagegen die Oberflächenspannung des Wassers erhöhen. Nun werden nach dem Gibbs-Thomson'schen Theorem gerade solche gelöste Stoffe an der Oberfläche der Lösung angehäuft, die die Oberflächenspannung des Lösungsmittels herabsetzen. Traube drückt das so aus: Je mehr ein gelöster Stoff die Oberflächen-

1) Das gleiche gilt von den Versuchen von Pinkus s ohn, Zeitschr. f. exper. Path. u. Pharm. Bd. 10 S. 308. 1912.

2) Biochem. Zeitschr. Bd. 39 S. 280. 1912; ferner Meigs Amer. Journ. of Physiol. vol. 26. 1911. - Moore, Pflüger's Arch. Bd. 147 S. 28.1912.

3) Vor allem Ruhland, Jahrb. f, wissensch. Bot. Bd. 46 S. 1. 1908, und Biochem. Zeitschr. Bd. 22 S. 409. 1909. - Ferner Höber, Biochem. Zeitschr. Bd. 20 S. 56. 1909. - A. Garmus, Zeitschr. f. Biol. Bd. 58 S. 185.1912 (unter A sher).

4) J. Traube, Pflüger's Arch. Bd. 105 S. 541 u. 559. 1904; Bd. 123 S. 419. 1908; Bd. 132 S. 511. 1910; Bd. 140 S. 109.1911. 
spannung des Lösungsmittels herabsetzt, desto geringer ist sein Bestreben, in der Lösung zu bleiben, desto geringer ist sein "Haftdruck ". Je geringer der Haftdruck, um so leichter wird der Stoff aus der Lösung entweichen und in eine andere Phase eindringen. Durch diese Anschauung glaubt Traube zu erklären, dass die Stoffe, die die Oberflächenspannung des Wassers herabsetzen, also einen geringen "Haftdruck" in der Lösung haben, leicht in Zellen eindringen.

Aber abgesehen davon, dass mit der Ansammlung eines Stoffes an der Oberfläche der Lösung das Eindringen in eine andere Phase, in die Zelle, noch nicht erklärt ist, sind zahlreiche Tatsachen mit dieser Anschauung nicht ohne weiteres zu verstehen, z. B. das Wassergleichgewicht von Zellen in isotonischen Lösungen ganz verschiedener Stoffe, in Lösungsgemischen ${ }^{1}$ ). Tra ube hat dann auch seine Theorie teilweise geändert und vor allem den Eigenschaften der Grenzschicht der Zellen mehr Rechnung getragen ${ }^{2}$ ).

Wenn nun auch die Stoffaufnahme der Zellen durch die Traubeschen Anschauungen kaum erklärt werden kann, so ist doch der anscheinend weitgehende Parallelismus zwischen Oberflächenaktivität und Eindringungsvermögen bzw. Lipoidlöslichkeit von grossem Interesse.

Es sei hier noch eine Untersuchung von $\mathrm{Czapek}^{8}$ ) erwähnt, nach der alle wasserlöslichen und oberflächenaktiven Stoffe auf die Exosmose von Inhaltsstoffen lebender Pflanzenzellen in solchen Konzentrationen zu wirken beginnen, die die Oberflächenspannung des Wassers um einen bestimmten, gleichen Bruchteil herabsetzen. Die Exosmose ist allerdings ein irreversibler Vorgang.

In einer kürzlich erschienenen Arbeit hat S. Loewe ${ }^{4}$ ) die physikalisch-chemischen Grundlagen der "Lipoidtheorie" Overtons einer sehr eingehenden Untersuchung und Kritik unterzogen. Danach

1) Vor allem auch das Verhalten zweier durch verschiedene Membranen getrennter Lösungen.

2) Interessant scheint mir, wenn Traube als einen Vorzug seiner Theorie anführt, dass sie die Annahme ermögliche, dass irgendeine (beliebige) Zellenmembran durch Adsorption zu einer lipoidartigen Membran werden könne. Pflüger's Arch. Bd. 123 S. 423. Das führt doch eben auf die Grundidee Overton's zurück.

3) Czapek, Über eine Methode zur direkten Bestimmung der Oberflächenspanpung der Plasmahaut von Pflanzenzellen. Jena 1911.

4) S. Loew e, Biochem. Zeitschr. Bd. 42 S. 150. 1912. 
ist die Aufnahme von in Wasser gelösten Substanzen (z. B. Farbstoffen, Narkotika) durch Lipoide nicht als Lösung sondern als Adsorption anzusehen.

Ein abschliessendes Urteil über die verschiedenen Versucbe, die Erscheinungen zu erklären, ist nicht möglich. Von den Beobachtungen möchte ich als wichtigste Ergebnisse hervorheben: für das Wassergleichgewicht der Zellen ist weitgehend der osmotische Druck der umgebenden Lösung massgebend. Während "lipoidlösliche" Stoffe fast durchweg sehr leicht in die Zellen diffundieren, sind die Bedingungen, unter denen andere Stoffe, z. B. Salze, von Zellen aufgenommen werden, augenblicklich nicht klar.

Es ist nun noch kurz zu besprechen, was über die speziellen Verhältnisse an Nierenzellen bekannt ist.

Gurwitseh ${ }^{1}$ ) hat zuerst darauf hingewiesen, dass Zellen der Froschnieren lipoidunlösliche Farbstoffe (indigschwefelsaures Natron, Kongorot und wasserlösliches Anilinblau) aufnehmen. Diese Farbstoffe werden nach Einführung in den Mund oder Rückenlymphsack lebender Frösche in den Vakuolen der Zellen des sogenannten zweiten Abschnittes aufgespeichert gefunden.

Im Anschlusse daran hat $\mathrm{Höb}$ e ${ }^{2}$ ) diese Verbältnisse eingehend untersucht; er kam zu dem Ergebnis, dass die Nierenepithelien des Frosches und anscheinend auch der Säugetiere solche Farbstoffe aufnehmen können, die nicht kolloidal gelöst sind oder bestimmte kolloidale Eigenschaften haben (hydrophil-kolloidal). Eine bestimmte Erklärung dieser Beobachtungen ist noch nicht möglich.

Schliesslich sei noch erwähnt, dass Filehne und Biberfeld ${ }^{3}$ ) Versuche mitteilen, in denen Rindenstückchen von Kaninchennieren aus einer 1,2-1,5\% igen, Stückchen von Nierenmark sogar aus einer 2,5\% igen Kochsalzlösung Wasser aufgenommen haben. Hirokawa $\mathbf{a}^{4}$ ) fand die Nierenrinde verschiedener Warmblüter ziemlich konstant mit $1-2 \%$ iger Kochsalzlösung, das Nierenmark dagegen mit konzentrierteren Lösungen im Gleichgewicht. Aus den Untersuchungen von $\mathrm{Hirokawa}$ geht hervor, dass in derartigen

1) Gurwitsch, Pflüger's Arch. Bd. 91 S. 71. 1902.

2) Höber und Königsberg, Pflüger's Arch. Bd. 108 S. 323. 1905, und Höber, Biochem. Zeitschr. Bd. 20 S. 56. 1909.

3) Filehne und Biberfeld, Pfläger's Arch. Bd. 91 S. 569. 1902.

4) Hirokawa, Hofmeister's Beiträge Bd. 11 S. 458. 1908. 
Versuchen der osmotische Druck des Urins in den Harnkanälchen für das Wassergleichgewicht massgebend ist ${ }^{1}$ ).

Ich habe nun das Verhalten von Froschnieren in verschiedenen Salzlösungen untersucht. Wie weit ist für das Wassergleichgewicht der Nieren der osmotische Druck der umgebenden Lösung massgebend? Nebmen die Nieren aus einer Lösung Salz auf? Lässt sich die Salzaufnahme beeinflussen? Solche Fragen erscheinen gerade für die Untersuchung sezernierender Zellen sehr wichtig.

Meine Versuche schliessen sich in der Anlage und in der Methode an die Untersuchungen von Overton über Froschmuskeln an. Es wurde mit isolierten, überlebeuden Froschnieren gearbeitet. Es sei hier ausdrücklich betont, dass für das Verständnis der normalen Zellfunktion nur reversible Beeinflussungen verwertet werden können. Nur wenn wir eine bestimmte Eigenschaft oder Funktion eines Organs reversibel beeinflussen, ist die Annahme erlaubt, dass die gleiche Eigenschaft oder Funktion des Organs auch im lebenden Tiere eine entsprechende Beeinflussung erleiden kann. Diese Beschränkung ist bei Versuchen an überlebenden Organen unerlässlich.

Bei der Arbeit hat mir Herr Dr. Warburg stets in freundschaftlicher Weise Rat und Unterstützung gewährt; ich schulde ihm dafür vielen Dank.

Ich werde nun meine Beobachtungen beschreiben. Erst zum Schlusse möchte ich anführen, wie weit die Erscheinungen durch diese oder jene Vorstellung erklärt werden können, und wie weit sie „spezifische Eigenschaften ${ }^{\prime}$ der Nieren erkennen lassen.

\section{Das Verhalten ïberlebender Froschnieren in $R$ in $g$ er'scher Lösung.}

Froschnieren eignen sich sehr gut zu Versuchen in vitro. Die kleinen, dünnen Organe ermöglichen bei einem Diffusionsgefälle einen raschen Ausgleich. Die Organe sind nur auf der einen Seite vom Peritoneum überzogen und haben keine Kapsel, die ein Diffusions-

1) Anmerkung bei der Korrektur: Erwähnt sei noch eine während der Drucklegung erschienene Untersuchung von Cohnheim (Sitzungsber. d. Heidelberger A kad. d. Wissensch., math.-naturw. Klasse Bd. 7. 1912), nach der die Niere (von Heteropoden) Säuren und Basen (Farbstoffe) durch eine chemische Reaktion fixiert. 
hindernis bedeuten könnte. Was den feineren Bau betrifft, so ist für die Versuche die Anordnung der Zellen in Kanälehen wichtig. Davon ist später zu reden. Hier sei nur noch erwähnt, dass eine Niere meiner Frösche etwa zwischen 30 und $100 \mathrm{mg}$ wog.

Bringt man sorgfältig präparierte Froschnieren in neutrale Ringer'sche Lösung, die mit Froschserum isotonisch ist, so bewahren die Organe bei niederer Temperatur $\left(0^{0}-4^{0}\right)$ etwa $8-10$ Tage lang ihr frisches Aussehen. Ich habe derartige Organe in Zupfpräparaten und in Schnitten untersucht und stets gut erhaltene Zellen, scharfe Kernfiguren gefunden.

Ich habe nun das Gewicht solcher überlebender Nieren von Zeit zu Zeit festgestellt. Dabei hat sich ergeben, dass die Organe in der ersten Zeit (etwa 2 T'age lang) abnehmen, dann lange (etwa 6 Tage) das gleiche Gewicht behalten und schliesslich wieder zunehmen. Die Gewichtszunahme beginnt, wenn die Organe ihr frisches Aussehen verloren haben. Die histologischen Bilder zeigen dann deutliche Veränderungen (vor allem fehlt die Kernzeichnung). (Vgl. Versuch 1 ff. S. 476 f.)

Die anfängliche Gewichtsabnahme war zuweilen recht erheblich; die Nieren nahmen oft um ein Fünftel des Gewichts ab. Hielt ich die Frösche vor der Präparation der Nieren längere Zeit in einem trockenen Glase, so fand ich meist eine wesentlich geringere Abnahme (z. B. Versuch 4 S. 477). In S erum (ich verdünnte inaktiviertes Säugetierserum, so dass es etwa isotonisch mit der Ringer-Lösung war) nahmen die Nieren ebenso ab wie in Ringer-Lösung (Versuch 6 S. 477).

Schliesslich habe ich Nieren sofort nach der Präparation und dann, nachdem sie 14 Stunden in Ringer-Lösung gelegen hatten, in Zenker'scher Flüssigkeit fixiert und in Paraffinschnitten untersucht ${ }^{1}$ ). Die Zellen zeigten dabei keinerlei Unterschiede.

Zur Erklärung der anfänglichen Gewichtsabnahme könnte man zunächst daran denken, dass der hypotonische Harn ${ }^{2}$ ) in den Harnkanälchen an die konzentriertere Aussenlösung Wasser abgibt. Es ist aber nicht anzunehmen, dass die Gewichtsänderung nur durch einen osmotischen Wasserverlust entsteht, denn bei verschiedenem

1) Die Präparate liess Herr Professor Braus im hiesigen anatomischen Institut aniertigen. Ich bin ihm dafür zu grossem Danke verpflichtet.

2) Der Harn von Fröschen ist bekanntlich dem Serum gegenüber hypotonisch. Vgl. Overton, Verhandl. der phys.-med. Gesellsch. N. F. Bd. 36 S. 277. Würzburg 1904. 
osmotischen Druck der Lösung tritt, wie wir sehen werden, viel rascher ein Gleichgewichtszustand ein. Und vor allem wäre bei einem osmotisehen Wasserverlust nicht zu versteben, dass die Organe in hypotonischen Lösungen erst an Gewicht zunehmen und dann abnehmen (vgl. Versuch 7 S. 478). Ich möchte annehmen, dass der Harn aus den Kanälchen und dem Nierenbecken allmählich abfliesst. Das Nierenbecken wurde in manchen Versuchen deutlich schlaffer. Dass der in den Harnwegen angesammelte Harn bei der Gewichtsabnahme eine Rolle spielt, dafür spricht, dass die Nieren von Trockenfröschen, die ja weniger und konzentrierteren Harn ausscheiden, weniger an Gewicht abnehmen. Eine sichere Erklärung vermag ich freilich nicht zu gegeben.

Dieser Verhältnisse wegen muss darauf verzichtet werden, die Konzentration der Salzlösung festzustellen, mit der frisch präparierte Froschnieren im Gleichgewicht sind. In den folgenden Versuehen, in denen die Gewichtsänderung der Nieren bei Änderung der umgebenden Lösung untersucht werden sollte, liess ich nun die Nieren stets erst längere Zeit (meist $1-2 \times 24$ Stunden) in Ring er'scher Lösung liegen und stellte vor dem Versuche durch einige Wägungen fest, ob sich die Organe im Wassergleichgewicht befanden.

Ausser den Gewichtsverhältnissen habe ich an den überlebenden Froschnieren auch den Sauerst offverbrauch untersucht. Die Versuche in Ringer'scher Lösung ergaben folgendes:

Der stündliche Sauerstoffverbrauch nimmt in den ersten 24 Stunden ab, etwa um $25-40 \%$, und bleibt dann mehrere Tage (bis zum neunten Tag) unverändert. $1 \mathrm{~g}$ Nierengewicht verbraucht bei $17,5^{\circ}$ in der Stunde zu Beginn des Versuches etwa 0,16-0,24 cem $\mathrm{O}_{2}$, in den späteren Versuchen ziemlich konstant etwa $0,13 \mathrm{ccm} \mathrm{O}_{2}$ (vgl. Versuch 74 ff. S. 510). Wie gleichmässig der Sauerstoffverbrauch in den Versuchen gefunden wird, ist besonders deutlich aus der graphisehen Darstellung eines zwölfstündigen Versuches zu sehen (vgl. Fig. 2).

Die Abnahme der Oxydationen entspricht dem Befunde Ver. non's ${ }^{1}$ ) an durchbluteten Säugetiernieren. Vernon fand uun eine erhebliche Steigerung der Oxydationen bei Zusatz von Serum zur Durchspülungsflüssigkeit. Ich habe daher die Oxydationen bei $\mathrm{Zu}$ satz von Froschserum (1:4) und in Säugetierserum unter-

1) Vernon, Journ. of physiol. vol. 35 p. 53.1906 ; vol. 36 p. 81.1907 vol. 39 p. 149. 1909. 
sucht: es ergab sich aber nur eine ganz geringe Zunahme der Oxydationen, die kaum grösser ist als die Schwankungen in Ringer.

Es erschien mir folgende Annahme möglich: Ich hatte in den Versuchen eine mit Natronlauge neutralisierte Ringer-Lösung, ohne Zusatz von Natriumbikarbonat, benutzt. In dieser Lösung nimmt während des Respirationsversuches durch Kohlensäurebildung die Azidität $\mathrm{zu}$, da "Puffer" fehlen. War deshalb diese Lösung ungünstiger als Serum? In der Tat fand sich eine allerdings geringe Zunahme der Oxydationen, wenn ich Natriumbikarbonat zusetzte. Ziehe ich das in Rechnung, so kann ich keinen deutlichen Unterschied der Oxydationen in Serum und in Ringer bei meinen Versuchen annehmen.

Für die weitere Untersuchung ist wichtig: An isolierten Froschnieren, die $1-2$ Tage in Ringer-Lösung bei $0^{\circ}$ gelegen baben, sind konstante Verhälnisse eingetreten, das Gewicht der Nieren und ebensoihrSauerstoffverbrauch bleiben mehrere Tage unverändert.

\section{Das Verhalten iiberlebender Froschnieren in anisotonischen R in g e r - Lösungen.}

Werden nun Nieren, die in der isotonischen Ringer-Lösung im Gleichgewicht sind, in eine verdünnte Ringer-Lösung gebracht, so nimm t das Gewicht zu. Von der dritten bis sechsten Stunde an - je nach der Grösse der Organe - ändert sich das Gewicht nicht mehr, die Nieren befinden sich also im Gleichge wicht mit der Lösung. In die ursprüngliche Lösung zurückversetzt, erlangen die Nieren in kurzer Zeit wieder ihr ursprüngliches Gewicht.

Es ist sehr wichtig, dass in Lösungen verschiedener Konzentrationen tatsächlich ein Gleichgewicht eintritt, und dass das Gleichgewicht lange festgehalten wird. Versuch Nr. 11 S. 479 zeigt z. B., dass Nieren, die in einer zur Hälfte verdünnten Ringer-Lösung ungefähr um $30 \%$ zugenommen haben, ibr Gewicht auch in mehreren Tagen nicht merklich ändern. Wird die Ringer-Lösıng noch weiter verdünnt, so dass ihre Konzentration ein Viertel der ursprünglichen beträgt, so tritt allerdings meist kein Gleichgewicht mehr ein: Das Gewicht steigt lange an und nimmt dann wieder ab. Schon ehe die Nieren das maximale Gewicht erreicht haben, wird der Vorgang meist irreversibel, d. h. die Nieren haben durch die grosse Volumenzunahme Schaden gelitten. 
Die Konzentration der zur Hälfte verdünnten $\mathrm{R}$ inger-Lösung möchte ich als die untere Grenzkouzentratiou bezeichuen, in der die Nieren stets einen Gleichgewichtszustand erreichen, ohne dass sie geschädigt werden.

Bringt man Nieren aus der normalen Lösung in eine k onzentriertere, so nimmt das Gewichtab. Es tritt ein Gleichgewichtszustand ein, noch in einer Lösung, die doppelt so konzentriert ist wie die normale. Der Vorgang ist vollkommen reversibel.

.Die Nierenkönnen also, ohnegeschädigtzuwerden, mit Lösungen im Gleichgewicht sein, deren Konzentration um das Vierfache voneinander abweicht. Und ausserdem ist bemerkenswert, wie lange die Organe in der verdünnten Lösung erhalten bleiben.

Diese Ergebnisse entsprechen ungefähr dem Verhalten der Froschmuskeln, wie es Overton beschrieben hat.

Es ist nun obne weiteres klar, dass die Gewichtsänderung der Organe in einer derartigen Salzlösung durch Wasseraufnahme oder -abgabe bedingt wird. Wir können daher das Ergebnis so ausdrücken: Werden überlebende Nieren aus einer Lösung, mit der sie im Gleichgewicht sind, in eine verdünntere Lösung gebracht, so nehmen sie Wasser auf, in einer konzentrierteren Lösung geben sie Wasser ab. Das erinnert unmittelbar an das Verhalten eines osmotischen Systems.

Wir müssen die quantitativen Beziehungen ins Auge fassen. Das Volumen einer idealen osmotischen Zelle ist bekanntlich dem osmotischen Drucke der umgebenden Lösung umgekehrt proportional. Steht nun auch die Gewichtsänderung der überlebenden Nieren in einem bestimmten Verhältnisse zur Konzentrationsänderung der umgebenden Lösung?

Zunächst muss aber hier erörtert werden, wie weit die Versuche überhaupt quantitativ zu verwerten sind. Ganz abgesehen davon, dass die Gewichtsänderungen verschiedener Organe nie genau übereinstimmen, muss vor allem bedacht werden, dass die Nieren nicht aus einer Ansammlung von Zellen bestehen, die ihr Volumen beliebig ändern können. Die Zellen hängen alle untereinander zusammen, so dass die Volumänderung jeder Zelle andere Zellen beeinflussen wird. Und nun setzen sich die Zellen zu einem System von Kanälchen zusammen, deren Hohlräume mit Flüssigkeit gefüllt sind. Diese Flüssigkeit steht in mehr oder weniger offener Verbindung 
mit der Lösung, in der die Organe liegen. Es lässt sich nun gar nicht sicher feststellen, in welcher Weise der Inhalt der Kanälchen an der Volumenänderung der Organe beteiligt ist.

Um eine ungefähre Vorstellung davon zu geben, wieviel der Inhalt der Kanälchen ausmachen kann, führe ich folgenden Versuch an (vgl. S. $519 \mathrm{ff}$.): Ich habe, worüber später vor allem zu reden ist, Aschenanalysen von Nieren ausgeführt. Nun habe ich einmal Nieren verascht, die in Ringer, also im wesentlichen in Kochsalzlösung gelegen hatten, und dann Organe, die einige Stunden in Rohrzuckerlösung waren. In dieser zweiten Portion war also die Kochsalzlösung in den Kanälchen, deren Lumen in offener Verbindung nit der äusseren Lösung steht, durch Zuckerlösung ersetzt. Die Differenz des Kocbsalzgehaltes gab daher einen Anhaltspunkt für das Volumen der Kanälchen. Der Versuch ergab, dass der In halt der Kanälchen etwa $30 \%$ des Nierengewichtes ausmachen kann. Freilich darf das nur als ungefähre Schätzung betrachtet werden.

Durch diese Verhältnisse wird natürlich die quantitative Verwertbarkeit der Versuche etwas eingeschränkt. Immerhin ergeben sich sichere Tatsachen, die für unsere Anschauung über die Ejgenschaften der Nierenzellen wichtig sind.

In der folgenden Tabelle habe ich die Gewichte der Nieren in Lösung'en verschiedener Konzentration zusammengestellt. Um die Werte vergleichbar zu machen, habe ich das Gewicht in der mit dem Serum isotonischen Lösung gleich 100 gesetzt und darauf die anderen Gewichte bezogen.

Tabelle.

\begin{tabular}{c|c|c}
\hline $\begin{array}{c}\text { Konzentration } \\
\text { der Lösung 1) }\end{array}$ & Nierengewichte & Mittlerer Wert \\
\hline $4 / 1$ & $81,83,73$ & 79 \\
$1 / 1$ & $100,110,100$ \\
$3 / 4$ & $112,110,125,130,139,122,125,128$ & 111 \\
$1 / 2$ & $122,132,127$ \\
$1 / 4$ & $177,155 ? 190 ?$ & 174
\end{tabular}

Aus der Tabelle lässt sich folgendes erkennen: Je niederer der osmotische Druck einer Lösung ist, desto grösser ist das Gewicht

1) Die mit dem Serum isotonische Lösung ist als $1 / 1$ bezeichnet. Der osmotische Druck ist der Konzentration sehr annähernd proportional. 
der Nieren. Das Gewicht der Nieren ist aber nicht umgekehrt proportional dem osmotischen Drucke, es ändert sich vielmehr weit weniger als der osmotische Druck; nimmt der osmotische Druck z. B. um die Hälfte ab, so nimmt das Gewicht der Nieren um $30 \%$ zu. Die Gewichtsänderung steht wenigstens annähernd in einem bestimmten Verhältnisse zur Änderung des osmotischen Druckes. Zwischen $\mathrm{c}=2 / 1$ und $\mathrm{c}=1 / 2$ ist das Verhältnis der Gewichtsänderung zur Änderung des osmotischen Druckes ziemlich konstant $(1 / 10: 1 / 4)$. Wenn der osmotische Druck noch niedriger wird, so scheint allerdings die relative Gewichtsänderung zuzunehmen. Die Werte bei $c=1 / 4$ sind zwar, wie oben ausgeführt, unsicher, aber es lässt sich doch aus den Versuchen erkennen, dass die Gewichtszunahme in $\mathrm{e}=1 / 4 \mathrm{mehr}$ als doppelt so gross ist wie die in $\mathrm{e}=1 / 2$.

Wenn nun auch die quantitativen Verhältnisse nur mit Vorsicht verwertet werden können, so ist doch die Annahme durchaus berechtigt, dass die Gewichtsänderung der Nieren im weseutlıchen durch eine Volumenänderung der Nierenzellen bedingt ist ${ }^{1}$ ). Danach fasse ich das Ergebnis so zusammen: Das Volumen der Nierenzellen nimmtzu, wenn der osmotische Druck der umgebenden Lösung abnimmt. Das Volumen der Zellen ist aber keineswegs dem osmotischen Drucke umgekehrt proportional; die Volumenänderung ist vielmehr weit geringer, als diesem Verhältnisse entspräche.

Es sei hier noch ein Versuch erwähnt, der zeigt, dass die Gewichtsänderung der Nieren bei Konzentrationsänderung der umgebenden Lösung eine Eigentümlichkeit unversehrter Zellen ist: Lässt man die Organe gefrieren und wieder auftauen, so bleibt ihr Gewicht in Lösungen verschiedener Konzentration gleich (vgl. Versuch 25, S. 484).

Die Oxydationsprozesse der Nieren haben sich von der Konzentration der umgebenden Lösung und damit auch vom Volumen der Zellen weitgehend unabhägiı erwiesen. Weder in verdünnteren noch in konzentrierteren Lösungeu

1) Es sei hier kurz darauf hingewiesen, dass im histologischen Bilde nur bei erheblicher Gewichtsänderung eine deutliche Volumenänderung der Zallen zu erwartèn ist, da die lineare Änderung doch nur die Kubikwurzel der Volımenänderung beträgt. 
war der stündliche Sauerstoffverbrauch merklich anders als in der isotonischen Lösung (vgl. Versuch 79, 80, S.513 f.). Ähnlich verhalten sich nach Warburg Vogelerythrocyten.

Besonders auffallend zeigt sich dieses Verhalten darin, dass die Nieren in destilliertem Wasser ebensoviel Sauerstoff verbrauchen wie in Ringer-Lösung, obwohl das Gewicht der Nieren in dem Versuche ungefähr verdoppelt wird (vgl. Versuch 80, S. 514). Bleiben die Nieren längere Zeit (etwa 7 Stunden) in Wasser, so werden sie allerdings dauernd geschädigt; die Gewichtszunahme ist dann irreversibel.

\section{Das Verhalten von Froschnieren in Kaliumchloridlösung.}

Bringt man Froschnieren aus der Ringer-Lösung in eine isotonische Lösung von Kaliumchlorid, so tritt sehr bald eine deutliche Veränderung ein: Die Organe werden meist schon nach 2 Stunden deutlich grösser, praller, etwas heller, das Gewicht nimmt zu (vgl. Versuch $18 \mathrm{ff}$., S. 482). DasGewicht ist ungefäbr nach 12 Stunden verdoppelt, nimmt dann noch etwa einen Tag lang wenig zu, bleibt etwa 2 Tage lang ziemlich gleich und nimmt dann wieder langsam, ab. Etwa vom zweiten bisdritten Tage an verschwindet die frische Farbe, die Organe werden trübe gelb.

Untersucht man die Nieren histologisch, so findet man nach. 14 stündiger Kaliumchloridwirkung schon ausgesprochene Veränderungen: Die Epithelzellen der Harnkanälchen haben. deutlich an Volumen zugenommen, das Protoplasma ist weniger intensiv gefärbt als bei Organen, die in Ringer gelegen haben und ganz entsprechend verarbeitet werden. Die Zellkerne zeigen jedoch ganz normale Verhältnisse, die Kernfigur ist vollkommen erhalten.

Haben die Organe 22 Stunden in Kaliumchloridlösung gelegen, so werden die Kernfiguren teilweise undeutlicher, einzelne Kernesehen geschrumpft aus. Nach mehrtägiger Einwirkung von Kaliumchlorid zeigt das mikroskopische Bild hochgradige Zerstörung von Zellen: nur wenige Kerne haben noch eine Zeichnung, die meisten sind homogen und deutlich geschrumpft. Das Protoplasma färbt. sich schlecht, die Zellkonturen sind verwaschen.

Wir finder also, dass die Nierenzellen in isotonischer Kaliumchloridlösung an Gewicht zunehmen. Das entspricht dem von. 
Overton ${ }^{1}$ ) beschriebenen Verhalten der Froschmuskeln. Overt on gibt nun an, dass die Muskeln erst dann in Kaliumchloridlösung an Gewicht zunehmen, wenn die Zellen abgestorben sind. Trifft dies auch für die Nieren bei meinen Versuchsbedingungen $\mathrm{zu}$, oder ist die Kaliumchloridwirkung reversibel?

Werden die Nieren aus der Kaliumchloridlösung in Ringer'sche Lösung zuräckversetzt, so nehmen sie an Gewicht ab, erlangen ihr ursprüngliches Gewicht wieder und behalten das mehrere Tage. In hypotonischer Ringer-Lösung nehmen solche Organe gerade so an Gewicht zu wie Kontrollorgane, die nicht in Kaliumchloridlösung gelegen hatten.

Die Untersuchung des Sauerstoffverbrauches ergab folgendes: Die Oxydationen waren in Kaliumehloridlösung etwa um $20-30 \%$ herabgesetzt und erlangten in Ringer'scher Lösung nach der Kaliumchloridwirkung wieder ihren ursprüng1 i che n Wert (vgl. Versuch 81, S. 515).

Nach diesen Versuchen glaube ich dazu berechtigt zu sein, die Kaliumchloridwirkung als einen reversiblen Vorgang anzuseben.

In einer verdünnten Kaliumehloridlösung nehmen die Nieren ungefähr ebenso zu, wie in der isotonischen. In einer konzentrierteren Lösung tritt erst eine Gewichtsabnahme, dann eine Zunahme ein. (Vgl. Versuch 23 und 24, S. 484.)

Um die Erscheinung weiter zu untersuchen, war vor allem festzustellen, ob die Zellen nur Wasser oder auch Kaliumchlorid aufnehmen. Ich habe daher Aschenanalysen ausgeführt. Dabei hat sich ergeben, dass die Nieren in Kaliumchloridlösung erheblich mehr Kaliumchlorid enthielten als in Ringer-oder in Kochsalzlösung. Die Zunahme an Kaliumchlorid stand zu der Gewichtsänderung ungefähr in dem Verhältnis, in dem das Salz in der isotonischen Kaliumchloridlösung enthalten ist (vgl. Versuche 90,91$)^{2}$ ). Damit ist der Beweis erbracht, dass die Zellen, ohne zerstört zu werden, Kaliumchlorid aufnehmen.

Nachdem das festgestellt war, untersuchte ich, ob die eigentümliche Kaliumchloridwirkung an das Vorhandensein un-

1) Pflüger's Arch. Bd. 105 S. 176. 1904.

2) Dabei ist berücksichtigt, dass die Harnkanälchen zum Teil $\mathrm{K}$ statt $\mathrm{Na}$ enthalten (vgl. S. 520). 
versehrter Zellen gebunden ist. Ich habe die Organe gefroren und wieder aufgetaut. Das Aussehen der Nieren wird dadurch zunächst nicht merklich verändert, sie behalten ihre normale Farbe, ihre Form, aber sie füblen sich wesentlich schlaffer an. In Zupfpräparaten erscheinen die Zellkonturen vollkommen zerstört, man sieht nur freie Kerne und körnigen Detritus.

Derartige Organe verhalten sich in Ringer-und Kaliumchlorid ganz gleich; sie nehmen meist erst um einige Milligramme zu und behalten dann längere Zeit gleiches Gewicht (vgl. Versuch 25, S. 484). Dagegen lassen sich an den gefrorenen Nieren Oxydationsprozesse sicher nachweisen (vgl. Versuch 88, S. 518). Der Sauerstoffverbrauch ist allerdings nur etwa halb so gross wie an unversehrten Organen ${ }^{1}$ ).

Fassen wir die Ergebnisse dieser Versuche zusammen: In Kaliumehloridlösung nehmen die Nierenzellen Wasser und Salz, ungefähr im Verbältnis der umgebenden isotonischen Lösung, auf. Dieser Vorgang verläuft reversibel und ist charakteristisch für die unversehrten Zellen.

\section{IY. Das Verhalten von Froschnieren in Lösungen von Lithium-,} Natrium-, Rubidium-, Cäsinm- und Ammoniumehlorid.

(Vgl. Versuch $26-34$, S. 485 ff.)

Bringt man Nieren, die in Ringer-Lösung im Gleichgewicht sind, in eine isotonische Lösung von Kochsalz oder von Lithiumchlorid, so tritt keine merkliche Gewichtsänderung ein. In diesen Lösungen bleiben die Organe beinahe ebenso lange erhalten wie in Ringer-Lösung, das Gewicht bleibt mehrere Tage unverändert. Werden frisch präparierte Nieren in die Kochsalzlösung gebracht, so nehmen sie zuerst ebenso an Gewicht $a b$ wie in Ringe $r$ - Lösung. In verdünnten Lösungen dieser Salze nimmt das Gewicht zu. In einer zur Hälfte verdünnten Kochsalzlösung wiegen die Organe etwa $30 \%$ mehr als in der isotonischen Lösung, was genau den Verbältnissen in Ring e r-Lösung entspricht. Wird die Lithïumchloridlösung zur Hälfte verdünnt, so ist die Gewichtszunahme anscheinend grösser: sie beträgt $40-60 \%$

1) Über die Oxydationsprozesse gefrorener Oxydationsprozesse vgl. Warburg, Zeitsehr. f. physiol. Chemie Bd. 70 S. 413.1911.

Pflüger's Archiv für Physiologie. Bd. 148. 
des ursprünglichen Gewichtes. Der Unterschied ist allerdings nicht sehr gross, vor allem, wenn man bedenkt, dass verschiedene Organe sich meist etwas verschieden verhalten. Es ist zu betonen, dass die Nieren in der verdünnten Lösung tatsächlich im Gleichgewicht sind, und dass sie, in die normale Lösung zurückversetzt, ibr ursprüngliches Gewicht wiedererlangen.

In isotoniseher Lösung von Rubidiumehlorid nehmen die Nieren dauernd an Gewicht zu, ganz ähnlich wie in Kaliumchlorid.

In Caesiumchlorid nehmen die Nieren in den ersten Stunden an Gewicht ab, dann dauernd $z u$, aber viel langsamer als in Kaliumoder Rubidiumehlorid.

Die Gewichtsänderung der Nieren in diesen Lösungen entspricht den Angaben von Overton über Frosehmuskeln. Freilich glaube ich auch hier nach meinen Versuchen annehmen zu müssen, dass eine deutliche Wirkung eintreten kann, ohne dass die Organe geschädigt werden. Bei längerer Einwirkung wird der Vorgang irreversibel. Aber es kommt vor allem darauf an, überhaupt eine reversible Gewichtsänderung in diesen Salzlösungen nachzuweisen.

In neutraler, isotonischer Lösung von Ammoniumchlorid nehmen die Nieren sehr rasch an Gewicht zu, viel rascher als in Kaliumchloridlösung. Wenn die Nieren z. B. nach 5 Stunden um beinahe $50 \%$ zugenommen haben, ist die Wirkung noch reversibel: Die Nieren erlangen in Ringer-Lösung: ihr ursprüngliches Gewicht wieder und nehmen in einer zur Hälfte verdünnten Ringer-Lösung um mehr als $30 \% \mathrm{zu}$. Daraus glaube ich schliessen zu können, dass die Zellen nicht geschädigt sind. Es können ja, wie Overton mitteilt, gewisse Zellen ohne Änderung der "osmotischen Eigenschaften" getötet werden. Aber bei den Nierenzellen habe ich nie etwas Derartiges gefunden. Geschädigte Organe behalten nie längere Zeit ein konstantes Gewicht und nehmen vor allem in verdünnter $R$ ing er - Lösung, wenn überhaupt, so doch viel weniger an Gewicht zu als gut erhaltene Organe. Nach längerer Zeit leiden die Organe natürlich Schaden. In Ammoniumchloridlösung wird das Gewicht schliesslich (nach 3 Tagen) verdreifacht. Eine derartige Zunahme fand ich sonst nur in destilliertem Wasser.

Die Ammoniumsalze schienen auch nach den Untersuchungen 
von Grynsi) und Hedin ${ }^{2}$ ) eine Ausnahme von der Overton. schen Regel zu macheu. Nach diesen Untersuchungen dringen manche Ammoniumsalze (wie Salmiak) leicht in die roten Blutkörperchen (Säuger) ein. Allerdings wurde nicht geprüft, ob der Vorgang reversibel ist, und $U$ verton ${ }^{3}$ ) erklärt deshalb den abweichenden Befund durch die Annahme, dass die Blutkörperchen geschädigt würden, dass erst nach der Schädigung Salz eindringe.

V. Das Verhalten von Froschnieren in Lösungen von Caleium-, Barium- und Magnesiumchlorid. (Vgl. Versuch 35-39, S. 488 ff.)

In isotonischen Lösungen von Chloriden zweiwertiger Kationen (Calcium, Barium und Magnesium) tritt rasch eine Gewichtsänderung der Nieren ein. Die Organe uehmen erst $a b$ und dannzu. Werden die Nieren nach einigen Stunden in Rin g er - Lösung zurückversetzt, so nähert sich ihr Gewicht dem ursprünglichen, ohne es freilich immer zu erreichen. In verdünnter Ringer-Lösung nehmen die Organe an Gewicht zu, nicht merklich weniger als unversehrte Organe. Nach meinen Versuchen wird die Wirkung dieser Salze allerdings viel bälder irreversibel als die des Kaliumchlorids. Vor allem ist wichtig, dass ich überhaupt den Vorgang nie mehr reversibel fand, wenn das Gewicht bereits wieder im Ansteigen begriffen war.

VI. Das Verhalten von Frosehnieren in Lösungen von Bromiden. (Vgl. Versuch $42-47$, S. 491 ff.)

Nur wenig ist uber die Wirkung der Bromide ${ }^{3}$ ) zu sagen: In den isotonischen Lösungen von Natrium- und Lithiumbromid bleibtdas Gewichtder Organemehrere Tage unverändert, in hypotonischen Lösungen nimmt es ganz entsprechend $\mathrm{zu}$, wie in den Lösungen der Chloride. In Kaliumbromid nehmen die Nieren dauernd an Gewicht $\mathrm{zu}$, jedoch erheblich langsamer als in Kaliumehlorid; der Vorgang ist

1) Gryns, I. c.

2) Hedin, 1. c.

3) Overton in Nagel's Handb. Bd. 2 S. 837.

4) Will man die reine Wirkung anderer Anionen als Chlor untersuchen, so muss man die stark korhsalzhaltige Zwischenflüssigkeit ausspülen. Ich habe dazu die Organe für einige Stunden (oder länger) in eine isotonische Zuckerlösung gebracht. 
nach 31 Stunden nach einer Gewichtszunahme um $60 \%$ noch reversibel. In einer isotonisehen Lösung, die die Ionen Kalium, Natrium, Chlor und Brom in gleicher Anzahl enthält, nimmt das Gewicht um etwa $25 \%$ zu und bleibt dann einige Zeit konstant.

Im ganzen wirkenalso Bromsalzegleich wie Chlorsalze.

VII. Das Verhalten von Froschnieren in Lösungen von Nitraten, Phosphaten und Sulfaten. (Vgl. Versuch $48-55$ und 84.)

Bringt man Froschnieren aus Ringer-Lösung oder isotonischer Rohrzuckerlösung in eine isotonische Lösung von Natriumnitrat, so bleibt das Gewicht etwa 6 Stunden lang ziemlich unverändert oder nimmt wenig ab. Bei längerem Verweilen in der Lösung nimmt das Gewicht ganz langsam etwas zu. Bringt man die Nieren aus der Rohrzucker- oder der Natriumnitratlösung in eine isotonische Lösung von Kaliumnitrat, so nimmt das Gewicht langsam zu. Nach 15 Stunden hat eine Niere von $50 \mathrm{mg}$ etwa um $10 \mathrm{mg}$ zugenommen, während in der gleichen Zeit in Kalinmehloridlösung das Gewicht annähernd verdoppelt wird. Bringt man die Organe aus den Nitratlösungen in die Ringer-Lösung zurück, so erlangen die Nieren noch nach 24 stündiger Nitratwirkung ihr ursprüngliches Gewicht wieder, behalten das lange Zeit (24 Stunden und mehr) unverändert bei. In verdünnten Ringer-Lösungen nehmen die Organe an Gewicht zu, allerdings weniger als unbeeinflusste Organe. Die Gewichtszunahme in einer zur Hälfte verdünnten Ring e - Lösung beträgt etwa $15-20 \%$, statt $25-30 \%$ des Gewichtes. Doch möchte ich hervorheben, dass in der verdünnten Lösung ein Gleichgewicht eintritt und mehrere Stunden (mindestens 6 Stunden) unverändert bleibt. In der normalen Lösung erlangt das Gewicht danach den ursprünglichen Wert wieder.

Obgleich sowohl in normaler wie in verdünnter Ringe r-Lösung längere Zeit Gewichtskonstanz besteht, können diese Organe nicht ohne weiteres als unbeschädigt angesehen werden, weil eben die Gewichtsänderung bei Verdünnung der Lösung so gering ist. In Nitratlösungen werden also die Eigenschaften der Nierenzellen schon nach einigen Stunden irreversibel beeinflusst.

In isotonischen Lösungen von sekundärem Natriumund Kaliumphosphat nimmt das Gewicht der Nieren erst etwas ab. Während danach das Gewicht in der Natriumphosphatlösung 
mehrere Stunden ziemlich unverändert bleibt, nimmt es in der Kaliumphosphatlösung bald wieder ganz langsam zu. Werden die Phosphatlösungen zur Hälfte verdünnt, so nimmt das Gewicht der Organe zu. Die Gewichtszunahme ist aber geringer als die in entsprechend verdünnter Ringer-Lösung. Es besteht auch in verdünnten Phosphatlösungen mindestens mehrere Stunden ein unverändertes Gleichgewicht. In Ringer-Lösung erlangen die Organe danach wieder ihr ursprüngliches Gewicht, das dann viele Stunden unverändert bleibt. In verdünnter $\mathrm{R}$ i ng e $\mathrm{r}-\mathrm{Lösung}$ nehmen die Organe allerdings etwas weniger zu als unbeeinflusste Organe.

Die Oxydationsprozesse der Nieren in Lösungen von Natrium- und Kaliumphosphat ändern sich mindestens während 12 Stunden nicht merklich, obwobl nach dieser Zeit die Organe in Kaliumphosphatlösung schon erheblich an Gewicht zugenommen haben (vgl. Versuch 84, S. 516).

In isotonischen Lösungen von Natrium-und Kaliumsulfat nimmt das Gewicht der Nieren etwas ab und bleibt dann mehrere Stunden ziemlich unverändert. Nach längerer Zeit tritt eine geringe Gewichtszunahme ein, die jedoch nicht reversibel ist.

In verdünnten Sulfatlösungen nimmt das Gewicht ungefähr ebenso rasch zu wie in verdünnter $\mathrm{Ringer-Lösung;} \mathrm{es} \mathrm{tritt}$ aber kein Gleichgewicht ein, die Gewichtsänderung wird bald irreversibel.

VIII. Das Verhalten von Froschnieren in Lösungsgemischen. (Vgl. Versuch $56-66$, S. 497.)

Im vorhergehenden wurde vor allem ausführlich die Wirkung des Kaliumchlorids besehrieben, die darin besteht, dass die Nieren aus der isotonischen Kaliumchloridlösung Wasser und Salz aufnehmen. Es frägt sich nun, wie dieser Vorgang durch andere Salze beeinflusst wird. Es sei hier zuvor erwähnt, dass die Kaliumchloridwirkung in reinen Kaliumehloridlösungen von der Konzentration weitgehend unabhängigg ist. Ganz anders verhalten sich aber die Organe, wenn die Lösung bei niederer Kaliumchloridkonzentration durch Zusatz eines anderen Salzes oder von Zucker mit dem Serum isotonisch gemacht wird. Mischt man z. B. gleiche Teile der isotonischen Kaliumehlorid- und Natriumchloridlösung, so dass das Lösungsgemisch isotoniseh ist, aber 
nur halb so viel Kaliumchlorid enthält wie die reine Lösung, so nehmen die Nieren zunächst nur um wenig $z u$, ungefähr um $10 \%(6-12 \%)$ und behalten dann etwa einen Tag lang nabezu das gleiche Gewicht oder nehmen sogar wieder etwas ab. Lässt man die Nieren mehrere Tage in der Mischung, so nimmt das Gewicht allerdings wieder zu; der Vorgang wird aber dann irreversibel, die Organe sind geschädigt, so dass die Versuche nicht weiter verwertet werden können.

In einer isotonischen Lösung, die 3 Mol. Kaliumchlorid auf 1 Mol. Natriumchlorid enthält, nehmen Nieren rascher zu. Das Gewicht hat nach 20 Stunden schon etwa $16 \%$ zugenommen.

Enthält die isotonische Lösung weniger Kaliumehlorid, so tritt doch eine merkliche Gewichtszunahme ein. Auch in einer Lösung. die nur $1 \mathrm{Mol}$. Kaliumchlorid auf $9 \mathrm{Mol}$. Natriumchlorid, also etwa $0,09 \%$ Kaliumchlorid enthält, nehmen die Nieren noch etwas zu. Die Gewichtszunahme in diesen Lösungen erscheint sogar nicht deutlich geringer als in Lösungen, die wesentlich mehr Kaliumehlorid ( $1 \mathrm{KCl}$ auf $1 \mathrm{NaCl}$ ) enthalten. Allerdings sind die Ausschläge so gering, dass ich von einer quantitativen Verwertung absehen möchte.

Wird in entsprechender Weise eine isotonische Kal i u $\mathrm{mchl}$ oridlösung mit einer isotonischen Traubenzuckerlösung gemischt, so finden sich ganz gleiche Verhältnisse: Die Nieren nehmen ungefähr ebenso zu wie in Mischungen von Kalium- und Natriumchlorid.

Demgegenüber ist der Einfluss der Erdalkalien sehr bemerkenswert: Mischt mangleiche Teile der isotonischen Calcium- und Kaliumchloridlösung, so ändertsichdas Gewicht der Nieren auch in mehreren Tagen nicht nachweisbar. Magnesiumchlorid wirkt ganz ebenso wie Calciumchlorid. Wird diese Mischung zur Hälfte verdünnt, so nehmen die Nieren an Gewicht zu und behalten auch in der hypotonischen Lösung lange das gleiche Gewicht. In der isotonischen Lösung erreicht das Gewicht danach wieder den ursprünglichen Wert.

Dieses Ergebnis ist sehr bemerkenswert: Während die Chloride der Erdalkalien und des Kaliums einzeln das Wassergleichgewieht der Nieren verändern, bleibt das Gleichgewicht lange Zeit erhalten, wenn ein zweiwertiges Kation und Kalium zusammen wirken.

Mischt man jedoch 3 Teile Kalium- und 1 Teil Calciumchloridlösung, so nimmt das Gewicht langsam zu. Die Wirkung ist noch nach 22 Stunden vollkommen reversibel. 
Mischt man die Chloride der Erdalkalien mit Kochsalz oder Ringer, so finden sich ganz ähnliche Verhältnisse wie bei der Mischung mit Kalium. Auffallend ist nur, dass in einer Mischung von Natrium- und Calciumchlorid $(1: 1)$ das Gewicht der Nieren immer zuerst abnimmt. Ich fand das ganz konstant. Die Abnahme ist zu gross, als dass sie durch eine geringe Konzentrationsverschiedenheit der Lösungen erklärt werden könnte. Nach dieser Abnahme blieb das Gewicht längere Zeit unverändert, hei Verdünnung der Mischung nahm es wie sonst zu.

IX. Das Verhalten von Froschnieren in Lösungen bei verschiedener Reaktion. (Vgl. Vers. 67-73 S. 501 ff. u. 85-87 S. 517 f.)

Es schien mir wichtig, zu untersuchen, welchen Einfluss alkalische oder saure Reaktion auf das Verhalten der Froschnieren in Salzlösungen hat. Als Säuren habe ich Essigsäure und Kohlensäure untersucht. Weder in Ringer'scher Lösung noch in Kaliumchloridlösung fand ich einen Unterschied dem Verhalten in neutralen Lösungen gegenüber, ohne dass die Säuren zu einer dauernden Veränderung geführt hätten. Es sei daher nur kurz angeführt, dass in Lösungen, die 1/100 normale Essigsäure enthalten, die Nieren rasch zugrunde gehen, während 1/500 n. Essigsăure in Ring er' scher Lösung in einigen Stunden keine schädliche Wirkung hat. - 1/100 n. Kohlensäure in R ing e r'scher Lösung hat innerhalb von 24 Stunden bei $0^{\circ}$ keinen Einfluss. In Ringer-Lösung, die mit Kohlensäure bei $20^{\circ}$ gesättigt ist, bleiben die Nieren bei $0^{\circ}$ einige Stunden erhalten, gehen aber bei $20^{\circ}$ rasch zugrunde ${ }^{1}$ ).

Demgegenüber führte die Untersuchung alkalischer Lös ung en zu sebr bemerkenswerten Ergebnissen. Die Nieren bleiben in Ring e r-Lösung, die $1 / 1000$ n. Natronlauge oder $1 / 1000$ n. Ammoniak enthält, mehrere Tage unverändert ${ }^{2}$ ). Werden aber nun die Nieren in eine Kaliumchloridlösung gebracht, der $1 / 1000 \mathrm{n}$. Natronlauge oder Ammoniak zugesetzt ist, so nehmen sie viel rascher an Gewicht $\mathrm{zu}$, als in neutraler Kaliumchloridlösung. Zum Vergleiche habe ich entsprechende Versuche an beiden Nieren eines Frosches ausgeführt: Die Niere in der alkalischen Kaliumchloridlösung nahm in der gleichen Zeit stets etwa dreimal

1) Diese Versuche sind den Anschauungen M. H. Fischer's (l. c.) gegenüber sehr bemerkenswert.

2) In Ringer, die $1 / 100 \mathrm{n}$. $\mathrm{NaOH}$ enthält, gehen sie rasch zugrunde. 
so viel an Gewicht zu wie die in neutraler Lösung. Dabei ist auch die Kaliumchloridwirkung bei alkaliseher Reaktion vollkommen reversibel.

Alkalische Reaktion, die in Ringer'scher Lösung wirkungslos ist, beschleunigt also die Gewichtszunahmeder Nieren in Kaliumchloridlösung ungefähr um das Dreifache.

Dass nicht jede Wasseraufnahme der Nieren durch alkalische Reaktion beschleunigt wird, geht aus folgenden Verșuchen hervor: Wird die ammoniakalische Ring e r - Lösung mit einer 1/1000 n. Ammoniaklösung zur Hälfte verdünnt, so nehmen die Nieren ganz ebenso an Gewicht zu wie bei entsprechender Verdünnung der neutralen Lösung.

Die Wasseraufnahme der Organe in hypotonischen Lösungen wird also dureh alkalische Reaktion nicht beeinflusst.

Ich habe auch die Oxydationsprozesse der Nieren bei alkalischer Reaktion untersucht. Die Untersuchung ist allerdings schwer, weil die gebildete Kohleusäure die Lösungen rasch neutralisiert. Immerhin scheinen die Versuche doch eine Zunahme des Sauerstoffverbrauches bei alkalischer Reaktion zu ergeben, was gat mit den Uutersuchungen Warburg' ${ }^{1}$ ) an Vogelerythrocyten übereinstimmt.

Mit Sicherheit lassen die Versuche erkennen, dass 1/1000 n. Ammoniak in Ringer sowie in Kaliumchlorid die Nieren nicht dauernd schädigt, dass die Wirkung vielmehr reversibel ist.

\section{Zusammenfassung.}

Ich fasse nun zusammen, was sich aus den Beobachtungen ergibt.

1. Zunächst zeigt sich, dass überlebende Frosehnieren in isotonischen Lösungen verschiedener Stoffe im Wassergleichgewicht sind. Solche Lösungen sind Ringer'sche Lösung, die Lösungen der Chloride und Bromide des Natriums und Lithiums, die Lösung von Natriumnitrat, eine Lösung von Kalium- und Calcium- oder Magnesiumchlorid in äquimolaren Mengen gemischt, und Rohrzuckerlösung. An diesen Lösungen lässt sich keine andere gemeinsame Eigensehaft erkennen als eben die Isotonie. Daraus kann man schliessen, dass in diesen Lösungen der osmotische Druck für das Wassergleichgewicht massgebend ist.

1) 1. c. und Grafe, Zeitschr. f. physiol. Chemie Bd.79 S. 421.1912. 
2. In diesen Lösungen ändert sich das Gewicht der Nieren, wenn die Konzentration der Lösung geändert wird. Je niederer der osmotische Druck der Lösung, desto grösser ist das Gewicht der Organe, desto grösser das Volumen der Nierenzellen.

Das Volumen der Nierenzellen ändert sich also bei Änderung des osmotischen Druckes der umgebenden Lösung im gleichen Sinne wie ein osmotisches System. Die Volumänderung der Nierenzellen bleibt aber hinter der einer idealen osmotischen Zelle weit zurück. Während das Volumen einer solchen dem osmotischen Druck umgekehrt proportional ist, nimmt das Volumen der Nierenzellen un gefähr um ein Viertel zu, wenn der osmotische Druck auf die Hälfte herabgesetzt wird. Davon ist später noch zu reden.

3. Alkalische oder saure Reaktion hat so lange keinen Einfluss auf das Wassergleichgewicht der Nieren in diesen Lösungen, als keine dauernde Schädigung der Zellen eintritt, solange die Zellen also intakt sind.

4. Volumenänderung bei Konzentrationsänderung der umgebenden Lösung zeigen nur unversehrte Zellen. Werden Strukturteile der Zellen durch Gefrieren und Auftauen zerstört, so wird das Gewicht der Nieren vom osmotischen Drucke der umgebenden Lösung unabhängig.

5. Wie ich in der Einleitung ausgeführt habe, werden vor allem zwei Erseheinungen, die von unorganischen Systemen bekannt sind, zur Erklärung des Wassergleichgewichts der Zellen herangezogen: die Wirkung des osmotischen Druckes und die Quellung kolloidaler Stoffe.

Von Quellungsvorgäugen sind keine Erscheinungen bekannt, die mit den beschriebenen Verhältnissen des Wassergleichgewichts vergleichbar wären. Quellungsvorgänge sind vor allem von der Reaktion der Lösung abhängig, das Wasserglejehgewicht der Nieren in diesen Lösungen ist von der Reaktion unabbängig. Die Quellung von Kolloiden wird durch Neutralsalze gehemmt. Damit könnte man die Gewichtsabnahme bei Konzentrationserhöhung vergleichen. Dem widerspricht aber, dass versehiedene Salze in gleicher molarer Konzentration gleich wirken, während der entquellende Einfluss der Neutralsalze von der Natur des Anions und Kations abbängt.

Die Verwertung der Beobachtungen an Kolloiden wird dadureh erschwert, dass verschiedene Kolloide sich verschieden verhalten, und 
dass die Kolloide der Zellen nicht unverändert untersucht werden können. Sie sind eben nur in der typischen Anordnung gegeben, wird diese zerstört, so kann damit eine Veränderung der Kolloide eintreten. Aus Untersuchungen an Fibrin, Gelatine usw. kann nur mit Reserve auf die Zellkolloide geschlossen werden.

Aus allem, was bekannt ist, ergibt sich jedenfalls ḱein positiver Anhaltspunkt dafür, dass das Wassergleichgewicht der Nieren in den angeführten Lösungen auf Quellungsvorgängen beruht, im Gegenteil, manche Erscheinungen widersprechen geradezu dieser Annahme.

Das Verhalten der Nieren in den Lösungen erinuert vielmehr ganz unmittelbar an das eines osmotischen Systems. Damit entsteht nun die Vorstellung, dass in den Zellen ein osmotischer Druck wirksam ist. Auch die Tatsache, dass die Verbältnisse durch Zerstörung der Struktur vollständig verändert werden, scheint mir für diese Vorstellung zu sprechen. Nimmt man aber einen osmotischen Druck in der Zelle an, so muss man annehmen, dass eine Phase in der Zelle einer verdünten Lösung entsprechende Eigenschaften hat, und dass diese Phase durch eine andere Phase begrenzt wird, die die Diffusion der gelösten Stoffe, vor allem der Salze he $\mathrm{mmt}$.

6. Wie ist aber nun zu verstehen, dass die Gewichtsänderung der Nieren hinter der Änderung des osmotischen Druckes der Lösung zurückbleibt? Davon, dass die quantitativen Verhältnisse wegen der Anordnung der Zellen, wegen der Kanälchen und ihres Inhaltes verwischt werden können, sehe ich hier $a b$, denn wie man diesen Fehler auch berechnet, so bleibt doch die Tatsache bestehen, dass die Volumenänderung der Nierenzellen viel geringer ist, als der Änderung des osmotischen Druckes der umgebenden Lösung entspräche.

In einem derartigen System aneinandergelagerter Zellen, wie es die Nieren darstellen, kann die einzelne Zelle ihr Volumen natürlich nicht beliebig vergrössern. Es wird nicht sowohl durch eine elastische Begrenzung der einzelnen Zelle als vielmehr durch die Aneinanderlagerung vieler Zellen der Ausdehnung der Zellen ein gewisser elastischer Widerstand entgegenstehen. Würde dieser Widerstand eine wesentliche Rolle spielen, so müsste die Gewichtszunahme 
der Nieren im Verhältnis zur Änderung des osmotischen Druckes um so kleiner werden, je mehr die Organe schon zugenommen haben. Dafür geben die Versuche aber keine Anhaltspunkte, im Gegenteil, sie sprechen für ein umgekehrtes Verbaltnis. Es ist aber überhaupt nicht wahrscheinlich, dass dieser elastische Gegendruck bei einer Gewichtszunahme der Organe um 25-30\% eine erhebliche Rolle spielt, da die Nieren doch ohne Schaden ihr Gewicht verdoppeln können.

Overton hat nun folgende Vorstellung entwickelt: Die wässerige Phase der Zelle, die ja an einer Zunahme bei herabgesetztem osmotischen Drucke zunächst beteiligt ist, macht nur einen Teil der Zelle aus. Sind auf die wässerige Phase die für „verdünnte Lösungen" geltenden Regeln anwendbar, so muss sich ihr Volumen verdoppeln, wenn der osmotische Druck der umgebenden Lösung auf die Hälfte herabgesetzt wird. Das führt zu folgender Berechnung: Nimmt die Zelle bei halbem osmotischen Drucke um ein Viertel ihres Volumens zu, so bildet der vierte Teil der Zelle die wässerige Phase, denn deren Volumen wird ja verdoppelt. Diese Berechnung ist nun in keinem Falle quantitativ anwendbar. Abgesehen davon, dass wir nicht genau wissen, um wieviel das Volumen der einzelnen Zelle zunimmt, sind verschiedene Korrekturen in Erwägung zu ziehen. Einmal enthalten die Zellen Kolloide; deren Quellungsgrad wird aber verändert werden, wenn durch Wasseraufnabme der osmotische Druck in der Zelle abnimmt. Und ausserdem sind die gewöhnlichen Regeln des osmotischen Gleichgewichtes eben nur auf "verdünnte Lösungen" anwendbar. Eine Ausnahme machen vor allem die Lösungen hochmolekularer Stoffe, wie z. B. Rohrzucker ${ }^{1}$ ), und die Zelle enthält nun bekanntlich Stoffe mit ausserordentlich hohem Molekulargewicht, von denen wenigstens ein Teil in der wässerigen Phase gelöst sein kann.

Aus alledem ergibt sich, dass von irgendeiner sicheren quantitativen Betrachtung nicht die Rede sein kann. Nur so viel lässt sich sagen: Da die Zelle etwa $80 \%$ Wasser enthält, kann keinesfalls alles Wasser als wässerige Lösung in der

1) In solchen Lösungen nimmt der osmotische Druck viel rascher zu, als das Volumen abnimmt. Es findet sich also eine Abweichung von dem gewöhnlichen Verhältnis im gleichen Sinne, wie sich aus den Versuchen an Organen ergibt. 
Zelle enthalten sein. Overton unterscheidet nun von der wässerigen Lösung das "Quellungswasser", das in irgendeiner nichtwässerigen Phase enthalten ist.

Von Untersuchungen an anderen Organen lassen sich mit den mitgeteilten Versuchen an Froschnieren am besten die von Overton an Froschmuskeln vergleichen. Die Verhältnisse stimmen sehr annähernd überein. Ich habe gefunden, dass eine Niere in einer zur Hälfte verdünnten Ringer-Lösung um etwa $30 \%$ zunimmt; nach Overton steigt das Gewicht eines Sartorius bei dieser Verdünnung von $31 \mathrm{eg}$ auf etwa $40 \mathrm{eg}$ oder von $17^{1 / 2} \mathrm{eg}$ auf $24^{1 / 2} \mathrm{eg}$. Das Gewicht nimmt danach um etwa $30-40 \%$ zu.

In Ringer'scher Lösung und in einigen anderen Salzlösungen verhalten sich die Froschnieren also bei Konzentrationsänderung wie Froschmuskeln. Auch die Blutkörperchen zeigen nach Untersuchungen von $\mathrm{Hed}$ in, $\mathrm{Ha} \mathrm{mburger}, \mathrm{K}$ oep pe (l. c.) und anderen entsprechende Verhältnisse.

7. In anderen isotonischen Lösungen als den unter 1 . aufgeführten ändert sich das Wassergleichgewicht der Nieren rasch. Ich bespreche zunächst das Verhalten in Kaliumchloridlösung, das am eingehendsten untersucht wurde.

In isotonischer Kaliumchloridlösung nimmt das Gewicht der Nieren zu. Die Organe nehmen aus der Lösung Wasser und Kaliumehlorid ungefähr im Verhältnis der Lösung auf. Der Vorgang ist noch nach 12-14 Stunden, wenn die Organe ihr Gewicht verdoppelt haben, vollk ommen reversibel.

Es ist sehr bemerkenswert, dass die Nieren, die in RingerLösung auch bei verschiedener Konzentration Salz weder abgeben noch aufnehmen, in Kaliumchloridlösung Salz aufnehmen. Damit ist wohl zum ersten Male bewiesen, dass tierische Zellen in derartigen osmotischen Versuchen ein anorganisches Neutralsalz reversibel aufnehmen.

Wie ist nun der Vorgang zu verstehen?

Nachdem wir im vorhergehenden gesehen haben, wie weitgehend das Wassergleichgewicht der Zellen vom osmotischen Drucke abhängig ist, liegt es am nächsten, diese Anschauung auch für die Erklärung der Wasseraufnahme in Kaliumchloridlösung zu benutzen. Man müsste dann annehmen, dass primär Kaliumchlorid in die Zelle eindringe, dass dadurch der osmotische Druck in der Zelle zunimmt, 
und dass dann sekundär, zum Ausgleich des osmotischen Druckes, Wasser aufgenommen wird. Dem entspricht die Tatsache, dass Wasser und Salz etwa im Verhältnis der umgebenden Lösung aufgenommen : werden.

8. Für diese Anschauung spricht vor allem auch die Tatsache, dass die Gewichtszunahme in Kaliumchlorid wie in anisotonisehen Lösungen nur dann eintritt, wenn die Struktur der Zellen unversehrt ist.

Es ist aber doch zu überlegen, ob nicht noch eine andere $\mathrm{Er}$ klärung des Vorganges möglich ist. Man könnte annehmen, dass die Kolloide der Zelle in Kaliumchloridlösung quellen, und dass sie im gequollenen Zustande Kaliumehlorid adsorbieren. Das Hydrogel der Kieselsäure adsorbiert z. B. nach van Bemmelen Alkalien, Chloride, Sulfate und Nitrate des Kaliums und Natriums aus wässeriger Lösung, „wobei aus diesen Lösungen so viel gebunden wird, als dem im Gel gebundenen Wasser und der Konzentration annähernd entspricht, so dass das Wasser des Gels gewissermaassen die gelöste Substanz mit dem Lösungswasser teilt " " $)$.

Eine sichere Entscheidung ist vorläufig nicht möglich, doch möchte ich glauben, dass die osmotischen Vorstellungen eher den Erscheinungen entsprechen.

Ich führe zunächst weitere Tatsachen an:

9. In einer verdünnteren Kaliumchloridlösung nimmt das Gewicht der Nieren ebenso $\mathrm{zu}$ wie in der isotonischen; in einer konzentrierteren nimmt es erst $a b$ und dannzu. Diese Erscheinungen lassen sich mit der Annahme einer osmotisehen Wirkung ohne weiteres erklären, sind dagegen als Quellungsvorgänge kaum zu verstehen.

10. Die Wirkung des Kaliumchlorides kann durch andere Stoffe gehemmt werden. Kochsalzund Traubenzucker wirken ungefähr gleich: Wird der normale osmotische Druck der Lösung zur Hälfte durch Kaliumchlorid, zur Hälfte durch Kochsalz oder Traubenzucker bewirkt, so nimmt das Gewicht der Nieren in einem Tage nur um etwa $10 \%$, statt um $100 \%$ in der reinen Kaliumchloridlösung zu. Es ist bemerkenswert, dass so verschiedene Stoffe wie Kochsalz und Traubenzucker gleich wirken.

1) Zit. nach A. Müller, Allgemeine Chemie der Kolloide. Bredig's Handb. d. angew. physikal. Chemie 1907 S. 130. 
11. Durch die Chloride zweiwertiger Kationen wird die Kaliumchloridwirkung stärker gehemmt als durch Kochsalz oder Traubenzucker. Wird der osmotische Druck der Lösung zur Hälfte durch Kaliumchlorid, zur Hälfte durch Calcium- oder Magnesiumchlorid bewirkt, so bleibt das Gewicht der Nieren mehrere Tage unverändert. Es ist also eine spezifische Gegenwirkung zweiwertiger Kationen nachweisbar. Bei gleichem Partiardruck des Kaliums tritt ohne zweiwertige Kationen eine Gewichtszunahme ein und bleibt bei Gegenwart von Calcium oder Magnesium aus. Das erinnert an den besonders von Jacques Lo eb mehrfach konstatierten Antagonisnus von Kalium und Calcium, von einwertigen und zweiwertigen Kationen überhaupt.

12. Alkalische Reaktion beschleunigt die Kaliumchloridwirkung ungefähr um das Dreifache, während das Wassergleichgewicht in Ringer'scher Lösung von der Reaktion unabhängig ist.

13. Verschiedene Kaliumsalze wirken sehr verschieden: In Kaliumbromidlösung nehmen die Nieren langsamer an Gewicht zu als in Kaliumchloridlösung, noch langsamer in der Nitrat- und Phosphatlösung. In Kaliumsulfatlösung nimmt das Gewicht überhaupt nicht merklich $z u$, solange die Organe intakt sind.

14. Aus allem, was über die Wirkung des Kaliums gesagt ist, möchte ich folgende Anschaung als die wahrscheinlichste entwickeln: Die Grenzschicht der Zellen ist für Kalium durchlässig. Diese Durchlässigkeit ist von der umgebenden Lösung, vom Milieu der Zelle abhängig. Durch zweiwertige Kationen (Calcium, Magnesium) kann sie aufgehoben, durch Kochsalz und Traubenzucker wenigstens herabgesetzt werden. Durch alkalische Reaktion wird die Durchlässigkeit für Kalium erhöht.

Verschiedene Kaliumsalze dringen ganz verschieden rasch in die Zellen ein. Das kann verschieden aufgefasst werden: Entweder ist die Durchlässigkeit der Grenzschicht an sich für verschiedene Anionen verschieden - Kalium kann ja ohne Avion nicht merklich eindringen, da sonst Spannungen entstehen -, oder verschiedene Anionen beeinflussen die Durchlässigkeit für Kalium verschieden. Durch eine Anionenwirkung muss wohl auch erklärt werden, dass das in der 
Zelle enthaltene Kalium unter gewöhnlichen Verbältnissen nicht aus den Zellen herausdiffundiert.

15. Von den Beobachtungen an anderen Salzlösungen möchte ich noch folgende hervorheben: In Ammoniumchloridlösung nehmen die Nieren sehr rasch an Gewicht zu, víel rascher als in Kaliumchloridlösung. Die Chloride $\mathrm{z}$ weiwertiger Kationen bewirken in kurzer Zeit eine Änderung des Wassergleichgewichtes: Die Nieren nehmen in isotonischen Lösungen erst $a b$, dann zu. Die Wirkung wird allerdings bald, jedenfalls dann, wenn die Organe wieder an Gewicht zunehmen, irreversibel.

In einer Lösung, die isosmotische Mengen von Kochsalz und einem Chlorid eines zweiwertigen Kations (Calcium, Magnesium oder Barium) enthält, nimmt das Gewicht der Nieren $a b$, bleibt dann aber konstant.

Auch in isotonischen Lösungen von Nitraten, Phosphaten und Sulfaten nehmen die Nieren an Gewicht ab. In Nitraten und Phosphaten nimmt das Gewicht dann langsam $z u$, in den Lösungen der Kaliumsalze rascher als in den der Natriumsalze. Die Wirkung wird allerdings bald irreversibel. Ich möchte jedoch die eine Tatsache betonen, dass in allen diesen Lösungen, auch wenn sie mit der Ringer-Lösung isotonisch sind, das Wassergleichgewicht nicht unverändert bleibt. Ich möehte diese Beobachtungen nicht zu erklären versuchen, sondern nur den Schluss daraus ziehen, dass nur unter ganz bestimmten Bedingungen das Wassergleichgewicht in isotonischer Lösung unverändert bleibt. Es ergibt sich daraus, wie vorsichtig man mit der Erklärung durch bestimmte Vorstellungen sein muss; die Erscheinungen sind noch zu vielgestaltig, als dass eine sichere Deutung möglich wäre.

16. Die Untersuchung der Oxydationsprozesse in den überlebenden Froschnieren diente zunächst nur zur Kontrolle, ob die Vorgänge reversibel verlaufen. Dennoch haben sich einige wichtige Tatsachen ergeben, die gerade darum wertvoll erscheinen, weil die Oxydationsprozesse in lebenden Zellen, besonders durch Warburg so eingehend untersucht sind.

Vor allem haben sich die Oxydationsprozesse vom Wassergehalt der Zellen weitgehend unabhängig erwiesen. Weder in verdünnter noch in konzentrierter RingerLösung wurde der Sauerstoffverbrauch verändert gefunden. Sogar 
in destilliertem Wasser zeigten die Nieren den gleichen Sauerstoffverbrauch, obwohl ihr Gewicht während des Versuches verdoppelt wurde. Wenn die Nieren Kaliumehlorid aufgenommen hatten oder aufnahmen, waren die Oxydationsprozesse nur wenig (reversibel) gehemmt, bei alkalischer Reaktion sogar nicht merklich verändert. Schliesslich scheint mir die Beobachtung interessant, dass Nieren, deren Struktur durch Gefrieren und A uftauen zerstörtist, nocheinendeutlichen Sauerstoffuerbrauch erkennen lassen.

Diese Beobachtungen entsprechen den Untersuchungen von W a rburg an Vogelerythrocyten. Es erscheint mir aber wichtig, dass die Verhältnisse an ganzen Organen so weitgehend mit denen an kernhaltigen Blutkörperehen übereinstimmen.

17. Zum Schlusse noch eine Bemerkung darüber, wie weit sich aus den Beobachtungen spezifische Eigenschaften der Nieren erkennen lassen.

Während die meisten bisher untersuchten tierischen Zellen in den einfachen osmotischen Versuchen nur lipoidlösliche Stoffe aufnehmen und dem Eindringen von Salzen einen gewissen Widerstand entgegensetzen, solange die Zellen intakt sind ${ }^{1}$ ), nehmen die Nieren Salze auf, ohne zerstört zu werden. Nur in ganz bestimmten Lösungen ist das Wassergleichgewicht der Nierenzellen nur von dem osmotischen Drucke der Lösung abhängig, in den meisten Lösungen tritt bei gleichem osmotischen Drucke eine Wasseraufnahme oder -abgabe ein, die nach Analogie der ausfühlich untersuchten Kaliumchloridwirkung mit Wahrscheinlichkeit auf Salzaufnahme oder - abgabe schliessen lassen. Ausserdem ist auffallend, wie widerstandsfähig die Nieren gegenüber einer Änderung des Wassergleichgewichtes sind.

Ich glaube, diese Verhältuisse sind von Bedeutung für die Anschauung über sezernierende Zellen, und abgesehen davon, für die allgemeine Erörterung über die Salzaufnahme und -abgabe tierischer Zellen.

1) In einer folgenden Mitteilung wird gezeigt werden, dass auch Froschmuskeln (Sartorien) bis zu einem gewissen Grade Kaliumchlorid reversibel aufnehmen können. 


\section{Methoden und Versuchsprotokolle.}

\section{A. Osmotische Untersuchungen.}

Methode: Es wurden Wasserfrösche, meist aus der Umgebung von Heidelberg, benutzt. Die Nieren wurden sorgfältig präpariert, teils von der Bauchseite aus nach Entfernung aller anderen Organe, teils rom Rücken aus nach Abtragung der Wirbelsäule. Es wurde mögliebst vermieden, die Organe zu zerren oder mit Metallinstrumenten zu berühren. Die präparierten Organe wurden nur mit Glaspinzetten angefasst. Zum Versuche wurden die Nieren in kleine Gläschen (15-20 cem Inhalt) mit Gasstopfen gebracht. Die Gläschen wurden bis zum Rande mit der betr. Lösung gefüllt, ohne Luftblase versehlossen und auf einer Scheibe befestigt, die dauernd (Tag und Nacht) in Eiswasser (oder in einem Thermostaten, wenn andere Temperatur angegeben ist) rotierte.

Auf diese Weise wird erreicht, dass die Organe frei in der Lösung schwimmen und diese gleichzeitig dauernd mischen. - Zu den Wägungen wurden die Organe mit Glaspinzetten aus den Gläschen genommen, auf Fliesspapier sorgfältig getrocknet und in Wiegegläschen auf einer analytischen Wage gewogen. Die Wägungen gehen sehr rasch, da die Wiegegläschen vorher gewogen sind und die Gewichte der Nieren meist auf einige Milligramme geschätzt werden können. Ich babe das Gewicht stets auf $1 \mathrm{mg}$ genau festgestellt. Durch das Abtrocknen der Organe entstehen, je nach deren Grösse Fehler von 1-3 mg (vgl. Wägungen unveränderter Organe).

Alle benutzten Gläser wurden mit Bichromat-Schwefelsäure gereinigt. Ich habe peinlich sauber, aber nicht aseptisch gearbeitet.

Zu den Lösungen wurde stets doppelt destilliertes Wasser benutzt. Fur die zweite Destillation wurde nur Jenaer Glas benutzt; der erste und letzte Teil des Destillates wurde verworfen. - Die Chemikalien waren durehweg reinste Präparate von Kahlbaum.

Die Lösungen der Halogene wurden nach Mohr mit 1/10 n. Silbernitratlösung titriert.

Der Gefrierpunkt wurde, wo angegeben, mit dem B eckmannschen Apparate bestimmt. Genauigkeit: 0,01 ${ }^{\circ}$.

Die Lösungen wurden, wo nicht etwas anderes angegeben, mit $1 / 10$ n. Natronlauge neutralisiert, so dass Phenolphthalein eben rosa Schimmer, Neutralrot gelbe Farbe gab. (Meist brauchte ich 10 Tropfen $1 / 10$ n. $\mathrm{NaOH}$ auf einen Liter Lösung.) 


\section{Versuchsprotokolle.}

Es werden immer nur einige Beispiele einer grösseren Zahl von Versuchen mitgeteilt.

Um das Aufsuchen zu erleichtern, habe ich die Versuche der Reihe nach numeriert.

In den Protokollen ist die Zeit, die Lösung und das Gewicht der Organe in Milligrammen angegeben.

\section{Froschnieren in Ring er'scher Lösung.}

Als Ringer'sche Lösung benutzte ich die von Overton angegebene Mischung: $0,65 \% \mathrm{NaCl}, 0,02 \% \mathrm{KCl}, 0,03 \% \mathrm{CaCl}_{2}$ (wasserfrei). $\Delta=0,41^{\circ}$ bis $0,42^{\circ}$.

Die Lösung wurde meist durch Mischung der einfachen isotonischen Lösungen hergestellt.

Nr. 1. 6. März 1912. $12^{\mathrm{h}} 15^{\prime}$ Präparat. Zwei Nieren in Ringer (Eis).

$\begin{array}{rrr}12^{\mathrm{h}} 30^{\prime} & 92 \mathrm{mg} \\ 3 \mathrm{~h} 40^{\prime} & 84 \% \\ 7 \mathrm{~h} 00^{\prime} & 77 \%\end{array}$

7. März 1912. 9 h $45^{\prime} \quad 70$,

11 h $45^{\prime}: 70$,

$4 \mathrm{~h}^{\prime} 30^{\prime} 68$ "

11 h $30^{\prime}$ p. m. 69 "

8. März 1912. 8 h $40^{\prime} \quad 70$ n

5 h $30^{\prime} 67$,

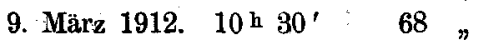

Resultat: Vom zweiten bis vierten Tage Gewichtskonstanz.

Nr. 2. 13. Sept. 1911. 7 h $30^{\prime}$ p. m. Präparat. Zwei Nieren in Ringer (Eis).

14. Sept. 1911. $10^{\mathrm{h}} 15^{\prime}$

$4^{\text {h }} 10^{\prime}$

7 h $15^{\prime}$

15. Sept. 1911. 9 b $15^{\prime}$

a) $52 \mathrm{mg}$ b) $52 \mathrm{mg}$

$4 \mathrm{~b}^{\prime}$

7 h $10^{\prime}$

16. Sept. 1911. $10^{\mathrm{h}} 20^{\prime}$

49 " 49 "

$47, \quad 49 \%$

$44 n \quad 45 n$

$43 n .46 n$

44,46 ,

42 " 44 ,

18. Sept. 1911. 11 h $00^{\prime}$ a. m. 42 , 44 ,

19. Sept. 1911. 11 h $00^{\prime}$ a.m. 44 n 45 n

21. Sept. 1911. 11 h $00^{\prime}$ a. $\mathrm{m} .44$ " 45 "

23. Sept. 1911. 11 h $45^{\prime}: 50^{\circ}$, 47 ”

Resultat: Vom dritten bis neunten Tage Gewichtskonstanz. 
Nr. 3. Frosch 6 Stunden in einem trockenen Glase.

25. Okt. 1911. 7 h $40^{\prime}$ p.m. beide Nieren frisch präpariert und gewogen :

26. Okt: 19]1. 11 h $30^{\prime}$

a) $77 \mathrm{mg} \quad$ b) $75 \mathrm{mg}$ in Ringer (Eis).

27. Okt. 1911. $10^{\mathrm{h}} 30^{\prime}$

73 ,

67 ,

28. Okt. 1911. $12^{\text {h }} 45^{\prime}$

$65 n .61 n$

66,59 ,

Resultat: Vom dritten Tage an Gewichtskonstanz. Anfängliche Gewichtsabnahme ca. $20 \%$.

Nr. 4. Frosch 24 Stunden in einem trockenen Glase.

7. März 1912. $11^{\mathrm{h}} 20^{\prime}$ a. m. eine Niere frisch präpariert und gewogen : $44 \mathrm{mg}$ in Ringer (Eis).

5 h $00^{\prime}$ p. m. 47 ,

11 h $45^{\prime}$ p. m. 43 ,

8. März 1912. 8 h $50^{\prime}$ 'a. m. 44 "

5 h $40^{\prime}$ p. m. 39 "

9. März 1912. $10^{\text {h }} 45^{\prime} \quad 40$,

6 h $00^{\prime} \quad 41$,

10. März 1912. $10^{\text {h }} 00^{\prime}$ a. m. 41 "

Resultat: Anfänglich Gewichtsabnahme ca. 10\%.

Nr. 5. Frosch 24 Stunden in einem trockenen Glase.

11. März 1912. $10^{\text {h }} 00^{\prime}$ a. m. Präparat. Zwei Nieren in Ringer (Eis). 4 h 25 ' p. m. $90 \mathrm{mg}$

5 h $25^{\prime} \quad 88$,

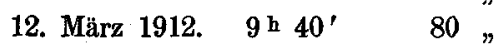

$10^{\mathrm{h}} 40^{\circ} \quad 80^{\prime}$ "

$11^{\mathrm{h}} 50^{\prime} \quad 79$,

12 h $40^{\prime} \quad 79$,

3 h $45^{\prime} \quad 78$,

$6^{\text {h }} 00^{\prime} \quad 79$,

8 h $00^{\prime} \quad 80$,

13. März 1912. $10^{\mathrm{h}} 45^{\prime}$ a. m. 77 "

Resultat: Vom zweiten Tage an Gewichtskonstanz.

Versuche mit Serum.

Steril aus der Vena mediana eines gesunden Menschen entnommenes Blut wird defibriniert, das Serum auf $56^{\circ}$ erhitzt und mit destilliertem Wasser zur Isotonie verdünnt..

Nr. 6. 31. Mai 1912. Präparat. Nieren sofort gewogen.

Erster Frosch

Zweiter Frosch

$10^{\mathrm{h}} \quad \begin{array}{llll}\text { a) } 94 \mathrm{mg} & \text { b) } 98 \mathrm{mg} & \text { a) } 79 \mathrm{mg} & \text { b) } 80 \mathrm{mg}\end{array}$ beide a) in Ringer, beide b) in Serum
5 h $30^{\prime}$
a) $71 \mathrm{mg}$ b) $67 \mathrm{mg}$
a) $67 \mathrm{mg}$ b) $61 \mathrm{mg}$

1. Juni 1912. 9h $30^{\prime}$

69 \% 67 "

$6 \mathrm{~h} 00^{\prime}$

70 "

$71 "$

58 " 59 ,

$57 "$ " 59 "

Resultat: Anfänglicbe Gewichtsabnahme in Ringer und in Serum gleich. 
Nr. 7. 17. Juli 1912. Grosser Frosch. Zwei Nieren frisch präpariert.

\begin{tabular}{|c|c|c|}
\hline $11^{\text {b }} 30^{\circ}$ & $\begin{array}{c}\text { a) } 119 \\
\text { in } 1 / 8 \mathrm{Ringer}\end{array}$ & $\begin{array}{c}\text { b) } 130 \\
\text { in } 3 / 4 \mathrm{Ringer}\end{array}$ \\
\hline $12 \mathrm{~h} 50^{\prime}$ & 133 & 140 . \\
\hline 3 h $40^{\prime}$ & 133 & 134 \\
\hline 5 h $00^{\prime}$ & 131 & 131. \\
\hline$b^{h}$ h $50^{\prime}$ & 129 & 130 \\
\hline $10^{\mathrm{h}} 30^{\prime}$ & 125 & 127 \\
\hline 9 h $10^{\prime}$ & 122 & 122 \\
\hline $7 \mathrm{~h} 20^{\prime}$ & 123 & 123 \\
\hline \multicolumn{3}{|c|}{ beide in $1 / 1$ Ringer } \\
\hline $9 \mathrm{~h} 40^{\prime}$ & 90 & 108 \\
\hline $4^{\text {h }} 20^{\prime}$ & 91 & 109 \\
\hline
\end{tabular}

Resultat: In verdünnter $R$ ing e r - Lösung erst Gewichtszunahme, dann langsame Abnahme; rom zweiten Tage an Gewichtskonstanz.

\section{Froschnieren in anisotonischen $R$ in $g$ e $r$ - Lösungen.}

In den folgenden Versuchen bedeutet stets $1 / 1$ Ringer eine dem Froschserum isotonische Lösung, $1 / 2$ Ringer eine auf die Hälfte verdünnte Lösung usw.

Nr. 8. 9. März 1912. Eine Niere seit zweimal 24 Stunden in Ringer (Eis).

$$
\begin{array}{r}
10^{\mathrm{h}} 45^{\prime} \\
6 \mathrm{~h} 00^{\prime}
\end{array}
$$

$40 \mathrm{mg}$

10. März 1912. $10^{\mathrm{h}} 00^{\prime}$ a. $\mathrm{m}$.

$11^{\mathrm{h}} 45^{\prime}$

41 ,

11. März 1912. 9 h $30^{\prime}$ a. m.
5 h $00^{\prime}$ p. m.

11. März 1912. 9 h $30^{\prime}$ a. m.
5 h $00^{\prime}$ p. m.

$$
\text { in } 1 / 2 \text { Ringer }
$$
$50 \mathrm{mg}$ $49 "$

12. März 1912.

$$
\begin{array}{cc}
9 \text { h } 40^{\prime} & \text { in } 1 / 1 \text { Ringer zurück } \\
6 \text { h } 00^{\prime} \text { p. m. } & 40 \mathrm{mg} \\
42, "
\end{array}
$$

Resultat: In $1 / 2$ Ringer um $22 \%$ zugenommen.

Nr. 9. 12. März 1912. Eine Niere seit 24 Stunden in Ringer (Eis).

$$
\begin{array}{r}
9 \text { h } 40^{\prime} \\
12^{\text {h }} 40^{\prime} \\
3 \text { h } 45^{\prime} \\
6 \text { h } 00^{\prime} \\
8 \text { h } 00^{\prime}
\end{array}
$$$$
73 \mathrm{mg}
$$$$
74 n
$$$$
74 \text {, }
$$$$
\text { in } 1 / 2 \text { Ringer }
$$$$
98 \mathrm{mg}
$$$$
98 \text {, }
$$

in $1 / 1 \mathrm{Ringer}$ zurück

13. März 1912. ' $10^{\text {h }} 45^{\prime}$ $69 \mathrm{mg}$

$$
5 \text { h } 00^{\prime}
$$

72 ,

14. März 1912. $11^{\mathrm{h}} 40^{\prime}$

71 "

Resultat: In $1 / 2$ Ringer um $32 \%$ zugenommen. 
Nr. 10. Zwei Nieren.

26. Juli 1911.

\begin{tabular}{|c|c|}
\hline 3 h $00^{\prime}$ & 76 , \\
\hline 3 h $40^{\prime}$ & 79 \\
\hline $4 \mathrm{~h} 20^{\prime}$ & 76 \\
\hline 4 h $55^{\prime}$ & $75 \%$ \\
\hline $4^{\text {h }} 58^{\prime}$ & in $1 / 2$ Ringer \\
\hline 5 h $50^{\prime}$ & $93 \mathrm{mg}$ \\
\hline $6 \mathrm{i}^{\mathrm{h}} 50^{\prime}$ & 94 n \\
\hline 8 h $45^{\prime}$ & 93 \\
\hline 8 h $50^{\prime}$ & in $1 / 1 \mathrm{Ringer}$ zurück \\
\hline 9 h $50^{\prime}$ & $72 \mathrm{mg}$ \\
\hline 10 h $50^{\prime}$ & $73 n$ \\
\hline $8^{\text {h }} 00^{\prime}$ & $75 \%$ \\
\hline 3 म $35^{\prime}$ & 67 \\
\hline 9 b $10^{\prime}$ & $71 ”$ \\
\hline 9 h $15^{\prime}$ & in $1 / 2 \mathrm{Ringer}$ \\
\hline $10^{\text {h }} 10^{\prime}$ & $92 \mathrm{mg}$ \\
\hline $11{\mathrm{~h} 05^{\prime}}^{\prime}$ & 91 \\
\hline $11^{\text {h }} 10^{\prime}$ & in $1 / 1 \mathrm{Ringer}$ zurüc \\
\hline
\end{tabular}

28. Juli 1911. $12^{\text {h }} 15^{\prime}$ a. $\mathrm{m}$.

$70 \mathrm{mg}$

10 h $45^{\prime}$

66 ,

$12^{\text {h }} 55^{\prime}$

69 ,

1 h $00^{\prime}$

in $3 / 4 \mathrm{Ringer}$

3 h $45^{\prime}$

$77 \mathrm{mg}$

5 h $25^{\prime}$

77 ,

5 h $30^{\prime}$

7 h $40^{\prime}$

in $1 / 1$ Ringer zurück

29. Juli 1911. 12 h $15^{\prime}$ p. m.

71 ,

12 h $20^{\prime}$

in $2 / 1 \mathrm{Ringer}$

5 h $55^{\prime}$

$61 \mathrm{mg}$

7 h $10^{\prime}$

$61 "$

7 h $15^{\prime}$

30. Juli 1911: $10^{\mathrm{h}} 30^{\text {, }}$

in $1 / 1 \mathrm{R}$ ing er zurück

$79 \mathrm{mg}$

Resultat: In $1 / 2 \mathrm{Ring}$ er $25 \%$ bzw. $30 \%$, in $3 / 4 \mathrm{Ringer} 12 \%$ zugenommen (in $2 / x \mathrm{Ring}$ or $14 \%$ abgenommen; unsicher, weil die Organe durch den langen Versuch geschädigt waren: Gewichtszunahme in $1 / 1$ Ringer!).

Nr. 11. Zwei Nieren. Zweimal 24 Stunden in Ringer (Eis).
3. Aug. 1911. 12 h $00^{\prime}$
$61 \mathrm{mg}$
$12 \mathrm{~h} 05^{\prime}$ p. m. in $1 / 2 \mathrm{Ringer}$
4. Ang. 1911. $9 \mathrm{~h} 30^{\prime}$ a. $\mathrm{m}$.
$82 \mathrm{mg}$
5. Aug. 1911. 1 h $00^{\prime}$ p. m.
$80 \mathrm{mg}$
7. Aug. 1911. $10 \mathrm{~h} 00^{\prime}$ a. $\mathrm{m}$. 82 "
8. Aug. 1911. $9 \mathrm{~h} 00^{\prime}$ a.m. 79 "

Resultat: In $1 / 2$ Ring er $33 \%$ zugenommen; $>4$ Tage Gewichtskonstanz. 
Nr. 12. Eine Niere eines ziemlich grossen Frosches.

1. April 1912. $12^{\mathrm{h}} 00^{\prime} \quad$ Präparat in Ringer (Eis).

2. April 1912. 5 h $^{\prime} 15^{\prime}$ p. m. $\quad 74 \mathrm{mg}$

3. April 1912. 7 h $10^{\prime}$ a. m. 73 ,

$$
\begin{array}{rc}
7 \mathrm{~h} 15^{\prime} & \text { in } 3 / 4 \mathrm{Ringer} \\
11 \mathrm{~h} 10^{\prime} & 79 \mathrm{mg}
\end{array}
$$$$
12 \text { h } 15^{\prime} \quad 80 \text {, }
$$$$
12 \mathrm{~h} 25^{\prime} \text { in } 1 / 1 \text { Ringer }
$$$$
4 \mathrm{~h} 00^{\prime} \quad 72 \mathrm{mg}
$$

4. April 1912. 9 h $15^{\prime} \quad 73$ n

$$
\begin{array}{ll}
6 \text { h } 40^{\prime} & 73 \text { " } \\
9 \text { h } 15^{\prime} & 73 \text { ” }
\end{array}
$$

$$
\begin{array}{ll}
11 \text { h } 30^{\prime} & 89 \mathrm{mg} \\
12 \text { h } 30^{\prime} & 88 \%
\end{array}
$$$$
\text { in } 1 / 1 \mathrm{R} \text { inger }
$$

$$
7 \text { h } 50^{\prime} \quad 74 \mathrm{mg}
$$

5. April 1912. $12^{\mathrm{h}} 30^{\prime} \quad 75 "$

Resultat: In $3 / 4$ Ringer $10 \%$, in $1 / 2$ Ringer $22 \%$ zugenommen.

Nr. 13. Kleiner Frosch. Zwei Nieren.

22. Juni 1912. Präparat.

24. Juni 1912. 12 h $30^{\prime}$
a) $36 \mathrm{mg}$
b) $43 \mathrm{mg}$

in $1 / 2$ Ringer in $1 / 4$ Ringer
5 h $30^{\prime}$
a) $45 \mathrm{mg}$
45 "
b) $76 \mathrm{mg}$
7 h $15^{\prime}$
in $1 / 1$ Ringer in $1 / 1$ Ringer

25. Juni 1912. $\begin{aligned} & 9 \mathrm{~h} 30^{\prime} \\ & 5 \mathrm{~h} 15^{\prime}\end{aligned}$
a) $35 \mathrm{mg}$
b) $56 \mathrm{mg}$

$\begin{array}{ll}35 " & 55 " \\ - & 56 "\end{array}$

26. Juni 1912. $9{\mathrm{~h} 00^{\prime}}^{\prime}$

Resultat: In $1 / 2$ Ringer $25 \%$, in $1 / 4$ Ringer $77 \%$ zugenommen. In 1/4 Ringer Gewichtskonstanz, aber nicht vollkommen reversibel.

\section{Nr. 14. Grosser Frosch. Zwei Nieren.}

22. Juni 1912. 6 h $^{\circ} 00^{\prime}$ p. m. Präparat in Ringer (Eis).

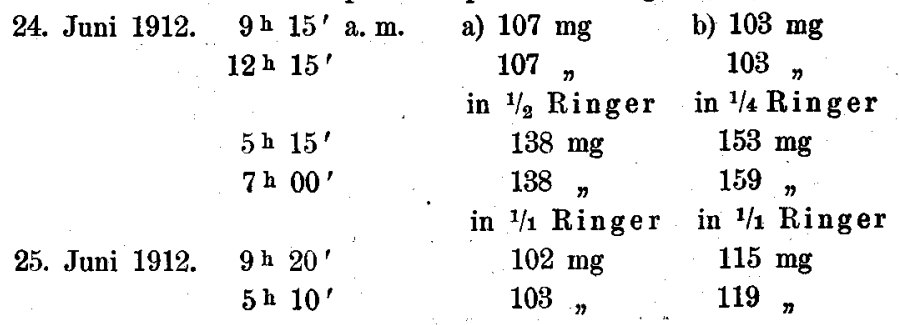

Resultat: In $1 / 2$ Ringer $28 \%$, in $1 / 4$ Ringer $>55 \%$ zugenommen (noch kein Gleichgewicht erreicht). 
Nr. 15. Frosch. Eine Niere.

31. Mai 1912. Präparat.

2. Juni 1912. $\quad 9^{\text {h }} 30^{\prime} \quad 62 \mathrm{mg}$ $7 \mathrm{~h} 00^{\prime} 60$,

3. Juni 1912. $7 \mathrm{~h} \mathrm{~h} 45^{\prime} \quad 60$, in $1 / 4$ Ringer

\begin{tabular}{|c|c|}
\hline $9 \mathrm{~h} 05^{\prime}$ & $83 \mathrm{mg}$ \\
\hline $10{\mathrm{~h} 00^{\prime}}^{\prime}$ & 97 \\
\hline $11^{\text {h }} 30^{\prime}$ & 108 \\
\hline 12 म $40^{\circ}$ & 115 \\
\hline $4^{\text {h }} 10^{\prime}$ & $\begin{array}{c}92 \\
n 1 / 18\end{array}$ \\
\hline
\end{tabular}

4. Juni 1912. 11 h $00^{\prime} 57$,

Resultat: In 1/4 Ringer um $90 \%$ zugenommen (kein Gleichgewicht).

Nr. 16. Je eine Niere von zwei Fröschen.

31. Mai 1912. $10^{\mathrm{h}} 00^{\prime}$ Präparat in Ringer (Eis).

2. Juni 1912 . 9 h 30 ' 7 h $00^{\prime}$

3. Juni $1912 . \quad 7$ b $45^{\prime}$
a) $71 \mathrm{mg}$
b) $58 \mathrm{mg}$
72 58 n
72 , 58 , beide in $2 / 1 \mathrm{R}$ inger

\begin{tabular}{|c|c|c|}
\hline 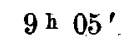 & $58 \mathrm{mg}$ & $48 \mathrm{mg}$ \\
\hline $10^{\mathrm{h}} 00^{\prime}$ & 57 & $\begin{array}{c}48 \\
\text { in } 1 / 1 \text { Ringer }\end{array}$ \\
\hline $12^{\text {h }} 40^{\prime}$ & $\begin{array}{c}58 \mathrm{mg} \\
\text { in } 1 / 1 \text { Ringer }\end{array}$ & $55 \mathrm{mg}$ \\
\hline $4^{\text {h }} 10^{\prime}$ & $69 \mathrm{mg}$ & $58 \mathrm{mg}$ \\
\hline 6 h $45^{\prime}$ & $72 \%$ & 58 , \\
\hline 11 h $00^{\prime}$. & $72 n$ & - \\
\hline
\end{tabular}

Resultat: ln $2 / 1$ Ringer $19 \%$ bzw. $17 \%$ abgenommen.

Nr. 17. Zwei Nieren in Ringer (Eis).

25. Juli 1911. 4 h 40 p. m. $\quad 60 \mathrm{mg}$

$$
\begin{aligned}
& 5 \text { h } 35^{\prime} \quad 63 \text {, } \\
& 7 \text { h } 05^{\prime} \quad 63 \text {, } \\
& 7^{\text {h } 10^{\prime}} \text { in } 2 / 1 \text { Ringer } \\
& 8 \text { h } 35^{\prime} \quad 47 \mathrm{mg} \\
& 10^{\mathrm{h}} 45^{\prime} \quad 45 \text {, } \\
& 11^{\mathrm{h}} 15^{\prime} 45 \text {, } \\
& \text { in } 1 / 1 \text { Ringer }
\end{aligned}
$$

26. Juli 1911. $12^{\mathrm{h}} 15^{\prime}$ a. m. $51 \mathrm{mg}$

$\begin{aligned} 8 \text { h } 00^{\prime} & 60 ", \\ 11 \text { h } 00^{\prime} & 59 " \\ 3 \text { h } 20^{\prime} & 58\end{aligned}$

Resultat: In $2 / 1$ Ringer $27 \%$ abgénommen. 


\section{Verhalten von Froschnieren in Kaliumehloridlösung.}

Lösung: $0,89 \%$ reinstes Kaliumehlorid; mit $1 / 10 \mathrm{n}$. Silbernitrat und Kaliumchromat titriert $=0,12$ norm. $A$ etwa $0,41^{\circ}$. Mit $1 / 10$ n. $\mathrm{NaOH}$ neutralisiert.

Nr. 18. 11. Aug. 1911. 9 h $25^{\prime}$

11 h $30^{\prime}$

$12^{\text {h }} 45^{\prime}$

$12^{\text {h }} 55^{\prime}$

$4^{\text {h }} 12^{\prime}$

$6 \mathrm{~h} 20^{\prime}$

$10^{\mathrm{h} 20^{\prime}}$ in $\mathrm{Ringer}$

$39 \mathrm{mg}$

40 ,

in Kaliumchlorid

$68 \mathrm{mg}$

79 n

83 ,

12. Aug. 1911. $10^{\mathrm{h}} 35^{\prime}$ a. m. 89 "

Nr. 19. 10. Aug. 1911. $1^{\text {h }} 45^{\prime}$ p. m. in Ringer (Eis)

$4 \mathrm{~h}^{\mathrm{h}} 50^{\prime} \quad 52 \mathrm{mg}$

5h $50^{\prime}$

53 ;

5 h $55^{\prime}$

6 h $55^{\prime}$

in Kaliumchlorid

7h $55^{\prime}$

$58 \mathrm{mg}$

$11^{\mathrm{h}} 05^{\prime}$

11. Aug. 1911. 9h $15^{\prime}$

$4^{\mathrm{h}} 20^{\prime}$

$10^{\mathrm{h}} 25^{\prime}$

77 ,

$96 \%$

106

108 "

$110 \%$

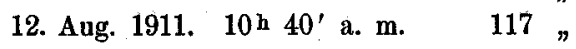

8 h $10^{\prime} \mathrm{p} \mathrm{m}$. 116 ,

13. Aug. 1911. $10^{\mathrm{h}} 00^{\prime}$ a. m. 115 n

14. Aug. 1911. $11^{\text {h }} 00^{\prime}$ a. m. 117 ,

15. Aug. 1911. $1^{\text {h }} 00^{\prime}$ p. m. $113^{\prime}$ "

16. Aug. 1911. 5h 25' 112 "

17. Aug. 1911. $10^{\text {h }} 00^{\prime} \quad 111$,

Nr. 20. 11. Aug. 1911. $10^{\mathrm{h}} 15^{\prime}$ in Ringer (Eis)

\begin{tabular}{|c|c|}
\hline $12^{\text {h }} 40^{\prime}$ & $44 \mathrm{mg}$ \\
\hline 4 h $08^{\prime}$ & 43 \\
\hline $4 \mathrm{~h} 10^{\prime}$ in & Kaliumchlorid \\
\hline 5 h $10^{\prime}$ & $57 \mathrm{mg}$ \\
\hline 5 h $13^{\prime}$ & in Ringer \\
\hline 6 h $13^{\prime}$ & $48 \mathrm{mg}$ \\
\hline 7 h $05^{\prime}$ & 45 \\
\hline $10^{\mathrm{h}} 15^{\prime}$ & $43 "$ \\
\hline $10^{\mathrm{h}} 30^{\prime}$ & $42 \mathrm{mg}$ \\
\hline $12^{\text {h }} 40^{\prime}$ & $43 \%$ \\
\hline 12 h $43^{\prime}$ in & n $1 / 2$ Ringe \\
\hline
\end{tabular}

12. Aug. 1911. $10^{\mathrm{h}} 30^{\prime} \quad 42 \mathrm{mg}$

$12 \mathrm{~h} 43^{\prime}$ in $1 / 2$ Ringer 
12. Aug. 1912. $4^{\text {h }} 50^{\prime} \quad 56 \mathrm{mg}$

6 h $10^{\prime} \quad 54$,

8 h $10^{\prime} 52$,

13. Aug. 1911. $10^{\mathrm{h}} 20^{\prime} \quad 52$ " $10^{\mathrm{h}} 25^{\prime}$ in $1 / 1$ Ringer

14. Aug. 1911. $10^{\mathrm{h}} 20^{\prime}$ a. m. $45 \mathrm{mg}$.

Resultat: In 1 Stunde in $\mathrm{KCl}$ um $14 \mathrm{mg}=>30 \%$ zugenommen; reversibel.

Nr. 21. Zwei Nieren. Kleiner Frosch.

11. Aug. 1911. $10^{\mathrm{h}} 45^{\prime}$ p. m. in Ringer (Eis).

12. Aug. 1911. 8 h $15^{\prime}$ $10 \mathrm{~h} 17^{\prime}$ $66 \mathrm{mg}$ 68 .

$\begin{array}{rc}10^{\mathrm{h}} 20^{\prime} & \text { in Kaliumchlorid } \\ 4 \mathrm{~h} 25^{\prime} & 74 \mathrm{mg} \\ 4 \mathrm{~h} 30^{\prime} & 106 \% \\ 5 \mathrm{~h} 30^{\prime} & \text { in Ringer } \\ 7 \mathrm{~h} 55^{\prime} & 88 \mathrm{mg}^{\prime}\end{array}$

13. Aug. 1911. $10^{\mathrm{h}} 00^{\prime}$ a.m. $68 "$

14. Aug. 1911. $10^{\mathrm{h}} 00^{\prime}$ a. $\mathrm{m}$. $67 \%$

$\begin{array}{cc}10 \mathrm{~h} 05^{\prime} & \text { in } 1 / 2 \mathrm{Ringer} \\ 5 \mathrm{~h} 08^{\prime} \text { p. m. } & 90 \mathrm{mg} \\ 7 \mathrm{~h} 05^{\prime} & 90 \% \\ 7 \mathrm{~h} 10^{\prime} & \text { in } 1 / 1 \mathrm{Ringer} \\ 12 \mathrm{~h} 30^{\prime} & 69 \mathrm{mg} \\ 6 \mathrm{~h} 15^{\prime} & 69,\end{array}$

Resultat: In 6 Stunden in $\mathrm{KCl}$ um $38 \mathrm{mg}=56 \%$ zugenommen; reversibel.

Nr. 22. Zwei Nieren. Kleiner Frosch.

18. Sept. 1911. In Ringer (Eis)

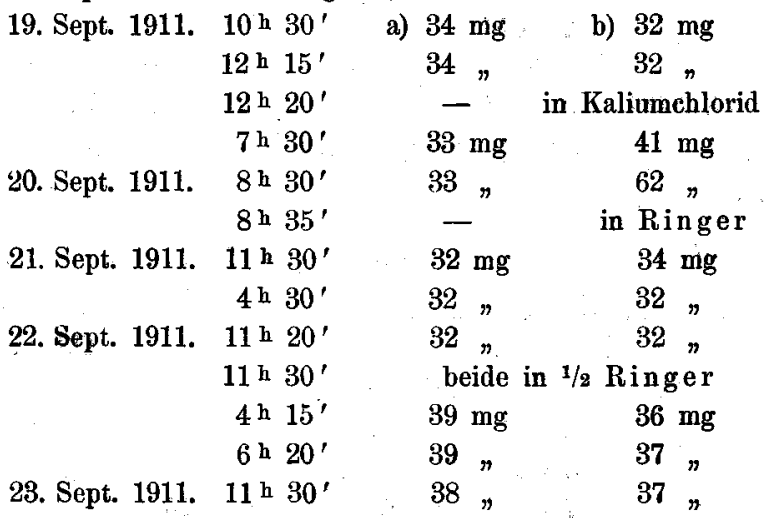

Resultat: In 18 Stunden in $\mathrm{KCl}$ um $>90 \%$ zugenommen; reversibel. 
Nr. ๑ิ. Eine Niere.

1. Nov. 1911. Präparat in Ringer (Eis).

3. Nov. 1911. $10^{\mathrm{h}} 15^{\prime}$ a. m. $51 \mathrm{mg}$ 5 h $10^{\prime}$ p. m. 49

4. Nov. 1911. 10 h $00^{\prime}$ a. $\mathrm{m}$. in $45 \%$ ige $\mathrm{KCl}-\mathrm{Lösung}$

5. Nov. 1911. $10^{\mathrm{h}} 00^{\prime}$ $101 \mathrm{mg}$

6. Nov. 1911. $12 \mathrm{~h} 00^{\prime}$ 112 " 114 ,

7. Nov. 1911, $10^{\mathrm{h}} 15^{\prime}$ 115

Nr. 24. Zwei Nieren von zwei verschiedenen Fröschen. Zweimal 24 Stunden in Ringer (Eis).

17. Juli 1912 . $8^{\text {h }} 30^{\prime}$ $10^{\text {b }} 40^{\prime}$ 10 h $50^{\prime}$

11 h $30^{\prime}$ 1 h $00^{\prime}$ 3 h $30^{\prime}$

4 h $50^{\prime}$ 7 h $00^{\prime}$ 10 h $20^{\prime}$

18. Juli 1912. 9 h $00^{\prime}$ $12^{\text {h }} 40^{\prime}$

$3 \mathrm{~b} 50^{\prime}$ 7 h $10^{\prime}$

19. Juli $1912 . \quad 9$ h $30^{\prime}$

$$
\begin{aligned}
& \text { a) } 103 \mathrm{mg} \quad \text { b) } 109 \mathrm{mg} \\
& 105 \pi \quad 113 \text { n } \\
& \text { beide in } 2 / 1 \mathrm{KCl} \\
& 94 \mathrm{mg} \quad 98 \mathrm{mg} \\
& 90 \text { n } 96 \text { " } \\
& 96.100 \\
& \text { in Ringer } \\
& 107 \mathrm{mg} \quad 104 \mathrm{mg} \\
& 110,109 \\
& 110 \text {. } 115 \% \\
& \text { - in Ringer } \\
& 111 \mathrm{mg} \quad 131 \mathrm{mg} \\
& \text { in } 1 / 2 \text { Ringer - } \\
& 138 \mathrm{mg} \\
& 142 \text { n } \\
& 144 \text {, } \\
& 131 \mathrm{mg} \\
& \text { in } 1 / 1 \mathrm{Ringer} \\
& 108 \mathrm{mg} \\
& 133 \mathrm{mg} \\
& 111 \mathrm{mg} \\
& \text { in } 1 / 2 \mathrm{Ringer} \\
& 170 \mathrm{mg} \\
& 171
\end{aligned}
$$$$
4 \text { h } 20^{\prime}
$$$$
7 \text { h } 00^{\prime}
$$

20. Juli 1912. 9 h $30^{\prime} \quad-\quad 129 \mathrm{mg}$.

Resultat: In hypertonischer Kaliumchloridlösung erst Gewichtsabnahme, dann Zunabme.

\section{Versuch an gefrorenen Nieren.}

Nr. 25. 20. Mai 1912. 5 h $00^{\prime}$ p. m. zwei Nieren eines mittelgrossen Frosches werden in einem Gefrierrohre in einer Mischung von $\mathrm{CO}_{2}$-Schnee und Äther gefroren und nach $15^{\prime}$ wieder aufgetant.

$$
\begin{array}{ccc}
5 \mathrm{~b} 30^{\prime} & \text { a) } 60 \mathrm{mg} & \text { b) } 68 \mathrm{mg} \\
5 \mathrm{~h} 35^{\prime} & \text { in Ringer } & \text { in KCl-Lösung } \\
7 \mathrm{~h} 05^{\prime} & 69 \mathrm{mg} & \mathbf{7 5 ~ \mathrm { mg }} \\
9 \mathrm{~h} 35^{\prime} & 70 \% & 77 \%
\end{array}
$$


21. Mai 1912. 7 h $30^{\circ} \quad 72 \mathrm{mg} \quad 72 \mathrm{mg}$

\begin{tabular}{rcr} 
& \multicolumn{2}{c}{ beide in $1 / 2$ Ringer } \\
$9 \mathrm{~h} 00^{\circ}$ & $69 \mathrm{mg}$ & $71 \mathrm{mg}$ \\
$10^{\circ} \mathrm{h} 35^{\prime}$ & $69 \%$ & $73 "$ \\
& in $1 / 1 \mathrm{Ringer}$ & - \\
$11 \mathrm{~h} 50^{\circ}$ & $68 \mathrm{mg}$ & -
\end{tabular}

Resultat: An gefrorenen Nieren in 1/2 Ringer und in KCl keine Änderung.

IV. Das Verhalten von Froschnieren in Lösungen von Halogensalzen der anderen Alkalien.

\section{Natriumchlorid.}

Lösung: $\quad 0,7 \%$ reinstes Natriumchlorid (Kahlbaum). Titriert $=0,12$ normal. $A$ etwa $0,41^{\circ}$.

Nr. 26. 14. Sept. 1911. Zwei Nieren präpariert in Ringer (Eis).

\begin{tabular}{|c|c|c|}
\hline $11^{\text {h }} 00^{\prime}$ & $\begin{array}{l}\text { a) } 64 \mathrm{mg} \\
\text { in } \mathrm{Ringer}\end{array}$ & $\begin{array}{l}\text { b) } 66 \mathrm{mg} \\
\text { in } \mathrm{NaCl}\end{array}$ \\
\hline 6 h $00^{\circ}$ & $49 \mathrm{mg}$ & $51 \mathrm{mg}$ \\
\hline 7 h $30^{\prime}$ & $50 "$ & $51 n$ \\
\hline 9 h $20^{\prime}$ & 47 & 47 \\
\hline $4 \mathrm{~h} 00^{\prime}$ & $47 "$ & 47 \\
\hline 7 h $20^{\prime}$ & $47 "$ & 47 \\
\hline $10^{\mathrm{h}} 45^{\prime}$ & $46 "$ & 45 \\
\hline $11 \mathrm{~h} 15^{\prime}$ & $46 "$ & 50 \\
\hline 9 h $45^{\prime}$ & 51 & 55 \\
\hline
\end{tabular}

Nr. 27. 4. Nov. 1911. $11^{\mathrm{h}} 15^{\prime}$ eine Niere präpariert in Ring er (Eis).

5. Nov. 1911. 12 h $30^{\prime} \quad 25 \mathrm{mg}$

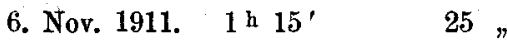
in $0,7 \%$ iges $\mathrm{NaCl}$

7. Nov. 1911. $10 \mathrm{~h} 00^{\prime} \quad 25 \mathrm{mg}$

8. Nov. 1911. $10^{\mathrm{h}} 30^{\prime} 25$ " in $0,35 \%$ iges $\mathrm{NaCl}$ 5 h $30^{\prime} \quad 32 \mathrm{mg}$

9. Nov. 1911. 9 h $^{4} 5^{\prime} \quad 31$ ” in $0,7 \%$ iges $\mathrm{NaCl}$

10. Nov. 1911. 9 h $30^{\prime} \quad 25 \mathrm{mg}$

2. Lithiumehlorid.

Lösung: $0,5 \% \mathrm{LiCl} ; 0,12 \mathrm{n}$.

Nr. 28. 4. Nov. 1911. $11^{\mathrm{h}} 15^{\prime}$ zwei Nieren (von verschiedenen Fröschen) präpariert in Ringer.
5. Nov, 1911. $12^{\text {h }} 30^{\prime}$
a) $24 \mathrm{mg}$
b) $35 \mathrm{mg}$
6. Nov. 1911. $1 \mathrm{~h} 15^{\prime}$
26 34 , beide in $\mathrm{LiCl}$ 
7. Okt. 1911. $10^{\mathrm{h}} 00^{\prime}$

8. Okt. 1911. $10^{\mathrm{h} 30^{\prime}}$

$5 \mathrm{~h} 30^{\circ}$

9. Okt. 1911. $9 \mathrm{~h}^{4} 5^{\prime}$

$$
5 \text { h } 30^{\prime}
$$

10. Okt. 1911. 9 h $30^{\prime}$ $\begin{array}{lr}24 \mathrm{mg} & 34 \mathrm{mg} \\ 26 \% & 37 \% \\ \text { beide in } & 0,25 \% \text { iges } \mathrm{LiCl} \\ 39 \mathrm{mg} & 60 \mathrm{mg}\end{array}$

39 " 60 ,

beide in $0,5 \%$ iges $\mathrm{LiCl}$

$26 \mathrm{mg} \quad 36 \mathrm{mg}$

27 "

36

Resultat: In $1 / 2 \mathrm{LiCl}$ um $50 \%$ bzw. $62 \%$ zugenommen.

Nr. 29. 24. Juni 1912. 6 h $^{\circ} 00^{\prime}$ p. m. Präparat. Drei Nieren von zwei Fröschen.

26. Juni 1912. $\quad 7_{\text {h }} 55^{\prime}$

$11^{\mathrm{h}} 30^{\prime}$

2 h $25^{\prime}$

2 h $30^{\prime}$

$5^{\text {h }} 20^{\prime}$

7 h $50^{\prime}$

$11^{\text {h }} 30^{\prime}$

27. Juni 1912. $9 \mathrm{~h} 30^{\prime}$

$12^{\text {h }} 10^{\prime}$

$7 \mathrm{~h} 50^{\prime}$

28. Juni 1912 . $10^{\text {h }} 00^{\prime}$ a) $103 \mathrm{mg}$

98

$\mathrm{LiCl}$

$95 \mathrm{mg}$

$1 / 2 \mathrm{LiCl}$

$114 \mathrm{mg}$

120 "

125

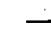

$133 \mathrm{mg}$

133 "

$1 / 1$ Ringer

$94 \mathrm{mg}$

96 , b) $88 \mathrm{mg}$

91 ,

c) $82 \mathrm{mg}$ 82 "

LiCl

Ringer $87 \mathrm{mg} \quad 78 \mathrm{mg}$

$1 / 2 \mathrm{Ringer}{ }_{1 / 2} \mathrm{LiCl}$

$105 \mathrm{mg} \quad 101 \mathrm{mg}$

120 " 109 ,

$109 \% 112 \%$

1/1 Ringer $1 / 1 \mathrm{LiCl}$

$81 \mathrm{mg} \quad 82 \mathrm{mg}$

$84 \pi 82$,

Ringer
$84 \mathrm{mg} \quad 85 \mathrm{mg}$

$84 \ldots 85$ ”

Resultat: In $1 / 2 \mathrm{LiCl}$ um $40 \%$ bzw. $44 \%$, in $1 / 2$ Ringer um $38 \%$ zugenommen.

\section{Rubidiumchlorid.}

Lösung: etwa $1,44 \% \mathrm{RbCl}$ (nach Overton mit $0,7 \%$ igen $\mathrm{NaCl}$ isotonisch) $0,12 \mathrm{n}$.

Nr. 30. 15. Jan. 1912. $10^{\mathrm{h}} 00^{\prime}$ zwei Nieren (von verschiedenen Fröschen) präpariert in Ringer (Eis).
16. Jan. 1912. $10^{\text {h }} 30^{\prime}$
$1^{\text {h }} 00^{\prime}$
a) $58 \mathrm{mg}$
b) $60 \mathrm{mg}$
59 , 58 , beide in Rubidiumchlorid
5 h $30^{\prime}$
17. Jan. 1912. $10^{\mathrm{h}} 30^{\prime}$ $66 \mathrm{mg}$
108 " $68 \mathrm{mg}$
in Ringer zurück 103 "

$\begin{array}{rll}4 \mathrm{~h} 30^{\circ} & 65 \mathrm{mg} & 108 \mathrm{mg} \\ 10 \mathrm{~h} 30^{\circ} & 55 \% & 120 " \\ 12 \mathrm{~h} 00^{\prime} & 53 " & 127 "\end{array}$
18. Jan. 1912. $10^{\mathrm{h}} 30^{\prime}$
19. Jan. 1912. $12^{\mathrm{h}} 00^{\prime}$
53 ,
127 " 


\section{Caesiumchlorid.}

Lösung: etwa 2,03\% $\mathrm{CsCl}$ (nach Overton) $0,12 \mathrm{n}$.

Nr. 31. 15. Jan. 1912. $10^{\mathrm{h}} 00^{\prime}$ zwei Nieren (von verschiedenen Fröschen) präpariert in Ringer.
16. Jan. 1912. $10^{\mathrm{h}} 30^{\prime}$
1 h $00^{\prime}$
a) $66 \mathrm{mg}$
b) $67 \mathrm{mg}$
5 h $30^{\prime}$
64 63 beide in $\mathrm{CsCl}$
17. Jan. 1912. $10^{\mathrm{h}} 30^{\prime}$ $58 \mathrm{mg}$ $58 \mathrm{mg}$
$4^{\text {h }} 30^{\prime}$
18. Jan. $1912.10^{\mathrm{h}} 30^{\prime}$ 65, 67 " $69 \mathrm{mg}$
19. Jan. 1912. $12 \mathrm{~h} 00$ ' 84 " in Ringer 103 $66 \mathrm{mg}$ 60 " 58

Nr. 32. 24. Juni 1912. $6 \mathrm{~h}^{\circ} \mathrm{\circ}$ p. m. Präparat in Ringer (Eis).

26. Juni 1912. 8 h $00^{\prime}$ 11 h $45^{\prime}$

\begin{tabular}{|c|c|}
\hline a) $87 \mathrm{mg}$ & b) $74 \mathrm{mg}$ \\
\hline 85 & 73 \\
\hline in $\mathrm{Cs} C l$ & in $\mathrm{RbCl}$ \\
\hline $84 \mathrm{mg}$ & $79 \mathrm{mg}$ \\
\hline $88 \eta$ & $86 ”$ \\
\hline - & in Ringer \\
\hline $92 \mathrm{mg}$ & $76 \mathrm{mg}$ \\
\hline in Ringer: & - \\
\hline $87 \mathrm{mg}$ & $73 \mathrm{mg}$ \\
\hline 82 & 72 \\
\hline $82 "$ & $71 ”$ \\
\hline beide in & Ringer \\
\hline $113 \mathrm{mg}$ & $102 \mathrm{mg}$ \\
\hline 113 & $101 "$ \\
\hline beide in & Ringer \\
\hline $78 \mathrm{mg}$ & $67 \mathrm{mg}$ \\
\hline $80 "$ & 71 \\
\hline 81 & $72 n$ \\
\hline
\end{tabular}

29. Juni 1912. 9 h $00^{\prime}$

Resultat: In $\mathrm{CsCl}$ und $\mathrm{RbCl}$ deutliche, reversible Gewichtsänderung,

5. Ammoniumchlorid.

Lösung: $0,66 \% \mathrm{NH}_{4} \mathrm{Cl}$, mit $1 / 100 \mathrm{n}$. $\mathrm{NaOH}$ neutralisiert.

Nr. 33. 1. Sept. 1911. $11 \mathrm{~h} 30^{\circ}$ zwei Nieren in Ringer.

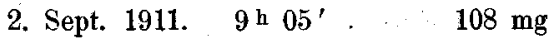
danach in $\mathrm{NH}_{4} \mathrm{Cl}$

$\begin{aligned} 10 \mathrm{~h} 45^{\prime} & 126 \mathrm{mg} \\ 12 \mathrm{~h} 40^{\prime} & 142 \mathrm{\prime} \\ 6 \mathrm{~h} 15^{\prime} & 206 \%\end{aligned}$



3. Sept. 1911. $9 \mathrm{~h}^{2} 5^{\prime}$
$274 \mathrm{mg}$
4. Sept. 1911. 12 h $20^{\prime}$
295
5. Sept. 1911. 5 h $^{\text {h }} 50^{\prime}$
300

Nr. 34. 4. Sept. 1911. $9 \mathrm{~h} 00^{\prime}$ zwei Nieren in Ringer.

$$
\begin{aligned}
& 5 \text { h } 50^{\prime} \text { p. m. } \quad 84 \mathrm{mg} \\
& \text { in } \mathrm{NH}_{4} \mathrm{Cl} \\
& 10^{\mathrm{h}} 45^{\prime} \quad 122 \mathrm{mg} \\
& \text { in Ringer zurück } \\
& 6 \text { h } 30^{\prime} \quad 105 \text {, }
\end{aligned}
$$

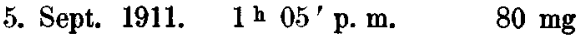

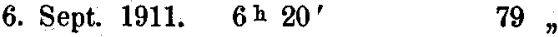

7. Sept. 1911. 12 h $35^{\prime}$ p. m. $108 \mathrm{mg}$

8. Sept. 1911. $1^{\text {h }} 15^{\prime} \quad 80 \mathrm{mg}$

Resultat: In $\mathrm{NH}_{4} \mathrm{Cl}$ in 5 Stunden um $38 \mathrm{mg}=45 \%$ zugenommen, reversibel.

\section{v. Das Verhalten von Frosehnieren in Lösungen von Calcium-, Baryum- und Magnesiumehlorid.}

Lösungen : 0,088 normal (mit 1/10 n. $\mathrm{AgNO}_{3}$ titriert, $\mathrm{BaCl}_{2}$ nach Volhard).

Nr. 35. 27. Juni 1912. Zwei Nieren von zwei verschiedenen Fröschen, zweimal 24 Stunden in Ringer (Eis).

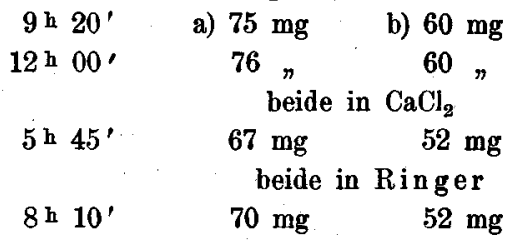

28. Juni 1912 . $10^{\mathrm{h}} 00^{\prime}$

$73+55$

2 b $30^{\prime}$

75,56 ,

beide in $1 / 2$ Ringer

7 h $45^{\prime} \quad 101 \mathrm{mg} \quad 74 \mathrm{mg}$

beide in $1 / 1$ Ringer

29. Juni 1912. $9^{\text {h }} 00^{\prime} \quad 74 \mathrm{mg} \quad 55 \mathrm{mg}$

6 h $45^{\prime} \quad 77$, 57 ,

30. Juni 1912. $10^{\mathrm{b} 00^{\prime}} 79$ n 58 n

Resultat: In $\mathrm{CaCl}_{2}$ reversible Gewichtsabnahme.

Nr. 36. Zwei Nieren vom gleichen Frosch.

6. Sept. 1911. 7 h $00^{\prime}$ p. m. in Ringer (Eis).

7. Sept. 1911. $11^{\mathrm{h}} 30^{\prime}$ 111 mg in $\mathrm{CaCl}_{2}$

$$
5 \text { h } 45^{\prime} \quad 89 \mathrm{mg}
$$



8. Sept. 1911. 12 h $50^{\prime}$
$117 \mathrm{mg}$
9. Sept. 1911. 1 h $00^{\prime}$ p. m.
142 ,
11. Sept. 1911. 12h $15^{\prime}$
150 ,

Nr. 37. Ein Frosch, zwei Nieren.

17. Okt. 1911. $7 \mathrm{~h} 00^{\prime}$ p. m. Präparat in Ringer (Eis).

18. Okt. 1911. $7 \mathrm{~h} 00^{\prime}$ p. m. $\quad$ a) $49 \mathrm{mg} \quad$ b) $45 \mathrm{mg}$

19. Okt. 1911. 12 h $30^{\prime}$ p. m. 46 " 44 "

\begin{tabular}{|c|c|}
\hline & - \\
\hline 6 h $30^{\prime}$ & $46 \mathrm{mg}$ \\
\hline
\end{tabular}

20. Okt. 1911. $10^{\text {h }} 45^{\prime}$

- in Ringer

21. Okt. 1911. 12 h $00^{\prime}$

22. Okt. 1911. 9 h $45^{\prime}$

$46 \mathrm{mg} \quad 36 \mathrm{mg}$

$45, \quad 37$,

44,37 ,

beide in $1 / 2$ Ringer

23. Okt. 1911, 9 h $45^{\prime}$

$55 \mathrm{mg} \quad 48 \mathrm{mg}$

4 h $30^{\prime}$

55 ,

48 ,

Nr. 38. Eine Niere.

8. Nov. 1911. $12^{\mathrm{h}} 15^{\prime}$ Präparat in Ringer (Eis).

10. Nov. 1911. $\quad 4^{\text {h }} 36^{\prime} \quad 67 \mathrm{mg}$

$6^{\text {h }} 00^{\prime} 67$, in $\mathrm{BaCl}_{2}$

11. Nov. 1911. $10^{\text {h }} 00^{\prime} \quad 55 \mathrm{mg}$

$6 \mathrm{~h} 15^{\prime} \quad 61$,

12. Nov. 1911. $11^{\mathrm{h} \mathrm{h}} 30^{\prime} \quad 71$,

13. Nov. 1911. $11^{\text {th }} 40^{\prime} \quad 86$,

14. Nov. 1911. $12^{\text {h }} 40^{\prime}$, 90 ,

15. Nov. 1911. $10^{\text {h }} 00^{\prime} \quad 89$,

16. Nov. 1911. $5^{\text {h }} 00^{\prime} \quad 86$,

Nr. 39. Eine Niere.

17. Okt. 1911. 7h $00^{\prime}$ p. m. Präparat in Ringer (Eis).

18. Okt. 1911. 7 h $00^{\prime}$

19. Okt. 1911, $12^{\text {h }} 30^{\prime}$

$44 \mathrm{mg}$

42 ,

in $\mathrm{BaCl}_{2}$

6 h $30^{\prime}$

$36 \mathrm{mg}$

20. Okt. 1911. $10^{\mathrm{h}} 45^{\prime}$

in Ringer

$41 \mathrm{mg}$

21. Okt. 1911. $12^{\mathrm{h}} 00^{\prime}$

22. Okt. 1911. $9 \mathrm{~h}^{\mathrm{h}} 45^{\prime}$

43 ,

41 ,

23. Okt. 1911. 9h $45^{\prime}$

$4^{\text {h }} 30^{\prime}$

24. Okt. 1911. $10^{\text {h }} 00^{\prime}$

in $1 / 2 \mathrm{Ringer}$

$49 \mathrm{mg}$

47 ,

48 ,

in $1 / 1 \mathrm{Ringer}$

4 h $30^{\prime}$

$37 \mathrm{mg}$ 
25. Okt. 1911. $11^{\mathrm{h}} 30^{\prime}$

$41 \mathrm{mg}$

26. Okt. 1911. 12 h $30^{\prime}$

40 ,

Resultat: In $\mathrm{BaCl}_{2}$ deutliche, reversible Gewichtsabnahme.

Nr. 40. Ein Frosch, zwei Nieren.

10. Nov, 1911. Zweimal 24 Standen in Ringer (Eis).

$\begin{array}{ccc}4 \text { h } 30^{\prime} \text { p. m. a) } 86 \mathrm{mg} & \text { b) } 95 \mathrm{mg} \\ 6 \mathrm{~h}^{\mathrm{h}} 00^{\prime} & 86 \% & 97 \% \\ & \text { beide in } \mathrm{MgCl}_{2}\end{array}$

11. Nov. 1911. 9h $30^{\prime}$

$66 \mathrm{mg}$

$79 \mathrm{mg}$

6 h $15^{\prime}$

in Ringer

12. Nov. 1911. 11 h $30^{\prime}$

$67 \mathrm{mg} \quad 91 \mathrm{mg}$

13. Nov. 1911. 11h $40^{\prime}$

79 n. 99 ,

14. Nov. 1911. $12 \mathrm{~h} \cdot 40^{\prime}$

$88, \quad 105 \%$

15. Nov. 1911. $11^{\mathrm{h}} 00^{\prime}$

$91 " 104 "$

16. Nov. 1911. 5 h $00^{\prime}$

$94, \quad 108$,

$94 \ldots 111 \%$

Nr. 41. Ein Frosch, zwei Nieren.

4. Sept. 1911. $99^{\mathrm{h}} 00^{\prime}$ Präparat in Ringer (Eis).

$6^{\mathrm{h}} 15^{\prime}$ p. m.

$11^{\mathrm{h}} 00^{\prime}$ p. m.

5. Sept. 1911. $\quad 1 \mathrm{~h} 15^{\prime}$

6. Sept. 1911. $\quad 6^{\text {h }} 45^{\prime}$

7. Sept. 1911. $12^{\mathrm{h}} 20^{\prime}$

6 h $25^{\prime}$

8. Sept. 1911. 12 i $55^{\prime}$
$119 \mathrm{mg}$ in $\mathrm{MgCl}_{2}$ $105 \mathrm{mg}$ in $\mathrm{Ringer}$ $115 \mathrm{mg}$ 117, in $1 / 2$ Ringer $166 \mathrm{mg}$ 165 in $1 / 1$ Ringer $131 \mathrm{mg}$.

VI. Das Verhalten von Froschnieren in Lösungen von Bromiden. Lösungen :

1. Lithiumbromid: $1,04 \%$ reinstes $\mathrm{LiBr}$ (Kahlbaum); $0,12 \mathrm{n}$.

2. Natriumbromid: $1,24 \% \mathrm{NaBr}(\mathrm{Kahlbaum}) ; 0,12$ n.

3. Kaliumbromid: $1,43 \% \mathbf{K}_{1} \mathrm{Br}$ (Kahlbaum); 0,12 $\mathrm{n}$.

Zur Ausspülung der chlorhaltigen "Zwischẹnflüssigkeit" wurden die Organe für einige Zeit in 7\% ige Rohrzuckerlösung oder in 3,9\% ige Traubenzuckerlösung gebracht. In diesen Medien bleibt das Gewicht der Nieren einige Zeit jedenfalls konstant. In Traubenzuckerlösung fand ich bei längerer Finwirkung meist eine Gewichtszunahme. Eingehendere Versuche darüber sind aber noch nicht abgeschlossen. 
Folgende Versuche zeigen, dass in kurzer Zeit die Chloride vollkommen ausgespült werden.

Nr. 42. Vier Nieren. Zweimal 24 Stunden. Ringer. (Eis.)

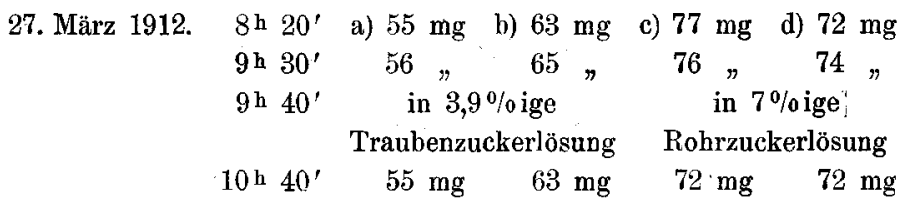

Alle 4 Zuckerlösungen geben mit $\mathrm{AgNO}_{3}$ nur minimale Trübung; etwa ähnliche Trübung gibt eine Lösung, die ein bis zwei Tropfen Ring e r-Lösung auf $100 \mathrm{ccm}$ $\mathrm{H}_{2} \mathrm{O}$ enthält. - Lösungen erneuert.

$11^{\mathrm{h}} 10^{\prime} \quad 57 \mathrm{mg} \quad 64 \mathrm{mg} \quad 71 \mathrm{mg} \quad 72 \mathrm{mg}$

Alle 4 Lösungen mit $\mathrm{AgNO}_{3}$ vollkommen klar.

Nr. 43. Kleiner Frosch. Zwei Nieren.

11. Nov. 1911. $11^{\mathrm{h}} 00^{\circ}$ Präparat in Ringer (Eis).
$6 \mathrm{~h} 30^{\prime}$
a) $25 \mathrm{mg}$
b) $23 \mathrm{mg}$

12. Nov. $1911.11^{\mathrm{h}} 00^{\prime}$ - in Rohrzuckerlörung $22 \mathrm{mg} \cdot 21 \mathrm{mg}$

13. Nov. 1911. $9 \mathrm{~h} 20^{\prime}$ in Robrzuckerlösung

\section{-} $23 \mathrm{mg} \quad 21 \mathrm{mg}$ in $\mathrm{NaBr}$ in $\mathrm{KBr}$ 3 h $45^{\prime}$ 9 h $00^{\prime}$

14. Nov. 1911. $9 \mathrm{~h} 45^{\prime}$ 4 h $15^{\prime}$ 7 h $30^{\prime}$

15. Nov. 1911. $9 \mathrm{~h} 45^{\prime}$

16. Nov. 1911. $12^{\mathrm{h}} 40^{\prime}$

17. Nov. $1911.10^{\mathrm{h}} 00^{\prime}$
$25 \mathrm{mg}$ 24 " 23 " 22 22 "

22 ,

22 "

21 " $24 \mathrm{mg}$ 25 " 31 " 33 " 36, 39 " 43 " $44 \pi$

Nr. 44. Kleiner Frosch. Zwei Nieren.

11. Nov. 1911. 11 h $00^{\prime}$ Präparat.
6 h $30^{\prime}$
a) $26 \mathrm{mg}$
b) $26 \mathrm{mg}$

12. Nov. 1911. $11^{\text {h }} 00^{\prime}$ $23 \mathrm{mg}$ in Rohrzuckerlösung

13. Nov. 1911. g $20^{\prime}$ in Rohrzuckerlösung $22 \mathrm{mg}$

$\begin{array}{cc}9 \mathrm{~b} 20^{\circ} & \begin{array}{c}24 \mathrm{mg} \\ \text { in } \mathrm{NaBr}\end{array} \\ 3 \mathrm{~h} 45^{\prime} & 26 \mathrm{mg} \\ 9 \mathrm{~h} 00^{\prime} \text { p. m. } & 25 \%\end{array}$

$22 \mathrm{mg}$
in $\mathrm{KBr}$
$25 \mathrm{mg}$
27
33

Pflüger's Archiv für Physiologie. Bd. 148. 
14. Nov. 1911. $\quad 9 \mathrm{~h} 45^{\prime}$ a. $\mathrm{m} . \quad 24 \mathrm{mg}$

4 h $15^{\prime}$

23 ,

$32 \mathrm{mg}$

7 h $30^{\prime}$

$23 \mathrm{mg}$

35 ,

9 h $45^{\prime}$

3 h $40^{\prime}$

16. Nov. 1911. 12 h $40^{\prime}$

$4 \mathrm{~h} 00^{\prime}$

17. Nov. 1911. $10^{\text {h }} 00^{\prime}$

4 h $30^{\prime}$

in $\mathrm{NaBr}$

15. Nov. 1911.

23 "

25 ,

$29 \mathrm{mg}$

beice

$33 \mathrm{mg}$

34 "

25 "

$25 "$

ide in $1 / 2 \mathrm{NaBr}$

18. Nov. 1911. $\quad 9^{\text {h }} 45^{\prime}$

beide in $1 / 1 \mathrm{NaBr}$

$24 \mathrm{mg} \quad 24 \mathrm{mg}$

26 " 25 ,

$25 "$

24,

Resultat: In $\mathrm{KBr}$ in ca. 30 Stunden um $60 \%$ zugenommen, reversibel.

Nr. 45. Kleiner Frosch. Eine Niere.

11. Nov. 1911. $11^{\mathrm{h}} 15^{\prime}$ Präparat.

$$
7 \mathrm{~h} 00^{\prime} \text { p. m. }
$$

$18 \mathrm{mg}$

in Rohrzuckerlösung

12. Nov. 1911. 11 h $15^{\prime}$ a. $\mathrm{m}$.

13. Nov. 1911. 9 h $00^{\prime}$ a. m. $17 \mathrm{mg}$

$18 \%$

$$
11^{\mathrm{h}} 10^{\prime}
$$

in $\mathrm{LiBr}$

4 h $10^{\prime}$

$19 \mathrm{mg}$

9 h $15^{\prime}$

19

14. Nov. 1911. $9{\mathrm{~h} 30^{\prime}}^{\prime}$

19

$4^{\text {h }} 00^{\prime}$

19 "

15. Nor. 1911. $\quad 9 \mathrm{~h} 30^{\prime}$

20 "

16. Nov. 1911. 1 h $00^{\prime}$ p. m.

21

Nr. 46. Kleiner Frosch. Zwei Nieren, zweimal 24 Stunden in Ringer (Eis).

17. Nov. 1911. $11^{\mathrm{h}} 00^{\prime}$

$$
\begin{array}{ll}
\text { a) } 42 \mathrm{mg} & \text { b) } 40 \mathrm{mg}
\end{array}
$$

beide in Rohrzuckerlösung

$\begin{array}{rll}4 \mathrm{~h}^{\prime} 30^{\prime} & 41 \mathrm{mg} & 40 \mathrm{mg} \\ & \text { in } \mathrm{KCl} & \text { in } \mathrm{KBr} \\ 7 \mathrm{~h} 15^{\prime} & 47(+6) & 44(+4) \\ 10 \mathrm{~h} 15^{\prime} & 68(+27) & 56(+16) \\ 6 \mathrm{~h} 00^{\prime} & 75(+34) & 62(+22) \\ 10 \mathrm{~h} 00^{\prime} & 84(+43) & 72(+32)\end{array}$

19. Nov. 1911. $10^{\mathrm{h}} 00^{\prime}$

$84(+43)$

$72(+32)$

Resultat: In $\mathrm{KCl}$ nimmt das Gewicht deutlich rascher zu als in $\mathrm{KBr}$.

Nr. 47. Kleiner Frosch. Zwei Nieren, zweimal 24 Stunden in Ringer (Eis).

17. Nov. 1911. $11^{\mathrm{h}} 00^{\prime}$

$$
40^{\prime}
$$

18. Nov. 1911. $10^{\mathrm{h}} 15^{\prime}$

6 h $^{\prime} 00^{\prime}$

19. Nov. 1911. $10^{\mathrm{h}} 00^{\prime}$ $\begin{array}{ll}\text { a) } 39 \mathrm{mg} & \text { b) } 36 \mathrm{mg}\end{array}$ beide in Rohrzuckerlösung $40 \mathrm{mg} \quad 36 \mathrm{mg}$ beide in $1 / 2 \mathrm{KCl}+1 / 2 \mathrm{NaBr}$ $52 \mathrm{mg} \quad 46 \mathrm{mg}$ $51 \pi \quad 46$,

$53 n \quad 48$,


VII. Das Verhalten von Froschnieren in Lösungen von Nitraten, Phosphaten und Sulfaten.

1. Natrium- und Kaliumnitrat:

Lösungen: $\mathrm{NaNO}_{3}(\mathrm{Kahlbaum})=$ ca. $1,05 \% . \quad \Delta=0,42^{\circ}$. $\mathrm{KNO}_{3}(\mathrm{Kahlbaum})=$ ca. $1,3 \% . \Delta=0,42^{\circ}$.

Nr. 48. 8. Juli 1912. Vier Nieren, zweimal 24 Stunden in Ringer (Eis).

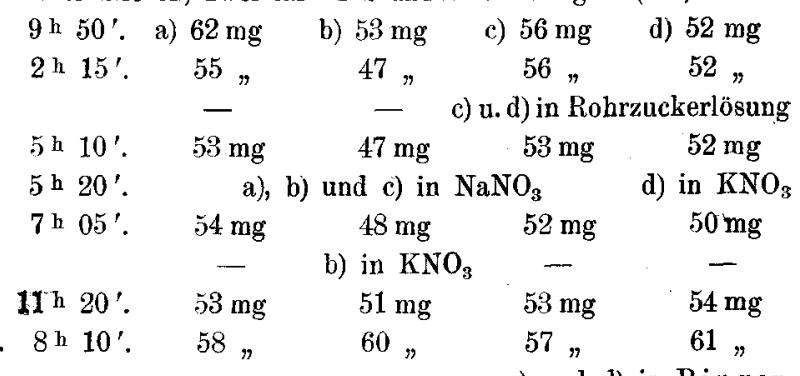

9. Juli 1912. 8 h $10^{\prime} . \quad 58 " \quad 60 ", \quad 57 "$ c) und d) in Ringer

$11^{\mathrm{h}} 40^{\prime} .55 \mathrm{mg} \quad 63 \mathrm{mg} \quad$ - $\quad$ -

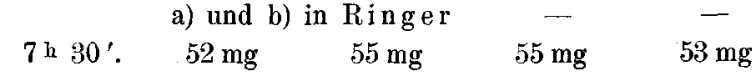

10. Juli 1912. $10^{\text {h }} 00^{\prime}$. 50 " 50 " $\quad 53$ ” 50 ”

1 h $20^{\prime}$. 52 ” $\quad 50$ ” $53 \%$,

$\begin{array}{lllll}4 \mathrm{~h}^{\prime} & 35^{\prime} . & 58 \mathrm{mg} & \text { alle in } 1 / 2 & \mathrm{Ringer} \\ 58 \mathrm{mg} & 61 \mathrm{mg} & 58 \mathrm{mg}\end{array}$

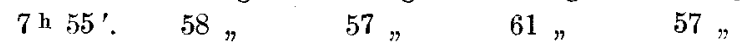

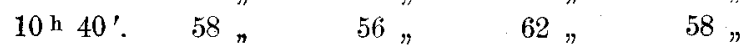

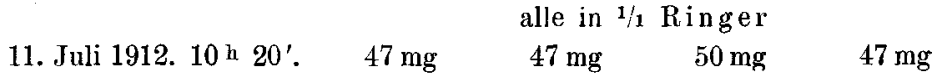

$7 \mathrm{~h} 20^{\prime} .48 \% \quad 48 \%$ " 41 " $49 "$

12. Juli 1912. $9 \mathrm{~h} 30^{\prime} .49$ " $49 ", 52 ", 51$,

Resultat: In $\mathrm{NaNO}_{3}$ keine wesentliche Änderung. In $\mathrm{KNO}_{3}$ langsame Gewichtszunahme. Danach sowohl in $1 / 1$ wie in $1 / 2$ Ringer Gewichtskonstanz aber in $1 / 2$ Ringer Gewichtszunahme um nur $16 \%$.

2. Natrium-und Kaliumphosphat.

Lösungen: $\mathrm{Na}_{2} \mathrm{HPO}_{4}: 500 \mathrm{ccm} 3,1 \%$ "Natriumphosphat zur Analyse" (Kahlbaum), + $3 \mathrm{ccm} 1,2 \% \mathrm{NaH}_{2} \mathrm{PO}_{4}$. . Lösung neutral. $\Delta=0,42^{\circ}$. - $\mathrm{K}_{2} \mathrm{HPO}_{4}: 1,64 \%$ "Kaliumphosphat, zweibasisch", mit $\mathrm{NaH}_{2} \mathrm{PO}_{4}$ neutralisiert. $\Delta=0,42^{\circ}$.

Nr. 49. Eine Niere, längere Zeit in Ringer (Eis).

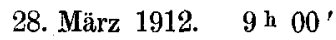

5 h $10^{\prime}$

$51 \mathrm{mg}$

$50 \#$ 
29. März 1912, $10^{\mathrm{h}} 15^{\prime}$ 10 h $20^{\prime}$ $10^{\text {h }} 50^{\prime}$ $52 "$
in $3,9 \%$ Traubenzucker
$54 \mathrm{mg}$
in $\mathrm{Na}_{2} \mathrm{HPO}_{4}$
$41 \mathrm{mg}$
43

30. März 1912. $8 \mathrm{~h} 40^{\circ}$ 5 h $10^{\prime}$ 8 h $30^{\prime}$ 45, in Ringer 6 h $30^{\prime} \quad 50 \mathrm{mg}$

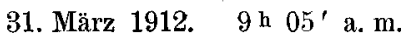
53 , 10 h $45^{\prime}$ p. m. in $1 / 2$ Ringer $78 \mathrm{mg}$

1. April 1912. $10^{\text {h }} 00^{\prime}$ 74 " in $1 / 1$ Ringer 5 h $30^{\prime}$ 56 ,

Resultat: In $\mathrm{Na}_{2} \mathrm{HPO}_{4}$ Gewichtsabnahme um etwa $10 \%$; dann langsame Zunahme; reversibel.

Nr. 50. Fine Niere, zweimal 24 Stunden in Ringer (Fis).

28. März 1912. $8 \mathrm{~h}^{15^{\prime}}$

4 h $10^{\prime}$

4 h $20^{\prime}$

5 h $10^{\prime}$

5 h $20^{\prime}$

7 h 45 '

$10 \mathrm{~h} 30^{\circ}$

29. März 1912. 9 h 20'

4 in $00^{\prime}$

8 h $10^{\prime}$

8 h $20^{\prime}$

30. März 1912. 8 h $50^{\prime}$

6 h $40^{\prime}$

31. März 1912. 8 h $40^{\prime}$

9 h $00^{\prime}$

$10 \mathrm{~h} 30^{\prime}$

12 h $30^{\prime}$

1. April 1912. $10^{\mathrm{h}} 30^{\prime}$

$52 \mathrm{mg}$
$51 "$
in $3,9 \%$ Traubenzucker
$48 \mathrm{mg}$
in $\mathrm{Na}_{2} \mathrm{HPO}_{4}$
$44 \mathrm{mg}$
$44 "$
$47 "$
$54 "$
$57 "$
in $\mathrm{Ring} \mathrm{er}$
$55 \mathrm{mg}$
$52 "$
$52 "$
in $1 / 2 \mathrm{Ringer}$
$59 \mathrm{mg}$
$59 "$
in $\mathrm{Ringer}$

$52 \mathrm{mg}$

Resultat: In $\mathrm{Na}_{2} \mathrm{HPO}_{4}$ Gewichtsabnahme, dann Zunahme; nicht vollkommen reversibel.

Nr. 51. Zwei Nicren; zweimal 24 Stunden in Ringer (Eis).
28. März 1912. 8 h $15^{\prime}$
4 h $10^{\prime}$
a) $57 \mathrm{mg}$
b) $48 \mathrm{mg}$
4 h $20^{\prime}$
$55 n$ 47 , beide in $3,9 \%$ Traubenzucker 
Über die „osmotischen Eigenschaften“ der Nieren.

28. März 1912. 5 h $10^{\prime}$ $52 \mathrm{mg} \quad 46 \mathrm{mg}$ beide in $\mathrm{K}_{2} \mathrm{HPO}_{4}$

$\begin{array}{rcc}7 \mathrm{~h} 45^{\prime} & 47 \mathrm{mg} & 42 \mathrm{mg} \\ 10^{\mathrm{h}} 30^{\prime} & 50 \mathrm{~m} & 42 " \\ 9 \mathrm{~h} 20^{\prime} & 63 " & 50 " \\ 4 \mathrm{~h} 00^{\prime} & 74 \% & 55 " \\ 8 \mathrm{~h} 10^{\prime} & \text { in } \mathrm{Na}_{2} \mathrm{HPO}_{4} & - \\ 8 \mathrm{~h} 20^{\prime} & 68 \mathrm{mg} & 60 \mathrm{mg} \\ 8 & \text { beide in Ringer }\end{array}$

30. März 1912. 8 h $50^{\prime}$ $57 \mathrm{mg}$ 57 , $51 \mathrm{mg}$ 6 h $40^{\prime}$

31. März $1912 . \quad 8^{\text {h }} 40^{\prime}$ 59 , 51 , beide in $1 / 2$ Ringer $10^{\mathrm{h}} 30^{\prime}$ 12 h $20^{\prime}$ $74 \mathrm{mg}$ 70 \% $58 \mathrm{mg}$

1. April 1912. $10^{\mathrm{b}} 30^{\prime}$ beide in $1 / 1$ Ringer 6 h $00^{\prime}$

$\begin{array}{ll}59 \mathrm{mg} & 51 \mathrm{mg} \\ 60 \mathrm{~N} & 51 \mathrm{n}\end{array}$

Resultat: In $\mathrm{K}_{2} \mathrm{HPO}_{4}$ erst Gewichtsabnahme, dann Zunahme; a) reversibel (nach 20 Stunden), b) unvollständig rev. (nach 24 Stunden).

Nr. 52. Eine Niere eines grossen Frosches. Zweimal 24 Stunden in Ringer(Eis)

10. Juli 1912. $9{\mathrm{~h} 35^{\prime}}^{\prime}$ $1 \mathrm{~h} 10^{\prime}$ $81 \mathrm{mg}$ 80 , in Rohrzuckerlösung

1 h $55^{\prime}$ $80 \mathrm{mg}$

2 h $00^{\prime}$

$4^{\text {h }} 30^{\prime}$ in $\mathrm{K}_{2} \mathrm{HPO}_{4}$ 6 h $20^{\prime}$ $72 \mathrm{mg}$ $75 \%$ in Ringer

$10 \mathrm{~h} 55^{\prime}$

11. Juli 1912. 9 h $50^{\prime}$ $77 \mathrm{mg}$ 80 , 5 h $10^{\prime} \quad 80$,

12. Juli 1912. 9 h $15^{\prime}$

82, in $1 / 2$ Ringer

11 h $20^{\prime}$ 3 h $45^{\prime}$ 103 ” 100 in $1 / 1$ Ringer

7 h $00^{\prime}$

13. Juli 1912. 9 h $20^{\prime}$ $78 \mathrm{mg}$ 80 ,

Resultat: In $\mathrm{K}_{2} \mathrm{HPO}_{4}$ Abnahme, dann beginnende Zunahme; reversibel.

Nr. 53. Vier Nieren, grosse Frösche. Zweimal 24 Stunden in Rĩnger (Eis). 10. Juli 1912. 9h 25 '

a) $77 \mathrm{mg}$ : b) $68 \mathrm{mg}$

c) $81 \mathrm{mg}$ d) $83 \mathrm{mg}$ alle in Ringer. $\left(\Delta=0,42^{\circ}.\right)$ 
10. Juli 1912. $12^{\mathrm{h}} 35^{\prime} \quad 80 \mathrm{mg}(?) \quad 71 \mathrm{mg} \quad 83 \mathrm{mg} \quad 85 \mathrm{mg}$

$1 \mathrm{~h} 00^{\prime} \quad$ alle in Rohrzuckerlösung. $\left(\Delta=0,42^{\circ}\right.$.)

$1 \mathrm{~h} 45^{\prime} \quad 74 \mathrm{mg} \quad 69 \mathrm{mg} \quad 81 \mathrm{mg} \quad 85 \mathrm{mg}$

$1 \mathrm{~h} 50^{\prime}$ a) in $\mathrm{Na}_{2} \mathrm{HPO}_{4}$ b) u. c) in $\mathrm{K}_{2} \mathrm{HPO}_{4}$ d) in $\mathrm{Na}_{2} \mathrm{HPO}_{4}$

$4 \mathrm{~h}^{\circ} \quad 71 \mathrm{mg} \quad 65 \mathrm{mg} \quad 77 \mathrm{mg} \quad 80 \mathrm{mg}$

$7 \mathrm{~h} 30^{\prime} \quad 71$, 66 , 79 , 78 ”

\begin{tabular}{|c|c|c|c|c|}
\hline & a) in $1 / 2 \mathrm{~N}_{2} \mathrm{HP}$ & in $1 / 2 \mathrm{~K}_{2} \mathrm{HP} 0_{4}$ & - & - \\
\hline $10^{\mathrm{h}} 30^{\prime}$ & $80 \mathrm{mg}$ & $80 \mathrm{mg}$ & $83 \mathrm{mg}$ & $77 \mathrm{mg}$ \\
\hline $11^{\mathrm{h}} 30^{\text {? }}$ & $81 "$ & $\begin{array}{l}83 \\
\text { alle in } \mathrm{R}\end{array}$ & $\begin{array}{l}86 " \\
\text { ger }\end{array}$ & 77 \\
\hline
\end{tabular}

11. Juli 1912. $9 \mathrm{~h} 45^{\prime} \quad 70 \mathrm{mg} \quad 67 \mathrm{mg} \quad 81 \mathrm{mg} \quad 82 \mathrm{mg}$

$5 \mathrm{~h} 00^{\prime} \quad 71$ " 68 " 81 " 84 "

12. Juli 1912. 9 h $00^{\prime} \quad 70 " \quad 67 ” \quad 82$ ” 84 ”

\begin{tabular}{rrrrr}
$9 \mathrm{~h} 15^{\prime}$ & \multicolumn{3}{c}{ alle in $1 / 2$ Ringer } \\
$12 \mathrm{~h} 00^{\prime}$ & $81 \mathrm{mg}$ & $77 \mathrm{mg}$ & $96 \mathrm{mg}$ & $101 \mathrm{mg}$
\end{tabular}

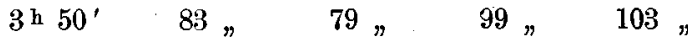

7 h $15^{\prime} \quad 85$ " 80 , 103 , 104 ”

\section{alle in $1 / 1$ Ringer}

13. Juli 1912. $9 \mathrm{~h}^{\prime} 15^{\prime} \quad 68 \mathrm{mg} \quad 64 \mathrm{mg} \quad 82 \mathrm{mg} \quad 81 \mathrm{mg}$.

Resultat: In $\mathrm{Na}_{2} \mathrm{HPO}_{4}$ Abnahme, dann Konstanz; in $1 / 2 \mathrm{Na}_{2} \mathrm{HPO}_{4}$ Zunahme um $14 \%$, reversibel? In $\mathrm{K}_{2} \mathrm{HPO}_{4} \mathrm{Abnahme,} \mathrm{dann} \mathrm{langsame} \mathrm{Zunahme,} \mathrm{reversibel} \mathrm{(c).}$

\section{Natrium-und Kaliumsulfat.}

Lösungen: a) $\mathrm{Na}_{2} \mathrm{SO}_{4} \cdot \Delta=0,42^{\circ}$. b) $\mathrm{K}_{2} \mathrm{SO}_{4} . \quad \Delta=0,41^{\circ}$ :

Nr. 54. Zwei Nieren, zweimal 24 Stunden in Ringer (Eis).
3. Juli 1912. 7 h $30^{\prime}$
a) $62 \mathrm{mg}$
60
b) $59 \mathrm{mg}$
$1 \mathrm{~h} 05^{\prime}$
a) in $\mathrm{Na}_{2} \mathrm{SO}_{4}$
b) in $\mathrm{K}_{2} \mathrm{SO}_{4}$ (mehrf. gewechselt)
$\begin{array}{rr}4^{\text {h }} & 40^{\prime} \\ 6 \text { h } & 00^{\prime} \\ 7 \text { h } & 30^{\prime} \\ 10^{\prime} & 05^{\prime}\end{array}$
$57 \mathrm{mg}$
$53 \mathrm{mg}$
57 ,
53 ,
$58 "$
54 "
58
56 ,
beide in Ringer
4. Juli 1912. $\begin{array}{rr}9 \mathrm{~h} & 30^{\prime} \\ 3 \mathrm{~h} & 10^{\prime}\end{array}$
$\begin{aligned} 6 \mathrm{~h} & 45^{\prime} \\ 11^{\mathrm{h}} & 10^{\prime}\end{aligned}$
$62 \mathrm{mg}$
$59 \mathrm{mg}$
62 "
59 ,
in $\mathrm{Na}_{2} \mathrm{SO}_{4}$
in $\mathrm{K}_{2} \mathrm{SO}_{4}$
$60 \mathrm{mg}$
$58 \mathrm{mg}$
58 ,
58 ,
5. Juli 1912. $9 \mathrm{~h} 25^{\prime}$
58 ,
59 "
7 h $20^{\prime}$
61
63
6. Juli 1912. 9 h $30^{\prime}$
63 "
64

Resultat: In $\mathrm{Na}_{2} \mathrm{SO}_{4}$ und $\mathrm{K}_{2} \mathrm{SO}_{4}$ Abnahme(?), dann konstant, schliesslich langsame Zunahme. 
Nr. 55. Vier Nieren, zweimal 24 Stunden in Ringer (Eis).

3. Juli 1912. 7 h $15^{\prime}$

1 h $30^{\prime}$

5 h $00^{\prime}$

5 h $45^{\prime}$

$7^{\text {h }} 15^{\prime}$

$10^{\text {h } 25^{\prime}}$

4. Juli 1912. $9 \mathrm{~h} 00^{\prime}$ a) $96 \mathrm{mg}$

95

92 "

b) $97 \mathrm{mg}$

83 ,

83 "

c) $95 \mathrm{mg}$

96

95 "

alle in Rohrzuckerlösung

$82 \mathrm{mg}$ $94 \mathrm{mg}$

d) ?

$98 \mathrm{mg}$ 94 "

$92 \mathrm{mg}$

b) und c) in $\mathrm{K}_{2} \mathrm{SO}_{4}$

$90 \mathrm{mg}$

a) in $\mathrm{Na}_{2} \mathrm{SO}_{4}$

$76 \mathrm{mg}$

$85 \mathrm{mg}$

d) in $\mathrm{Na}_{2} \mathrm{SO}_{4}$

$87 \mathrm{mg}$

78 n

87 "

$82 \mathrm{mg}$

87 "

73

91 "

?" a) in $1 / 2 \mathrm{Na}_{2} \mathrm{SO}_{4}$

b) in $1 / 2 \mathrm{~K}_{2} \mathrm{SO}_{4}$

$\begin{aligned} 2 \mathrm{~h} 50^{\prime} & 109 \mathrm{mg} \\ 6 \mathrm{~h} 30^{\prime} & 113 \% \\ 11 \mathrm{~h} 20^{\prime} & 115 \%\end{aligned}$

$93 \mathrm{mg}$

$91 \mathrm{ng}$ $101, \quad 97$,

108 "

$98 n$

alle in Ringer

5. Juli 1912. $9 \mathrm{~h} 10^{\prime}$

$98 \mathrm{mg}$

$7 \mathrm{~h} 30^{\prime} \quad 101$ "

$\begin{array}{lll}95 \mathrm{mg} & 110 \mathrm{mg} & 105 \mathrm{mg} \\ 90, & 119, & 115,\end{array}$

Resultat: wie $\mathrm{Nr}$. 54. In $1 / 2 \mathrm{Na}_{2} \mathrm{SO}_{4}$ und $\mathrm{K}_{2} \mathrm{SO}_{4}$ Gewichtszunahme, kein Gleichgewicht, irreversibel.

\section{Das Verhalten von Froschnieren in Lösungsgemischen.}

Nr. 56. Mittelgrosser Frosch. Zwei Nieren, zweimal 24 Stunden in R in ger (Eis).

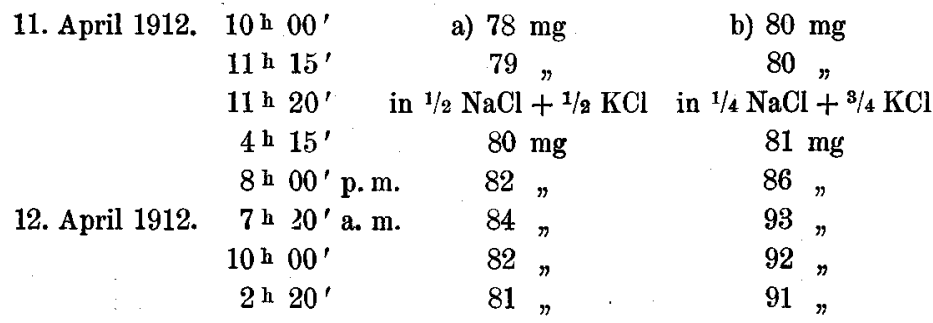

Resultat: Zunahme bei a) um $6 \%$, bei b) um $16 \%$.

Nr. 57. Zwei Frösche. Vier Nieren, zweimal 24 Stunden in Ringer (Eis).

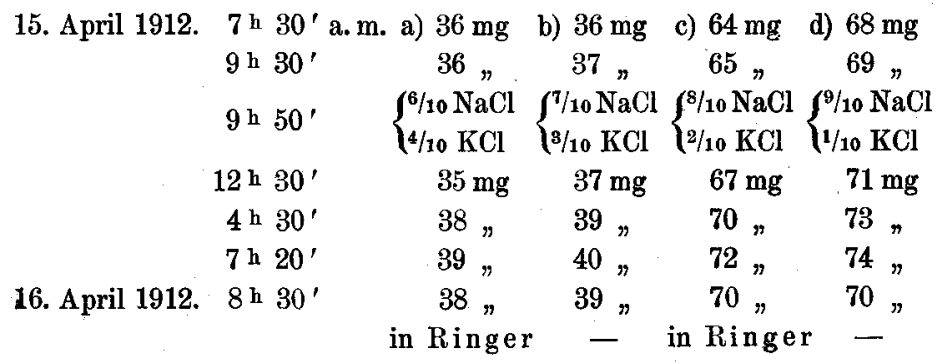




$\begin{array}{llcccc}\text { 16. April 1912. } 6 \text { h } 45^{\prime} & 36 \mathrm{mg} & 40 \mathrm{mg} & 65 \mathrm{mg} & 73 \mathrm{mg} \\ \text { 17. April 1912. } & 9 \text { h } 30^{\prime} \text { a. m. } & -36 \mathrm{mg} & 37 \mathrm{mg} & 64 \mathrm{mg} & 68 \mathrm{mg} \\ & 7 \mathrm{~h} 45^{\prime} & 35 \% & 37 \% & 65 \% & 70 \%\end{array}$

Resultat: Zunahme bei a) um $8 \%$, b) um $8 \%$, c) um $11 \%$, d) um $7 \%$. Nr. 58. Mittelgrosser Frosch. Zwei Nieren.

23. Okt. 1911. $10^{\mathrm{h}} 00^{\circ}$ a. m. Präparat in Ringer (Eis).

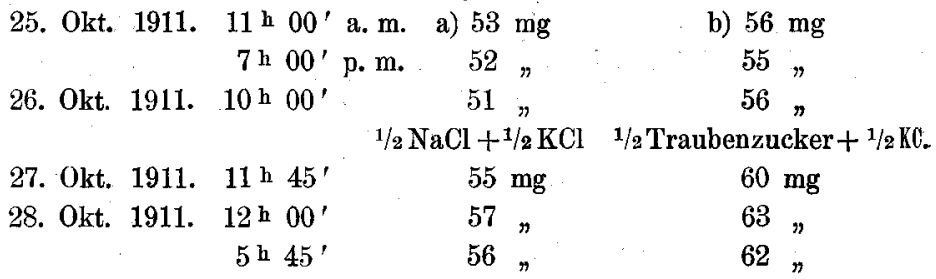

Resultat: Zunakme bei a) um $12 \%$, bei b) um $13 \%$.

Nr. 59. Zwei kleine Frösche, je eine Niere.

4. Nov. 1911. $11 \mathrm{~h} 00^{\prime}$ Präparat in Ringer (Eis).
6. Nov. 1911. $1^{\text {h }} 00^{\prime}$ p. m. a) $39 \mathrm{mg} \quad$ b) $35 \mathrm{mg}$

$$
6 \text { h } 30^{\prime} \quad 38 \text { " } 35 \text { ” }
$$$$
\text { in } 1 / 2 \mathrm{NaCl}+1 / 2 \mathrm{KCl} \text { in } 1 / 2 \mathrm{CaCl}_{2}+1 / 2 \mathrm{KCl}
$$

7. Nov. 1911. $10^{\mathrm{h}} 00^{\prime}$ a. m. $42 \mathrm{mg} \quad 34 \mathrm{mg}$

$7 \mathrm{~h} 00^{\prime}$ p.m. 44 " 36 "

8. Nov. 1911. $10^{\mathrm{h}} 00^{\prime}$ a. m. 46 " 35 "

Resultat: In $1 / 2 \mathrm{NaCl}+1 / 2 \mathrm{KCl}$ langsame Zunahme; in $1 / 2 \mathrm{CaCl}_{2}+1 / 2 \mathrm{KCl}$ in 40 Stunden keine Änderung.

Nr. 60. Kleiner Frosch. Eine Niere.

23. Okt. 1911. $10^{\text {h }} 00^{\prime}$ a. m. Präparat in Ringer (Eis).

25. Okt. 1911. 11 h $00^{\prime}$ a. m. $\quad 34 \mathrm{mg}$

$$
7 \text { h } 00^{\prime} \text { p. m. } \quad 34 \text {, }
$$

26. Okt. 1911. $10^{\mathrm{h}} 00^{\prime}$ a. m. 33 "

$$
\text { in } 1 / 2 \mathrm{CaCl}_{2}+1 / 2 \mathrm{KCl}
$$

27. Okt. 1911. $11^{\mathrm{h} 45^{\prime}} \quad 32 \mathrm{mg}$

28. Okt. 1911. $12^{\mathrm{h} 00^{\prime}} 33$ "

Resultat: In $1 / 2 \mathrm{CaCl}_{2}+1 / 2 \mathrm{KCl}$ in zweimal 24 Stunden keine Änderung.

Nr. 61. Kleiner Frosch. "Zwei Nieren.

20. Sept. 1911. 7 h $00^{\prime}$ p. m. Präparat in Ringer (Eis).

21. Sept. 1911. 5 h $05^{\prime}$ p. m. $\quad$ a) $38 \mathrm{mg} \quad$ b) $39 \mathrm{mg}$ $1 / 2 \mathrm{CaCl}_{2}+1 / 2 \mathrm{KCl} 1 / 2 \mathrm{MgCl}_{2}+1 / 2 \mathrm{KCl}$

$77^{\mathrm{h} 30^{\prime}} \quad 37 \mathrm{mg} \quad 39 \mathrm{mg}$

22. Sept. 1911. 12 h $50^{\circ} \quad 38$ " 40 "

6 h $15^{\prime} \quad 38$ " 40 ” 
23. Sept. 1911. $11 \mathrm{~h}^{\prime} 5^{\prime}$

25. Sept. 1911. 11 h $00^{\prime}$

26. Sept. $1911 . \quad 5$ h $15^{\prime}$

28. Sept. 1911. 12 h $00^{\prime}$ a) $38 \mathrm{mg}$ 39 ”

39 "

40 b) $40 \mathrm{mg}$ 40 , 39 , 39,

Resultat: In $1 / 2 \mathrm{CaCl}_{2}+1 / 2 \mathrm{KCl}$ sowie $1 / 2 \mathrm{MgCl}_{2}+1 / 2 \mathrm{KCl}$ in 7 Tagen keine Änderung.

Nr. 62. Eine Niere.

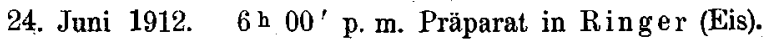

26. Juni 1912

$$
\begin{array}{rc}
7 \text { h } 55^{\prime} & 68 \mathrm{mg} \\
11 \mathrm{~h} 30^{\prime} & 66 " \prime \\
12 \mathrm{~h} 00^{\prime} & \text { in } 1 / 2 \mathrm{CaCl}_{2}+1 / 2 \mathrm{KCl} \\
2 \mathrm{k} 25^{\prime} & 62 \mathrm{mg} \\
& \text { in } 1 / 4 \mathrm{CaCl}_{2}+1 / 4 \mathrm{KCl} \\
5 \mathrm{~h} 20^{\prime} & 80 \mathrm{mg} \\
7 \mathrm{~h} 50^{\prime} & 89 " \\
11 \mathrm{~h} 30^{\prime} & 89 " \\
& \text { in } 1 / 2 \mathrm{CaCl}_{2}^{\prime}+1 / 2 \mathrm{KCl}
\end{array}
$$

27. Juni 1912. $9{\text { h } 30^{\prime}}^{\prime}$

$$
12 \text { h } 10^{\prime}
$$

$64 \mathrm{mg}$

67 ,

Resultat: In $1 / 2 \mathrm{CaCl}_{2}+1 / 2 \mathrm{KCl}$ konstant; bei Verdünnung zur Hälfte $\mathrm{Zu}$ nahme um $44 \%$ !

Nr. 69. Eine Niere, zweimal 24 Stunden in Ringer (Eis).

27. Juni 1912. 9 h $20^{\prime}$ 12 h $00^{\prime}$

$$
5 \text { in } 45^{\prime}
$$

8 h $10^{\prime}$

11 h $20^{\prime}$

28. Juni 1912. $10^{\text {h }} 00^{\prime}$

$$
7 \text { h } 45^{\prime}
$$

29. Juni 1912. $9 \mathrm{~h}^{\circ} 0^{\prime}$

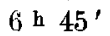

30. Juni 1912. '10 h $00^{\prime}$
$59 \mathrm{mg}$

59, in $1 / 4 \mathrm{CaCl}_{2}+3 / 4 \mathrm{KCl}$ $63 \mathrm{mg}$ 64 . 66 , 69 " in $\mathrm{Ringer}$ $59 \mathrm{mg}$ 61 , in $1 / 2$ Ringer. $83 \mathrm{mg}$ in $1 / 1 \mathrm{Ringer}$ $61 \mathrm{mgg}$.

Resultat: In ${ }^{1 / 4} \mathrm{CaCl}_{2}+{ }^{3 / 4} \mathrm{KCl}$ langsame, reversible Gewichtszunahme.

Nr. 64. Kleiner Frosch. Eine Niere, zweimal 24 Stunden in Ringer (Eis).

25. Okt. 1912. 11 h $00^{\prime}$ a. $\mathrm{m}$. $40 \mathrm{mg}$

$$
7 \text { h } 00^{\prime} \text { p. m. }
$$$$
39 \text {, }
$$

26. Okt. 1912. $10 \mathrm{~h} 00^{\prime}$ a. m. 40 "

$$
\text { in } 1 / 2 \mathrm{MgCl}_{2}+1 / 2 \mathrm{KCl}
$$

27. Okt. 1912. $11^{\text {h }} 45^{\prime}$ $38 \mathrm{mg}$ 
28. Okt. 1912. 12 h $00^{\prime}$ $39 \mathrm{mg}$ in $1 / 4 \mathrm{MgCl}_{2}+1 / 4 \mathrm{KCl}$

29. Okt. $1912.10^{\mathrm{h}} 30^{\prime}$ $54 \mathrm{mg}$

$6 \mathrm{~h}^{\mathrm{h}} 00^{\prime} \mathrm{p.m}$ 56 54,

30. Okt. 1912. $11^{\text {h }} 00^{\prime}$ 55 "

$$
6 \text { h } 00^{\prime} \text { p. m. } \quad 37 \mathrm{mg}
$$

31. Okt. 1912. $10^{\mathrm{h} \mathrm{h}} 00^{\prime}$ a. m. 37 "

Resultat: In $1 / 2 \mathrm{MgCl}_{2}+1 / 2 \mathrm{KCl}$ konstant; bei Verdünnung zur Hälfte $\mathrm{Zu}$ nahme um $41 \%($ !).

Nr. 65. Zwei kleinere Frösche. Vier Nieren.

18. Okt. 1911. 7 h $00^{\prime}$ p. m. Präparat in Ringer (Eis).
19. Okt. 1911.12 h $00^{\prime}$
a) $34 \mathrm{mg}$
b) $31 \mathrm{mg}$
c) $55 \mathrm{mg}$
d) $54 \mathrm{mg}$
5 h $30^{\prime}$
33 ,
32 ,
55 " 57 " in $\left.1 / 2 \mathrm{BaCl}_{2}\right\}$ in $\left.1 / 2 \mathrm{MgCl}_{2}\right)$ in $\left.1 / 2 \mathrm{CaCl}_{2}\right\}$ in Ringer
20. Okt. 1911. $11^{\text {h }} 15^{\prime}$ $+1 / 2$ Ringer $\}+$
21. Okt. 1911. 12 h $20^{\prime}$ $31 \mathrm{mg}$ 38 " $30 \mathrm{mg}$ $47 \mathrm{mg}$ $56 \mathrm{mg}$
22. Okt. 1911. 9 ㄴ $30^{\prime}$ 34 , 30 , 47 " 54 ,
23. Okt. 1911. $10^{\text {h }} 00^{\prime}$ 33 , 29 , 47 , 53 "
24. Okt. 1911. $10^{\mathrm{h}} 20^{\prime}$ 34 , 29 " 46 , 51 ” 29 , $45 \%$ 50 ,

Resultat: In $1 / 2 \mathrm{BaCl}_{2}+1 / 2 \mathrm{Ringer}$ keine Veränderung; in $1 / 2 \mathrm{MgCl}_{2}+$ $1 / 2$ Ringer keine Veränderung; in $1 / 2 \mathrm{CaCl}_{2}+1 / 2$ Ringer Abnahme, dann Konstanz.

Nr. 66. Zwei mittelgrosse Frösche. Vier Nieren.

24. Okt. 1911. $4^{\text {h }} 00^{\prime}$ Präparat in Ringer (Eis).

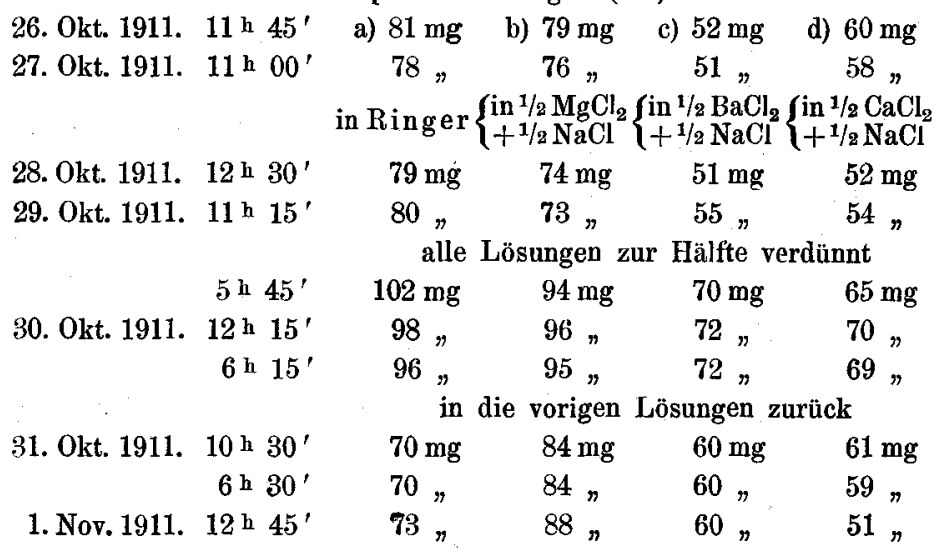

Resultat: In $1 / 2 \mathrm{MgCl}_{2}+1 / 2 \mathrm{NaCl}$ keine Änderung; in $1 / 2 \mathrm{BaCl}_{2}+1 / 2 \mathrm{NaCl}$ ebenso; in $1 / 2 \mathrm{CaCl}_{2}+1 / 2 \mathrm{NaCl}$ Abnahme; bei Verdünnung zur Hälfte Zunahme um etwa $30 \%$. 


\section{Froschnieren in Lösungen bei alkalischer Reaktion.}

1. Natronlauge.

In $\mathrm{Ringer-Lösung} \mathrm{mit} 1 / 100 \mathrm{n}$. $\mathrm{NaOH}$ gehen die Nieren rasch zugrunde, es tritt eine irreversible Gewichtsänderung ein.

In Ringer-Lösung mit 1/1000, $1 / 10000 \mathrm{n}$. $\mathrm{NaOH}$ tritt in mehreren Tagen keine Änderung ein, z. B.:

Nr. 67. Zwei Nieren eines kleinen Frosches.

25. Aug. 1912. 11 h $40^{\prime}$ Präparat in Ringer (Eis).

$$
\begin{array}{cc}
5 \text { h } 38^{\prime} & 37 \mathrm{mg} \\
5 \text { h } 40^{\prime} & \text { in Ringer }+1 / 1000 \mathrm{n} . \mathrm{NaOH}
\end{array}
$$

26. Aug. 1911. $11^{\mathrm{h}} 15^{\prime} \quad 37 \mathrm{mg}$

27. Aug. 1911. 7 h $10^{\prime}$ p. m. 37 "

28. Aug. 1911. 11 h $10^{\prime}$ a. m. 38 "

29. Aug. 1911. $10^{\mathrm{h} 10^{\circ}} 39$ "

30. Aug. 1911. $12^{\mathrm{h}} 10^{\prime} 38$ "

Nr. 68. Zwei Nieren. Zweimal 24 Stunden in Ringer (Eis).

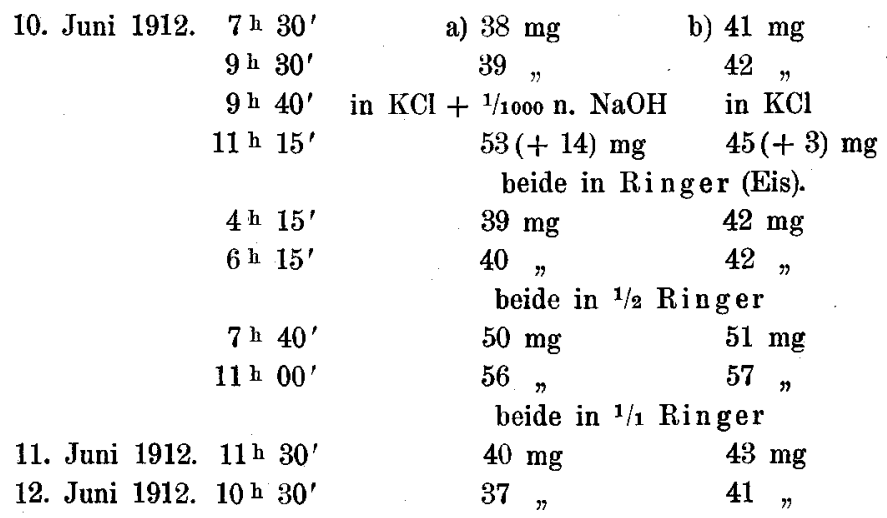

Resultat: In $\mathrm{KCl}+{ }^{1}{ }_{1000}$ n. $\mathrm{NaOH}$ viel raschere Gewichtszunahme als in $\mathrm{KCl}$ nentral.

\section{Ammoniak.}

Nr. 69. Zwei Nieren; zweimal 24 Stunden in Ringer (Eis).
14. Juni 1912. $\begin{array}{r}9 \text { h } 50^{\prime} \\ 3 \text { h } 40^{\prime}\end{array}$
a) $60 \mathrm{mg}$
b) $68 \mathrm{mg}$
59
67
$4^{\text {h }} 50^{\prime}$
61
in $\mathrm{Ringer}+1 / 1000 \mathrm{n} . \mathrm{NH}_{3}$
5 h $50^{\prime}$
$63 n$
$64 \mathrm{mg}$
6 h $00^{\prime}$
in $1 / 2$ Ringer in $1 / 2$ Ringer $+1 / 1000 \mathrm{n} . \mathrm{NH}_{3}$
7. h $00^{\prime}$
$73(+10) \mathrm{mg}$
$73(+11) \mathrm{mg}$ 
14. Juni 1912. $8 \mathrm{~h} 00^{\prime}$ $11{\mathrm{~h} 00^{\prime}}^{\prime}$

15. Juni $1912 . \quad 7$ h $45^{\prime}$ 9 h $45^{\prime}$

11 h $30^{\prime}$

11 h $45^{\prime}$

12 h $45^{\prime}$

1 h $15^{\prime}$

5 h $30^{\prime}$

7 h $30^{\prime}$

$$
78(+15) \mathrm{mg} \quad \text { verloren! }
$$$$
83(+20)
$$

in Ringer

$59 \mathrm{mg}$

60 "

in $\mathrm{Ringer}+1 / 1000 \mathrm{n} . \mathrm{NH}_{3}$

$58 \mathrm{mg}$

$$
\text { in } 1 / 2 \text { Ringer }+1 / 1000 \mathrm{NH}_{3} \text {, }
$$$$
72(+14) \mathrm{mg}
$$$$
76(+18) \text { n }
$$$$
79(+21)
$$$$
79 \mathrm{mg}
$$

in Ringer

16. Juni $1912.9 \mathrm{~h} 30^{\prime}$

17. Juni 1912. 9 h $30^{\prime}$
$59 \mathrm{mg}$

60 "

Resultat: In 1/1000 $\mathrm{NH}_{3}$ - Ringer keine Änderung; Gewichtszunahme bei $1 / 2$ osmotischem Druck wie bei neutraler Reaktion.

NB. Die alkalische Reaktion nimmt in den Versuchen bei niederer Temperatur nicht ab (Kontrolle durch Indikatoren).

Nr. 70. Vier Nieren; 36 Stunden in Ringer (Eis).
14. Febr. 1912. $10^{\text {h }} 00^{\prime}$
a) $51 \mathrm{mg}$
b) $58 \mathrm{mg}$
c) $52 \mathrm{mg}$
d) $45 \mathrm{mg}$
$11^{\mathrm{h}} 45^{\prime}$
49
57 ,
$51 \%$
43 "
11 b $50^{\prime}$
a), c) und
d) in R. $+1 / 1000 \mathrm{NH}_{3}$,
b) in $R$.
$6 \mathrm{~h}^{\circ} 5^{\prime}$
$43 \mathrm{mg}$
$58 \mathrm{mg}$
$44 \mathrm{mg}$
$39 \mathrm{mg}$
6 h $10^{\prime}$
$8 \mathrm{~h} 2$
$\mathrm{KCl}+\mathrm{NH}_{3} \quad \mathrm{KCl}$
$\mathrm{KCl}+\mathrm{NH}_{3}$
8 h 20
$62(+19) \mathrm{mg} 63($
a) u. b) in $R$. $56(+17) \mathrm{mg}$ $48 \mathrm{mg}$
$53 \mathrm{mg}$
c) u. d) in R. $+\mathrm{NH}_{\mathbf{8}}$
15. Febr. 1912. $11^{\text {h }} 00^{\prime}$

$$
\begin{aligned}
& 6 \text { h } 20^{\prime} \\
& 6 \text { h } 30^{\prime}
\end{aligned}
$$
- -
$45 \mathrm{mg}$
$37 \mathrm{mg}$
a) u. b) in $1 / 2 \mathrm{R}$.
c) u. d) in $\mathrm{R} .+\mathrm{NH}_{8}$.
$53(+7) \mathrm{mg} 63(+11)$
$45 \mathrm{mg}$
$37 \mathrm{mg}$
16. Febr. 1912. 9 h $45^{\prime}$
c) u. d) in $1 / 2 \mathrm{R} .+\mathrm{NH}_{3}$
4 h $45^{\prime}$
$50 \mathrm{mg} \quad 58 \mathrm{~m}$
alle in $1 / 1 \mathrm{R}$. $54(+9) \mathrm{mg} 50(+13) \mathrm{mg}$

17. Febr. 1912. $10^{\mathrm{h}} 15^{\prime} \quad 42 \mathrm{mg} \quad 48 \mathrm{mg} \quad 44 \mathrm{mg} \quad 36 \mathrm{mg}$

Resultat: 1. In Ringer, auch bei Verdünnung, kein Unterschied zwischen neutraler und alkalischer Reaktion. 2. In Kaliumchlorid Gewichtszunahme bei alkalischer Reaktion mehr als dreimal so gross wie bei neutraler Reaktion.

Nr. 71. Drei Nieren; zweimal 24 Stunden in Ringer (Eis).
12. Juni 1912. $10^{\text {h }} 00^{\prime}$
$3^{\text {h }} 00^{\prime}$
a) $66 \mathrm{mg}$
72
b) $72 \mathrm{mg}$
76 "
c) $74 \mathrm{mg}$
3 h 15'
in $\mathrm{KCl}$
75 


\begin{tabular}{|c|c|c|c|c|}
\hline \multirow{3}{*}{ 13. Juni 1912.} & $4^{\mathrm{h}} 15^{\prime}$ & $72(+0) \mathrm{mg}$ & $83(+7) \mathrm{mg}$ & $74 \mathrm{mg}$ \\
\hline & 5 h $10^{\prime}$ & $\begin{array}{l}80(+8) " \\
\text { in Ringer }\end{array}$ & $\begin{array}{l}99(+23) " \\
\text { in Ringer }\end{array}$ & $72 "$ \\
\hline & 7 h $15^{\prime}$ & $75 \mathrm{mg}$ & $80 \mathrm{mg}$ & $\begin{array}{c}72 " \\
\text { in Ringer }\end{array}$ \\
\hline \multirow[t]{4}{*}{ 13. Juni 1912.} & 9 h $45^{\prime}$ & 70 & 76 & $73 \mathrm{mg}$ \\
\hline & 3 h $40^{\prime}$ & $71 "$ & alle in $1 / 2 \mathrm{R}$ inger & 76 \\
\hline & 5 h $40^{\prime}$ & $89(+18) \mathrm{mg}$ & $97(+21) \mathrm{mg}$ & $93(+17) \mathrm{mg}$ \\
\hline & 7 h $15^{\prime}$ & $91(+20) "$ & $\begin{array}{c}99(+20) " \\
\text { in } 1 / 1 \text { Ringer }\end{array}$ & $100(+24)$ \\
\hline \multirow[t]{2}{*}{ 14. Juni 1912.} & 9 h $45^{\prime}$ & $67 \mathrm{mg}$ & $72 \mathrm{mg}$ & $72 \mathrm{mg}$ \\
\hline & 6 h $00^{\prime}$ & $72 \%$ & 74 & $74 \eta$ \\
\hline \multirow[t]{8}{*}{ 15. Juni 1912.} & $10^{\mathrm{h}} 00^{\prime}$ & $72 "$ & $75 "$ & 75 \\
\hline & \multicolumn{4}{|c|}{ b) u. c) in R. $+1 / 1000 \mathrm{n} . \mathrm{NH}_{3}$} \\
\hline & $11^{\text {h }} 40^{\prime}$ & $73 \#$ & $75 \mathrm{mg}$ & $72 \mathrm{mg}$ \\
\hline & $11^{\mathrm{h}} 45^{\prime}$ & in $1 / 2$ Ringer & \multicolumn{2}{|c|}{ b) u. c) in $1 / 2$ R. $+1 / 1000 \mathrm{NH}_{3}$} \\
\hline & 12 h $45^{\prime}$ & $93 \mathrm{mg}$ & $87(+12) \mathrm{mg}$ & $82(+10) \mathrm{mg}$ \\
\hline & 1 h $05^{\prime}$ & - & $91(+16)$ & $86(+14)$ \\
\hline & 5 h $35^{\prime}$ & & $93(+18)$ & $91(+19)$ \\
\hline & 7 h $30^{\prime}$ & & $96(+21)$ & $94(+22)$ \\
\hline 16. Juni 1912. & $9 \mathrm{~h} 15^{\prime}$ & & \multicolumn{2}{|c|}{ beide in Ringer } \\
\hline 17. Juni 1912. & 9 h $40^{\prime}$ & & $78 \mathrm{mg}$ & $79 \mathrm{mg}$ \\
\hline
\end{tabular}

Resultat: In Ringer kein Unterschied; in KCl Zunahme bei alkalischer Reaktion dreimal so gross.

Nr. 72. Je eine Niere von zwei Fröschen; zweimal 24 Stunden in Ringer (Eis).

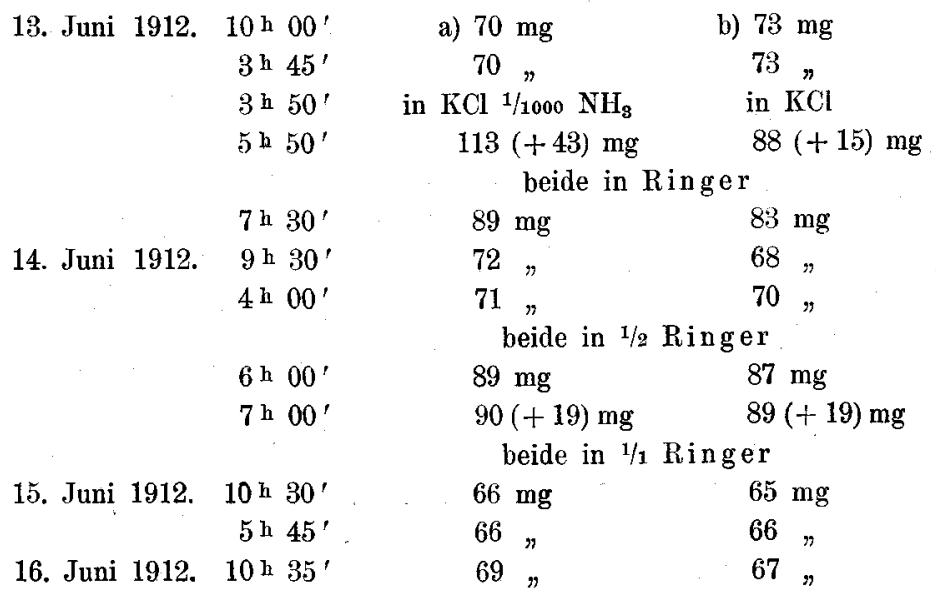

Resultat: wie $\mathrm{Nr} .71$, reversibel. 
Nr. 73. Zwei Nieren eines grossen Frosches; zweimal 24 Stunden in Ringer (Eis).

10. Juni 1912.

$$
\begin{array}{r}
7_{\text {h }} 30^{\prime} \\
9 \text { h } 30^{\prime} \\
9 \text { h } 40^{\prime} \\
11^{\text {h }} 15^{\prime}
\end{array}
$$

4 h $15^{\prime}$

$6 \mathrm{~h}^{\mathrm{h}} 15^{\prime}$

7 h $40^{\prime}$

$11^{\text {h }} 00^{\prime}$

Resultat wie vorige Nummern.

\section{B. Untersuchungen des Sauerstoffverbrauches.}

\section{Methode.}

In früheren Versuchen hatte ich die Methode benutzt, mit der auch $\mathrm{Usui}^{1}$ ) unter Warburg den Sauerstoffverbrauch überlebender Organe untersuchte ${ }^{2}$ ). Während bei dieser Methode die Organe in einer Blutkörperchensuspension schwimmen, schien es mir für meine Versuche vorteilhafter, die Organe in reinen Salzlösungen zu untersuchen. Nach einem Prinzip, das ebenfalls Warburg für Versuche mit Gänseblut und Hefe angewandt hatte, traf ich folgende Anordnung, die mir für Untersuchungen an überlebenden Organen mit geringem Sauerstoffverbrauch sehr brauchbar erscheint. Ein grosser Vorzug der Methode ist, dass jederzeit der Sauerstoffverbrauch unmittelbar abgelesen werden kann.

Das Gefäss, in dem die Organe schwimmen, wird unmittelbar an ein Barcroft'sches Manometer ${ }^{3}$ ) angeschlossen. Wird nun dafür gesorgt, dass dauernd die gebildete Kohlensäure absorbiert wird und die Flüssigkeit, in der die Organe schwimmen, mit Luft gesättigt ist, so kann aus der Druckabnahme direkt der Sauerstoffverbrauch berechnet werden.

Für die Wahl des Gefässes waren folgende Gesichtspunkte bestimmend: Einmal sollte das Luftvolumen im Gefässe klein sein,

1) Usui, Pflüger's Arch. Bd. 147 S. 100. 1912.

2) Ich teile diese Versuche nicht mit, da ich sie alle mit der neueren Methode - mit dem gleichen Resultate - wiederholt habe.

3) Vom Barcroft'schen Gasanalysenapparat. Vgl. Barcroft, Ergebn. d. Physiol. Bd. 7 S. 699.1908. 
damit schon ein geringer Gasverbrauch zu einer deutlichen Druckabnahme führt; dann sollte die Sättigung der Flüssigkeit im Gefässe mit Luft möglichst erleichtert sein, die Lösung sollte also grosse Oberfläche und geringe Tiefe haben. Schliesslich musste noch ein kleiner Behälter für Natronlauge zur Absorption von Kohlensäure angebracht werden.

Das Gefäss ist in Fig. 1 abgebildet ${ }^{1}$ ). Das Rohr $a$, das mit einem dickwandigen, sehr gut schliessenden Gummischlauch an das Manometer (wie sonst das Gefäss zur Gasanalyse) angeschlossen wird, ist unten $\mathrm{zu}$ einem Glasstöpsel mit Schliff $(b)$ aufgetrieben, der das Gefäss verschliesst. Im Gefäss ist in der Mitte des Bodens ein kleiner Behälter (c) angebracht, in den aus einer Burette $0,2 \mathrm{ccm} 1 / 1 \mathrm{n}$. Natronlauge gegeben werden. ZurVergrösserung derOberfläche der Lauge werden in den Behälter ein paar Glaskapillaren gestellt, die aber nicht ganz bis zum oberen Rande des Behälters reichen sollen, damit keine Natronlauge verspritzt wird. Das ganze Gefäss hat einen Inhalt von etwa $13 \mathrm{ccm}$.

In das Gefäss werden nun mit einer Pipette $2 \mathrm{ccm}$ der

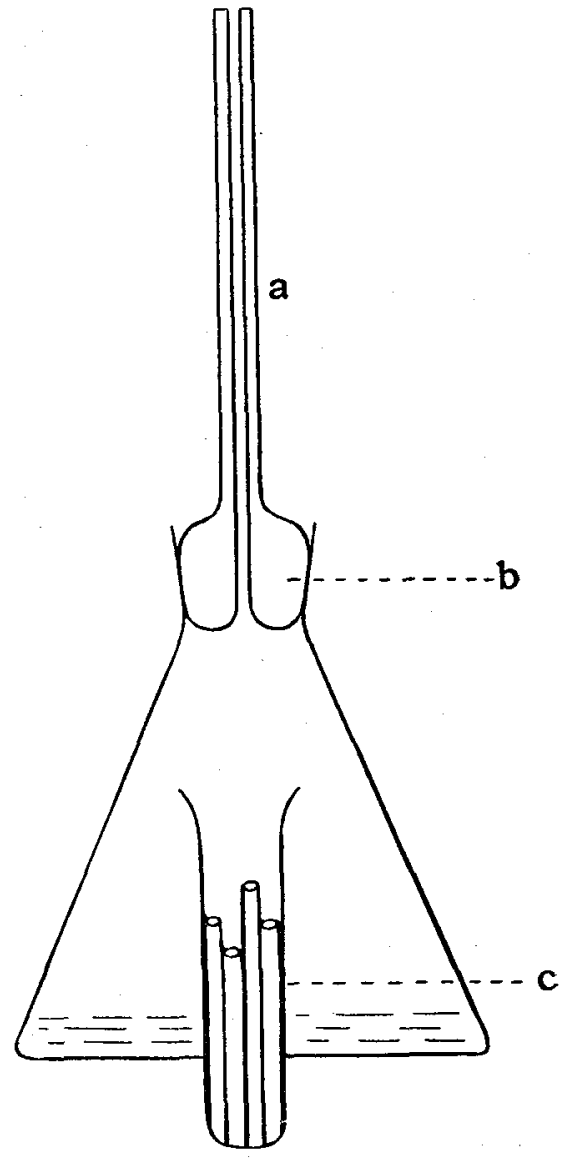

Fig 1.

Lösung gegeben, in der Organe untersucht werden sollen. Die Organe werden mit einer Glaspinzette vorsichtig an die Wand des Gefässes gebracht und in die Lösung gespült. Darauf wird das Gefäss ge-

1) Die Gefässe wurden bei C. Desaga in Heidelberg geblasen (Glasbläser Greiner). 
schlossen und, verbunden mit dem Manometer, in einen gut regulierten, gut gemischten Thermostaten gehängt. Im Thermostaten rotiert eine vertikale, gut zentrierte Achse, die unten Flügel zur Mischung trägt. In der Höhe des Rohres $a$ des im Thermostaten hängenden Apparates sind an der Achse vier Federn angebracht, die leicht an den Gummischlauch am Rohre $a$ anschlagen. Dadurch wird die Flüssigkeit im Gefäss dauernd etwas geschüttelt, die Organe bewegen sich in der Flüssigkeit, so dass die Flüssigkeit dauernd mit Luft gesättigt wird. Wie bei der Barcr oft'schen Analyse wird ein zweiter Kontrollapparat, ohne Organe, in den Thermostaten gehängt, der als Thermobarometer dient. Die Differenz: Druckänderung im Bestimmungsapparat - Druckänderung im Thermobarometer, gibt die Druckänderung, die im Bestimmungsapparat bei gleicher Temperatur und gleichem Barometerstande eingetreten wäre. Aus der Druckabnahme und dem Volumen des Gasraumes (im Gefäss und der Verbindung zum Manometer) kann der Sauerstoffverbrauch berechnet werden, wenn eben, was durch Kontrollen zu erweisen ist, alle Kohlensäure absorbiert und die Flüssigkeit dauernd mit Luft gesättigt wird.

Das Volumen des Gasraumes wird folgendermaassen berechnet: Die Gefässe werden durch Wägen mit Wasser, die Kapillaren des Manometers und des Verbindungsstückes mit Quecksilber geeicht.

Inhalt des Gefässes (Nr. 1): $13,7 \mathrm{ccm}$. Verbindung bis zur Manometerfüssigkeit (Marke 260): $0,7 \mathrm{~cm}$. Davon ist abzuziehen: $2 \mathrm{ccm}$ eingefüllte Lösung, $0,2 \mathrm{ccm}$ Natronlauge, $0,1 \mathrm{ccm}$ für die Glaskapillaren, ca. 0,2 cem für die Organe. Das Volumen des Gasraumes ist also: $(13,7+0,7)-(2+0,2+0,1+0,2)=11,9$ cem. Für die Genauigkeit der Messungen ist zu bedenken, dass $0,1 \mathrm{ccm}$ einen Fehler von nur $1 \%$ bedeutet.

Als Manometerflússigkeit habe ich eine Lösung von gallensaurem Natrium benutzt, deren spezifisches Gewicht so eingerichtet ist, dass der Druck von $10000 \mathrm{~mm}$ dem von $760 \mathrm{~mm} \mathrm{Hg}$. entspricht. Bei einer Druckabnahme um $100 \mathrm{~mm}$ ist dann der Sauerstoffverbrauch $=\frac{11,9 \cdot 100}{10000}=0,119 \mathrm{ccm}$.

Im Verlaufe des Versuches verschwindet Sauerstoff, der Sauerstoffpartiardruck im Gefäss nimmt ab; dann nimmt natürlich auch der in der Flüssigkeit absorbierte Sauerstoff ab. Die entsprechende Grösse ist zu der aus der Druckabnahme berechneten zu addieren. Bei den angegebenen Grössen ist am Ende des Versuches 
in der Lösung $\frac{\left.100 \cdot 2 \cdot \alpha^{1}\right)}{10000}=0,0006 \mathrm{ccm} \mathrm{O}_{2}$ weniger absorbiert. Der Unterschied beträgt also etwa $0,5 \%$ und kann daher vernachlässigt werden.

Ich habe die Volumina nicht auf $0^{\circ}$ und $760 \mathrm{~mm}$ Druck reduziert, da die Korrektur innerhalb der Fehlergrenzen liegen würde. Die Temperatur ist stets angegeben.

Zur Prüfung der Methode wurden folgende Kontrollversuche ausgeführt:

1. Es war zu untersuchen, ob durch das Anschlagen der Federn, durch das dauernde rhythmische Schütteln nicht eine Volumenänderung des Gasraumes verursacht würde (Lockerung des Schlauches oder des Glasstopfens).

2. Genügt die Anordnung zur Absorption der Kohlensäure?

Beide Fragen sind durch eine Versuchsanordnung zu beantworten: In das Oxydationsgefäss werden statt der Nährlösung $2 \mathrm{ccm}{ }^{1 / 100}$ n. Salzsäure gefüllt. Ein kleines U-Röhrchen, das mit einer Lösung von Natriumbicarbonat gefüllt ist, wird so in das Gefäss gestellt, dass sein Inhalt zunächst nicht mit der Salzsäure in Berührung kommt. Der Behälter für die Natronlauge ist wie gewöhnlich gefüllt. Nun wird der Apparat in den Thermostaten gehängt und so lange gewartet, bis die Temperatur ausgeglichen, die Flüssigkeit (Salzsäure) für die Temperatur mit Luft gesättigt ist. Zur Kontrolle wird der Hahn des Manometers geschlossen und geprüft, ob keine Druckänderung (im Vergleich zum Thermobarometer) mehr eintritt. Durch eine Schuttelbewegung wird das U-Röhrchen mit der Bicarbonatlösung umgeworfen, es wird dadurch Kohlensäure entwickelt, das Manometer steigt an. Es ist die Frage, ob und in welcher Zeit der Druck wieder zur ursprünglichen Höhe absinkt.

\section{Versuch 1.}

Gefäss mit $2 \mathrm{ccm} 1 / 100 \mathrm{n} . \mathrm{HCl}, 0,2 \mathrm{ccm} 1 / 1 \mathrm{NaOH}$ und einige Tropfen $\mathrm{NaHCO}_{3}$-Lösung in einem U-Röhrchen wird

7 h $40^{\prime}$ a. $\mathrm{m}$. in den Thermostaten gehängt.

Von $8^{\mathrm{h}} 10^{\prime}$ bis $9^{\mathrm{h}} 10^{\prime}$ keine Änderung des Druckes.

$9 \mathrm{~h} 25^{\prime}$ geschüttelt, $\mathrm{CO}_{2}$ entwickelt.

$9 \mathrm{~h} 30^{\prime}$ Druckänderung: +89

$10 \mathrm{~h} 15^{\prime}$ Druckänderung: +2

$9 \mathrm{~h} 35^{\prime}$

$+53$

10 h 35

9 h $40^{\prime}$

$+29$

10 h $50^{\prime}$

0

9 h $50^{\prime}$

$+15$

11 h $30^{\prime}$

0

$10^{\mathrm{h}} 00^{\prime}$

$+5$

1) $\boldsymbol{\alpha}=$ Absorptionskoeffizient des Sauerstoffes.

Pflüger's Archiv für Physiologie. Bd. 148. 
Versuch 2. Ebenso.

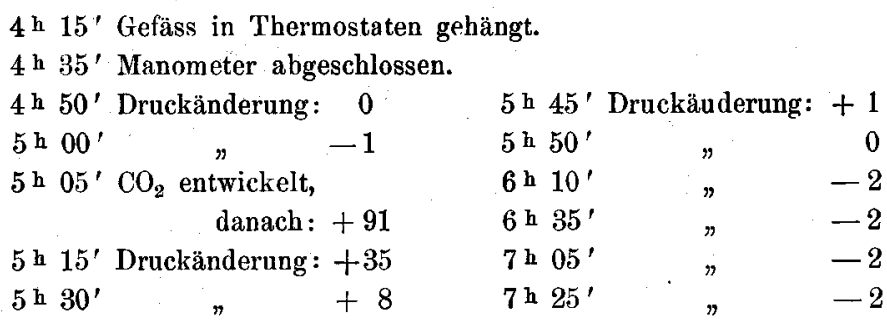

Ergebnis: 1. Absorption von Kohlensäure. Eine Kohlensäuremenge, die einer Druckzunahme von etwa $90 \mathrm{~mm}$ entspricht, also etwa $0,1 \mathrm{ccm}$, wird in $3 / 4-1$ Stunde vollständig absorbiert. Es kommt mehr auf die Vollständigkeit der Absorption als auf deren Geschwindigkeit an, da natürlich in den Versuchen niemals so rasch solche Mengen von Kohlensäure gebildet werden.

2. Die Einstellung des Manometers an dem Gefässe, das durch den Federapparat dauernd leicht geschüttelt wurde, hat sich nicht deutlich geändert: im ersten Versuche blieb die Eiustellung in 2 Stunden absolut gleich, im zweiten Versuch nahm der Druck in beinahe 3 Stunden um $2 \mathrm{~mm}$ ab, was dem Ablesungsfehler entspricht.

3. Genügt das Schütteln des Gefässes durch den Federapparat dazu, die Flüssigkeit, aus der doch durch die Oxydationsprozesse stets Sauerstoff verschwindet, dauernd mit Luft gesättigt zu erhalten? Das ist für eine genügende Sauerstoffversorgung der Organe notwendig. Zur Kontrolle liess ich einen Oxydationsversuch längere Zeit ablaufen und schüttelte dann das Gefäss energisch mit der Hand, dass die Flüssigkeit sicher gesättigt wurde. Es hätte dann eine weitere Volumenabnahme eintreten müssen, wenn die Flüssigkeit nicht gesättigt gewesen wäre.

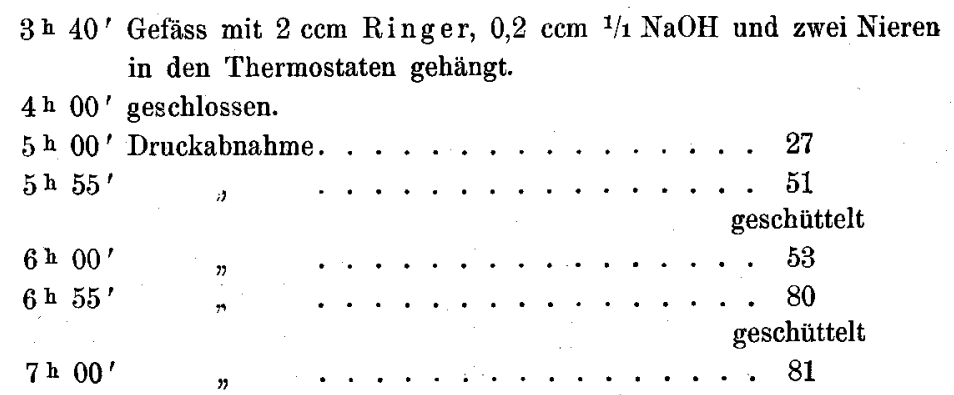

Die Druckabnahme während des Schüttelns und des Temperaturausgleichs danach ist der dauernden Druckabnahme proportional. 
Dass die Flüssigkeit dauernd gesättigt blieb, dass die Kohlensäure dauernd absorbiert wurde, beweist vor allem der gleichmässige Verlauf des Sauerstoffverbrauches in länger dquernden Versuchen (vgl. besonders Nr. 74 u. 84).

Die Brauchbarkeit der Methode an sich ist damit erwiesen. Bei der Bestimmung des Sauerstoffverbrauches überlebender Organe sind aber stets bakterielle Oxydationsprozesse durch besonders sorofältige Prüfung auszuschliessen.

Ich habe natürlich nicht "aseptisch" (das lässt sich gar nicht durchführen), aber peinlich sauber gearbeitet. Vor allem wurden die Lösungen oft frisch bereitet, die Gläsehen vor jedem Versuch mit Bichromat, Schwefelsäure usw. gereinigt.

Zur Kontrolle habe ich folgende Untersuchungen vorgenommen:

1. Ich habe die Organe, die ich zu einer Reihe von Versucben benutzt habe, zerstampft und einen Tropfen des Breies untersucht. Darin fanden sich fast keine oder keine Bakterien ${ }^{1}$ ).

2. Dass die Lösungen und Apparate nicht merklich mit Bakterien verunreinigt sind, beweisen folgende Versuche: Am Ende der Versuche nahm ich die Organe aus der Lösung, verschloss die Gefässe wieder und brachte sie unverändert wieder in den Thermostaten. Ich fand dann in 5-6 Stunden meist keine deutliche Druckabnahme $(2-3 \mathrm{~mm})$, nur einmal eine solche von $9 \mathrm{~mm}$ in 6 Stunden.

3. Ich habe mehrfach benutzte Organe etwa 20 Stunden auf $37-38^{\circ}$ erwärmt. Führte ich mit diesen dann einen Versuch aus, so fand ich eine Druckabnahme von etwa $8 \mathrm{~mm}$ in 2 Stunden.

4. Vor allem möchte ich zum Beweise, dass die Oxydationsprozesse nicht auf Bakterien zu beziehen sind, anführen, dass ich in länger dauernden 'Versuchen einen ausserordentlich gleichmässigen Sauerstoffverbrauch fand, sowie dass in zahlreichen Versuchen der Sauerstoffverbrauch pro $1 \mathrm{~g}$ Nierensubstanz sehr annähernd übereinstimmte.

Ich lasse nun die Protokolle folgen. Während ich die ersten Versuche etwas ausführlicher mitteile, gebe ich von den weiteren nur die Resultate tabellarisch an.

Zwischen den Versuchen (nachts) wurden die Organe stets bei $0^{0}$ aufbewahrt.

1) Benutzte ich zeratörte Organe längere Zeit bei Zimmertemperatur, oder arbeitete ich absichtlich unsauber, so waren fast in jedem Gesichtsfeld Bakterien zu sehen. 


\section{Versuche.}

\section{In isotonischer $\mathrm{Ring} \theta \mathrm{r}-$ Lösung.}

Nr. 74. Grosser ungarischer Frosch 9.

I. 25. April 1912. $9 \mathrm{~h} 15^{\prime}$ a. m. Präparat, beide Nieren in das Gefäss, in Ringer-Lösung.

$9 \mathrm{~h} 45^{\prime}$ Das Gefäss in den Thermostaten $\left(17,3^{\circ}\right)$.

25. April 1912. $10^{\mathrm{h}} 00^{\prime}$ Manometer geschlossen.

$10^{\mathrm{h}}$ 15' Druckabnahme: 11, pro $15^{\prime}: 11$

$10 \mathrm{~h} 30^{\prime} .20, \quad 9$

$10^{\text {h }} 45^{\prime} \quad 28, \quad 8$

11 h $00^{\prime} \quad 39, \quad .11$

$11^{\mathrm{h} \mathrm{h}} 15^{\prime} \quad 49, \quad 10$

$\begin{array}{lll}11 \mathbf{h ~}^{\mathrm{h}} 30^{\prime} & 59, & 10\end{array}$

$11^{\text {h }} 45^{\prime} \quad 67, \quad 8$

$12{\mathrm{~h} 00^{\prime}}^{\circ} \quad 75, \quad 8$

Dann die Nieren in Ringer (Eis).

Resultat: Druckabnahme in der ersten Stunde 39, in der zweiten Stunde 36.

II. 25. April 1912. 3 h $40^{\prime}$ p. m. Dieselben Nieren in Ringer. Apparat in Thermostat $\left(17,3^{\circ}\right)$.

$4 \mathrm{~h}^{\prime} 00^{\prime}$ Apparat geschlossen. $\quad 6 \mathrm{~h}^{\prime} 00^{\prime}$ Druckabnahme: 53

5 h $00^{\prime}$. Druckabnahme: $27 \quad 7^{\circ}$ h $00^{\prime} \quad 81$

Resultat: Druckabnahme in der ersten Stunde 27, in der zweiten Stunde 26, in der dritten Stunde 28.

III. 26. April 1912. $7 \mathrm{~h} 15^{\prime}$ a. m. Dieselben Nieren in Ringer, 17,3 .

7 h $45^{\prime}$ Manometer geschlossen.

9 h $05^{\prime}$ Druckabnahme: 31

9 b $50^{\prime}$

10 h $05^{\prime}$

$10^{\mathrm{h}} 45^{\prime}$

$10^{\text {h }} 50^{\prime} \quad 74$

$11^{\text {h }} 05^{\prime}$

11 h $20^{\prime}$

12 b $20^{\prime} \quad 111$

1 h $45^{\circ}$. 148

2 h $00^{\prime} \quad 155$

2 h $20^{\prime} \quad 164$

3 h $45^{\prime} \quad 202$

4 h $^{\prime} 40^{\prime} \quad 224$

4 h $45^{\prime} \quad 228$

5 h $45^{\prime}$

6 म $45^{\prime} \quad 280$

$7 \mathrm{~h} 45^{\prime} \quad 305$ (geschüttelt)

7 h $50^{\prime}$

7 h $55^{\prime} \quad 310$

8 h $00^{\prime} \quad 312$ 
Über die „osmotischen Eigenschaften“ der Nieren.

Ich habe den Verlauf der Druckabnahme in diesem 12 stündigen Versuch in Fig. 2 graphisch dargestelit. Durch Interpolation ergibt sich die stündliche Druckabnahme:

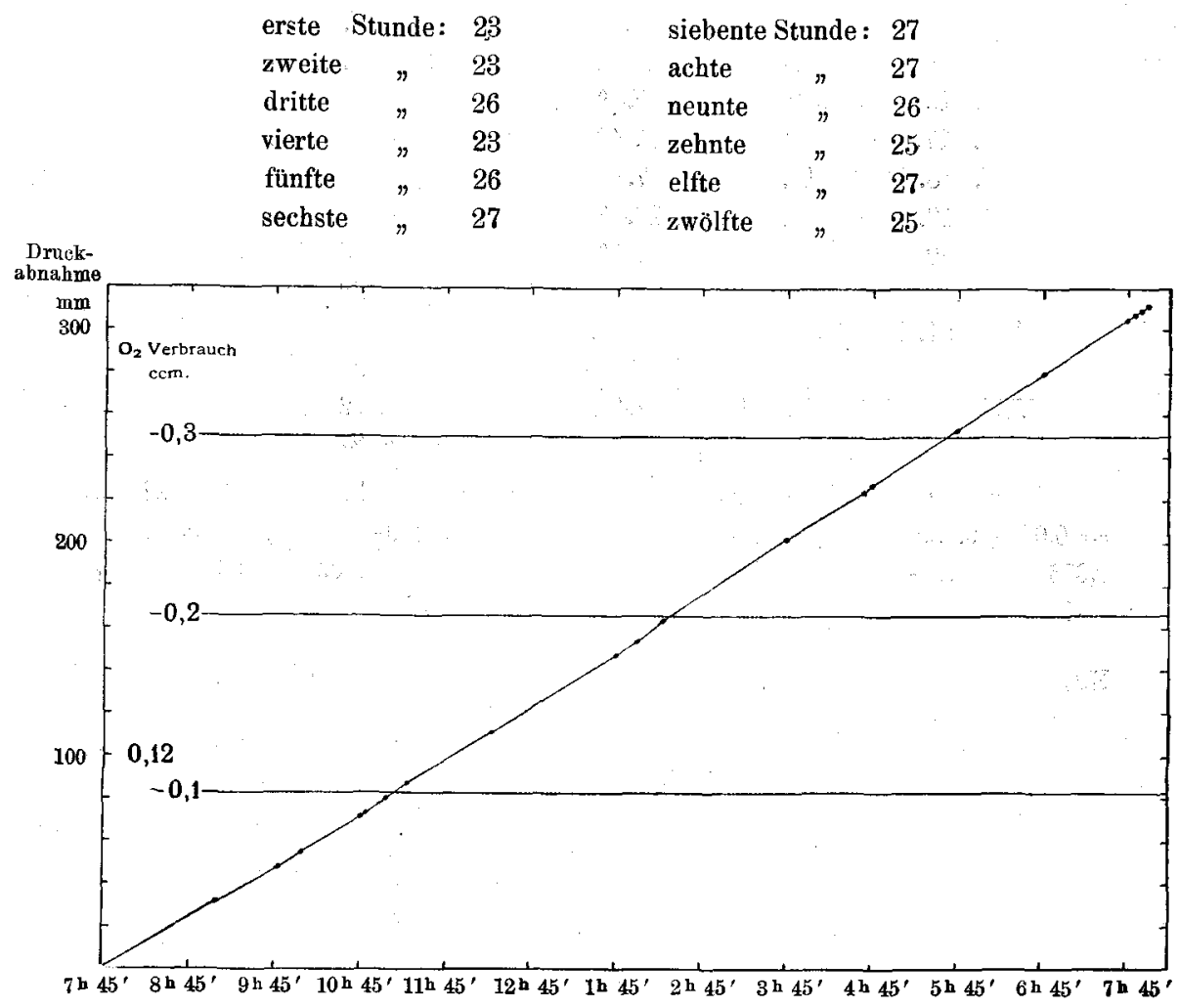

Fig. 2. Zwei Froschnieren. Druckabnahme bzw. Sauerstoffverbrauch in 12 Stunden. Abszisse: Zeit. Ordinate: Druckabnahme in Millimetern bzw. $\mathrm{O}_{2}-$ Verbrauch in Kubikzentimetern.

IV. 27. April 1912. $7 \mathrm{~h} 35^{\prime}$. Dieselben Nieren in Ring er, $17,2^{\circ}$. Druckabnahme in der ersten Stunde 23, in der zweiten. Stunde 23.

Zusammenfassung und Berechnung des Sauerstoffverbrauches pro Stunde.

Am ersten Tage, vormittags: $(36-39 \mathrm{~mm})=0,040-0,044 \mathrm{ccm} \mathrm{O}_{2}$, nachmittags: $(26-28 \mathrm{~mm})=0,029-0,031 \mathrm{ccm} \mathrm{O}_{2}$,

am zweiten Tage: $(23-27 \mathrm{~mm})=0,026-0,030 \mathrm{ccm} \mathrm{O}_{2}$,

am dritten Tage: $(23 \mathrm{~mm})=0,030 \mathrm{~cm} \mathrm{O}_{2}$.

Nr. 75. Grosser ungarischer Frosch. Gewicht beider Nieren: 0,18 g.

I. 15. Mai 1912. $10^{\mathrm{h}} 40^{\prime}$ a. m. bis $8 \mathrm{~h} 00^{\prime}$ p. m. $17,4^{\circ}$. 
Druckabnahme pro Stunde:

in der ersten Stunde . . . . . . . . . 39

in der zweiten bis dritten Stunde. . . . . . . . 29

in der vierten bis sechsten Stunde . . . . . . 27

in der siebenten Stunde . . . . . . . . . . 30

in der achten bis neunten Stunde . . . . 31

II. 16. Mai 1912. Temp. 17,4 $4^{\circ}$ Erste und zweite Stunde je 23

III. 17. Mai 1912. Temp. $17,4^{\circ}$. Erste bis dritte Stunde je 20

IV. 18. Mai 1912. Temp. $17,4^{\circ}$. Erste bis zweite Stunde je 22

V. 19. Mai 1912. Temp. 17,40. Erste bis zweite Stunde je 23

VI. 20. Nai 1912. Temp. $17,4^{\circ}$. Erste Stunde 23

Zweite Stunde 20

VII. 21. Mai 1912. Temp. $17,4^{\circ}$. Erste Stunde 23

Zweite Stunde 21

VIII. 23. Mai 1912. Temp. $17,4^{0}$. Erste Stunde 22

Zweite Stunde 22.

Resultat: Stündlicher Sauers t of fverbrauch: Erster'Tag: (39-27 mm) $=0,043-0,029 \mathrm{ccm} 0_{2}$. Zweiter bis neunter Tag: $(20-23 \mathrm{~mm})=0,022$ bis $0,025 \mathrm{ccm} \mathrm{O}_{2}$. - Pro $1 \mathrm{~g} \mathrm{Nierengewicht:} \mathrm{Erster} \mathrm{Tag:} 0,024-0,016 \mathrm{ccm} \mathrm{O}_{2}$. Folgende Tage: ca. $0,013 \mathrm{ccm} \mathrm{O}_{2}$.

Nr. 76. Grosser ungarischer Frosch. Gewicht beider Nieren: 0,22 g.

20. Mai 1912. Präparat.

21. Mai 1912. Temp. 17,40. Erste Stunde 2:3

Zweite Stunde 25

22. Mai 1912.

Erste Stunde 25

Zweite Stunde 25

23. Mai 1912.

Erste Stunde 22

24. Mai 1912.

Zweite Stunde 21

Erste Stunde 24

Zweite Stunde 26

25. Mai 1912.

Erste Stunde 21

Zweite Stunde 23

Stündlicher Sauerstoffverbrauch: $0,023-0,029 \mathrm{ccm} O_{2}$.

Pro $1 \mathrm{~g} \mathrm{Nierengewicht:} \mathrm{ca.} 0,013 \mathrm{ccm} \mathrm{O}_{2}$.

In allen Versuchen reagiert die Ring e r-Lösung am Ende des Versuches mit Phenolphthalein farblos.

Nr. 77. Versuch mit Serum. Grosser ungarischer Frosch. Gewicht beider Nieren : $0,27 \mathrm{~g}$.

28. Mai 1912. $6^{\text {h }} 00^{\prime}$ p. m. Präparat in Ringer (Eis).

29. Mai 1912. $8^{\text {h }} 00^{\prime}$ a. m. Ringer $17,5^{\circ}$. Erste Stunde 33

Zweite Stunde 35

3 h $00^{\prime}$ p. m. Ringer $17,5^{\circ}$. Erste Stunde 33

Zweite Stunde 33 
29. Mai 1912. 5 h $45^{\prime}$ p. m. Serum ${ }^{1}$ ) $17,5^{\circ}$. Erste Stunde 38 Zweite Stunde 39

30. Mai 1912. 7 h $55^{\prime}$ a. m. Ringer $17,5^{\circ}$. Erste Stunde 32 Zweite Stunde 32

$10^{\mathrm{h}} 45^{\prime} \quad$ Serum $\left.{ }^{2}\right) \mathbf{1 7 , 5 ^ { \circ }}$. Erste Stunde 35 Zweite Stunde 38

Dritte bis vierte Stunde 38.

Nr. 78. Versuch mit Ringer-Lösung, die mit Natriumbicarbonat (statt mit Natronlauge) neutralisiert wurde.

Die gewöhnliche $\mathrm{Ringer}$ - Lösung (mit etwas weniger $\mathrm{CaCl}_{2}$, da sonst $\mathrm{CaCO}_{3}$ ausfällt) wird mit so viel isotonischer Lösung von $\mathrm{NaHCO}_{3}$ versetzt, dass die Mischung mit Phenolphthalein rosa Schimmer, mit Neutralrot gelbe Farbe gibt. Gehalt an $\mathrm{NaHCO}_{3}$ etwa $0,1 \%$. Diese Lösung ist mit Ringer II bezeichnet.

Zwei grosse ungarische Frösche (a und b).

10. Juni 1912. 6 h $00^{\prime}$ p. m. Präparat. a) $0,27 \mathrm{~g}$; b) $0,24 \mathrm{~g}$.

11. Juni 1912. 9 h a. m. Ringer I, Temp. $17,5^{\circ}$. In 2 Stunden: a) 62 , b) 53

12. Juni 1912. $10^{\mathrm{h}}$ a. m. Ring er II, Temp. 17,60. In 2 Stunden: a) 68 , b) 65

Ringer II gibt nach dem Versuche mit Phenolphthalein noch rosa Schimmer.

\section{In anisotonischer $\mathrm{Rin}$ g e $\mathrm{r}-\mathrm{Lösung}$.}

Nr. 79. Grosser ungarischer Frosch.

Leit Lösung Temp. Druckabnahme Gewicht

20. Mai 1912. $12^{\text {h }} 00^{\prime}$

$12^{\mathrm{h}} 36^{\prime}$ bis $22^{\mathrm{h}} 36^{\prime} \quad$ Ringer $\quad \begin{array}{cccc}17,4^{\circ} & - & 0,20 \mathrm{~g}\end{array}$

$2^{\mathrm{h}} 36^{\prime}$ bis $3^{\mathrm{h}} 36^{\prime} \quad-\quad-\quad-\quad 23 \quad-$

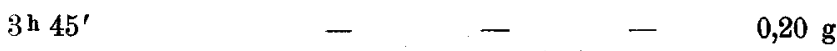

$4^{\mathrm{h}} 00^{\prime} \quad$ Ringer Eis - -

21. Mai 1912. $10^{\mathrm{h}} 00^{\prime}$

$10^{\mathrm{h}} 30^{\prime}$ bis $11^{\mathrm{h}} 30^{\prime}$

$11^{\mathrm{h}} 30^{\prime}$ bis $12^{\mathrm{h}} 30^{\prime}$

$12 \mathrm{~h} 45^{\prime}$

22. Mai 1912. 7 h $20^{\prime}$

8 h $02^{\prime}$ bis $9^{\text {h }} 02^{\prime}$

9 h $02^{\prime}$ bis $10^{\text {h }} 02^{\prime}$

Ringer $\quad{ }_{17,4^{\circ}}$

$10^{\mathrm{h}} 10^{\prime}$

$10^{\mathrm{h}} 30^{\prime}$

$\begin{array}{llll}- & - & 22 & - \\ - & - & - & 0,16 \mathrm{~g}\end{array}$

Ringer Eis $\quad-\quad-$ 
Zeit Lösung Temp. $\begin{gathered}\text { Druckabnahme } \\ \text { pro Stunde }\end{gathered}$ Gewicht

22. Mai 1912. $10^{\mathrm{h}} 55^{\prime}$ bis $11^{\mathrm{h}} 55^{\prime}$ 1/2 Ringer - 23

$\begin{array}{lllll}11 \mathrm{~h}^{\prime} 55^{\prime} \text { bis } 12^{\mathrm{h}} 55^{\prime} & - & - & 22 & - \\ 1 \mathrm{~h} 00^{\prime} & & - & -\end{array}$

1 h $00^{\prime}$

4 h $35^{\prime}$

Ringer Eis

$5^{\text {h }} 05^{\prime}$ bis 7 h $05^{\prime}$

Ringer 17 ,

-

(2) $05^{\prime}$ bis 7 h $05^{\prime}$

23. Mai 1912. 10 上 50 !

$11^{\mathrm{h}} 45^{\prime}$ bis $12^{\mathrm{h}} 45^{\prime}$

Ringer

Eis

$12^{\mathrm{h}} 45^{\prime}$ bis $1^{\text {h }} 45^{\prime}$

ger

$17,4^{0}$

$-$

$0,13 \mathrm{~g}$

24

-

7 h $45^{\prime}$

$8 \mathrm{~h} 30^{\prime}$ bis $9 \mathrm{~h} 30^{\prime}$

Ringer $17,4^{\circ}$

$0,14 \mathrm{~g}$

9 h $30^{\prime}$ bis $10^{\text {h }} 30^{\prime}$

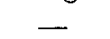

$-$

20

-

$\begin{array}{ll}- & 0,14 \mathrm{~g} \\ 22 & - \\ 22 & -\end{array}$

Nr. 80. Grosser ungarischer Frosch.

Zeit

31. Mai 1912.

1. Juní 1912.

3. Juui 1912. $7 \mathrm{~h} 30^{\prime}$

$$
7 \text { h } 35^{\prime}
$$

8 h $00^{\prime}$ bis $10^{\text {h }} 00^{\prime}$

$10^{\mathrm{h}} 05^{\prime}$

$10 \mathrm{~h} 10^{\prime}$

$10^{\mathrm{h}} 30^{\prime}$ bis $11^{\mathrm{h}} 25^{\prime}$

$11^{\mathrm{h}} 25^{\prime}$ bis $12^{\mathrm{h}} 30^{\prime}$

$12 \mathrm{~h} 35^{\prime}$

$$
4 \text { h } 00^{\prime}
$$

Lösung Temp. $\begin{gathered}\text { Druckabnahme } \\ \text { pro Stunde }\end{gathered}$ Gewicht

$\begin{array}{cccc}\text { Ringer } & \text { Eis } & - & - \\ \text { Ringer } & 17,5^{0} & 37 & - \\ - & - & 35 & - \\ \text { 2/1 Ringer } & 17,5^{0} & - & - \\ - & - & 33 & - \\ - & - & 36 & - \\ 1 / 1 \text { Ringer } & 17,6^{0} & - & - \\ - & - & 27(?) & - \\ - & - & 36 & - \\ 1 / 2 \text { Ringer } & 17,6^{\circ} & - & - \\ - & - & 36 & - \\ - & - & 39 & - \\ 1 / 1 \text { Ringer } & 17,6^{\circ} & - & - \\ - & - & 37 & -\end{array}$

$\begin{array}{lllll}- & - & - & - & 0,35 \mathrm{~g}\end{array}$

Ringer $17,6^{\circ} \quad-\quad-$

- $\quad-\quad 34 \quad-$

$\begin{array}{llll}- & - & - & 0,32 \mathrm{~g}\end{array}$

$\begin{array}{cccc}\text { Wasser } & 17,5^{\circ} & - & - \\ - & - & 34 & -\end{array}$

- $\quad-\quad 33 \quad-$

- $\quad-\quad 0,65 \mathrm{~g}$

$\begin{array}{cccc}\text { Ringer } & \text { Eis } & - & - \\ - & - & - & 0,38 \mathrm{~g}\end{array}$ 


\section{In Kaliumchloridlösung.}

Nr. 81. Grosser ungarischer Frosch.

Zeit Lösung Temp. Druckabnahme pro Stunde Gewicht

15. Mai 1912. $10^{\mathrm{h}} 00^{\prime}$

Ringer $17,4^{\circ}$ pro Stunde -

11 h $00^{\prime}$ bis $12^{\text {h }} 00^{\prime}$

$12 \mathrm{~h} 00^{\prime}$ bis $1^{\mathrm{h}} 45^{\prime}$

$1^{\text {h }} 45^{\prime}$ bis $4^{\text {h }} 40^{\prime}$

$\begin{array}{lll}- & - & 26\end{array}$

$4^{\text {h }} 40^{\prime}$ bis 6 h $10^{\prime}$

$6^{\text {h }} 10^{\prime}$ bis 8 h $00^{\prime}$

16. Mai 1912. $9 \mathrm{~h} 35^{\prime}$ bis $10^{\mathrm{h}} 35^{\prime}$

$10^{\mathrm{h}} 35^{\prime}$ bis $11^{\mathrm{h}} 35^{\prime}$

$11^{\mathrm{h} \mathrm{h}} 45^{\prime}$

$11^{\text {h }} 50^{\prime}$

12 h $30^{\circ}$ bis 2 h $30^{\prime}$

$-$

19

- $\quad-\quad 21$

$2^{\mathrm{h}} 35^{\prime}$

2 h $40^{\prime}$

17. Mai 1912. $9 \mathrm{~h} 30^{\prime}$

$10^{\mathrm{h}} 05^{\prime}$ bis $12^{\mathrm{h}} 50^{\prime}$

- $\quad-\quad 20$

Ringer Eis

Ringer $\quad 17,4^{\circ}$

21

$1 \mathrm{~h}^{\circ} 00^{\prime}$

18. Mai 1912. $10^{\mathrm{h}} 00^{\prime}$

$10^{\mathrm{h}} 35^{\prime}$ bis $12^{\mathrm{h}} 35^{\prime}$

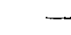

$\begin{array}{cccc}- & - & 19 & - \\ - & - & - & 0,15 \mathrm{~g} \\ \mathrm{KCl} & 17,4^{0} & - & - \\ - & - & 15 & - \\ - & - & - & 0,26 \mathrm{~g} \\ \text { Ringer } & \text { Eis } & - & - \\ \text { Ringer } & 17,4^{0} & - & - \\ - & - & 20 & - \\ - & - & - & 0,16 \mathrm{~g} \\ - & - & - & 0,16 \mathrm{~g} \\ \text { Ringer } & \mathbf{1 7 , 4}^{\circ} & 20 & -\end{array}$

Nr. 82. Grosser ungarischer Frosch.

Zeit

20. Mai 1912. $12^{\mathrm{h}} 00^{\prime}$

$12^{\text {h }} 30^{\prime}$ bis $12^{\mathrm{h}} 36^{\prime}$

$12^{\text {h }} 36^{\prime}$ bis $3 \mathrm{~h}^{\prime} 36^{\prime}$

3 h $45^{\prime}$

21. Mai 1912. 10 h $00^{\prime}$

$10^{\mathrm{h}} 30^{\prime}$ bis $11^{\mathrm{h}} 30^{\prime}$

$11^{\text {h }} 30^{\prime}$ bis $12^{\mathrm{h}} 30^{\prime}$

$12 \mathrm{~h} 45^{\prime}$

22. Mai 1912. 7h $20^{\prime}$

8.h $02^{\prime}$ bis 9 h $02^{\prime}$

9 h $02^{\prime}$ bis $10^{\text {h }} 02^{\prime}$

10 h $10^{\prime}$

$10^{\mathrm{h}} 80^{\prime}$

$10^{\text {h }} 55^{\prime}$ bis 11 h $55^{\prime}$

$11^{\text {h }} 55^{\prime}$ bis $12^{h}$ h $55^{\prime}$

1 h. $00^{\prime}$

23. Mai 1912 . $10^{\text {h }} 50^{\prime}$

$11^{\text {h }} 45^{\prime}$ bis 12 h $45^{\prime}$

$12^{\mathrm{h}} 45^{\prime}$ bis $1^{\text {h }} 45^{\prime}$

$1^{\text {h }} 50^{\prime}$
Lösung

Ringer

Temp. $\underset{\text { pro Stande }}{\text { probnahme Gewicht }}$

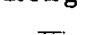

$17,6^{\circ}$

-

$0,22 \mathrm{~g}$

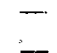

Ringer

$-$

32

$-$

$0,19 \mathrm{~g}$
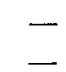

$-$

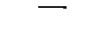

Ringer

$\overline{-}$
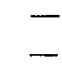

$\mathrm{KCl}$

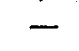

$-$

$17,4^{0}$

- -

- $\quad-$

- -

-

$17,4^{\circ}$

-

-
$-$

26

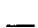

$-$

-

28

-

$0,17 \mathrm{~g}$

$0,17 \mathrm{~g}$

$0,16 \mathrm{~g}$

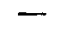

$\longrightarrow$

-

23

21

-

$0,30 \mathrm{~g}$

0,15

32

28 
24. Mai $1912 . \quad 7 \mathrm{~h}^{\prime} 5^{\prime}$

Zeit Lösung Temp. $\begin{gathered}\text { Druckabuahme } \\ \text { pro Stunde Gewicht }\end{gathered}$

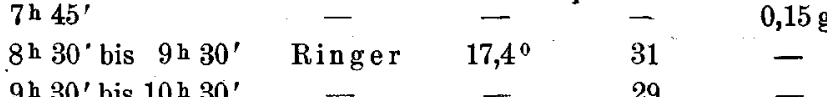

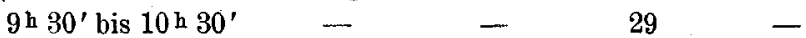

Nr. 83. Grosser ungarischer Frosch.

Zeit Lösung Temp. Druckabnahme Gewicht

28. Mai 1912. 6 h $^{0} 00^{\prime}$ p. m.

Ringer Eis -

29. Mai 1912. 7h $25^{\prime}$ a. m.

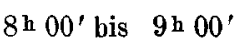

- $\quad-$

$9 \mathrm{~h}^{\prime} 00^{\prime}$ bis $10^{\mathrm{h}} 00^{\prime}$

Ringer $\quad 17,5^{\circ}$

$-m$

$0,21 \mathbf{g}$

$10^{\mathrm{h}} 15^{\prime}$

30. Mai 1912 .

\section{7 h $15^{\prime}$}

$7^{\text {h }} 55^{\prime}$ bis 8 h $55^{\prime}$

-

-

23

-

Ringer Eis

$-$

$0,21 \mathrm{~g}$

8 h $55^{\prime}$ bis 9 h $55^{\prime}$

Ringer

$17,5^{\circ}$

$-$

$0,19 \mathrm{~g}$

$10^{\mathrm{h}} 00^{\prime}$

$11^{\mathrm{h}} 15^{\prime}$

4 h $00^{\prime}$

$4^{\text {h }} 45^{\prime}$ bis 5 h $45^{\prime}$

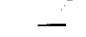

$-$

22

-

$5^{\mathrm{h}} 45^{\prime}$ bis $6 \mathrm{~h}^{\mathrm{h}} 45^{\prime}$

KC

Eis

23

$-$

6 h $50^{\prime}$

31. Mai 1912. $7^{\text {h }} 00^{\prime}$ a. m.

$7 \mathrm{~h} 45^{\prime}$ bis 8 h $45^{\prime}$

KCl

$17,5^{\circ}$

$$
-
$$

- $\quad-$

$-\quad 0,26 \mathrm{~g}$

8 b $45^{\prime}$ bis 9 h $45^{\prime}$

Ringer Eis

18

$-\quad 0,35 \mathrm{~g}$

\section{In Phosphorlösungen.}

Nr. 84. Drei grosse Frösche: I, II und III.

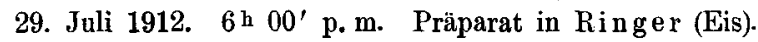

p. = Druckabnahme pro $30^{\prime}$. G. $=$ Gewicht (Gramm). Temp.: $17,1^{\circ}$ bis $17,4^{\circ}$.

Zeit

30. Juli 1912. $\quad 7^{\text {h }} 05^{\prime}$

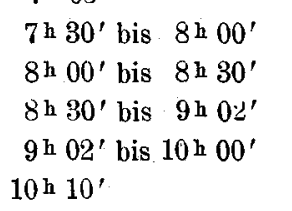

$10^{\mathrm{h}} 30^{\prime}$

$11^{\text {h }} 00^{\prime}$ bis $11^{\text {h }} 30^{\prime}$

$11^{\mathrm{h}} 30^{\prime}$ bis $12^{\mathrm{h}} 00^{\prime}$

$12^{\mathrm{h}} 00^{\prime}$ bis $12 \mathrm{~h} 30^{\prime}$

$12^{\mathrm{h}} 30^{\prime}$ bis $11^{\mathrm{h}} 00^{\prime}$

$1^{\text {h }} 00^{\prime}$ bis $2 \mathrm{~h}^{\prime} 00^{\prime}$
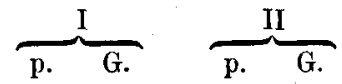

$\overbrace{\text { p. } \quad \text { G. }}^{\text {III }}$

- $0,17 \quad-\quad 0,15$

$14-11$ -

$13-$

12 -

12 -

- 0,18

in Ringer

12

12

13

1

12
$11-13$

$9-$

10 -

$-0,16$

in $\mathrm{K}_{2} \mathrm{HPO}_{4}$

8 -

9

$9-$

$8-$

$8-$
$0,22 \mathrm{~g}$

26

28 
Zeit

30. Juli 1912. $2^{\text {h }} 00^{\prime}$ bis 3 h $00^{\prime}$

3 h $02^{\prime}$ bis $4^{\text {h }} 02^{\prime} \quad 12$ -

$4^{\text {h }} 02^{\prime}$ bis $4^{\text {h }} 32^{\prime} \quad 11$ -

$4^{\text {h }} 32^{\prime}$ bis $5^{\text {h }} 32^{\prime} \quad 12$ -

5 h $32^{\prime}$ bis $6^{\text {h }} 02^{\prime} \quad 13$ -

$6^{\text {h }} 06^{\prime}$ bis 8 h $06^{\prime} \quad 13$ -

$8 \mathrm{~h} 06^{\prime}$ bis $10 \mathrm{~h} 06^{\prime} \quad 12,5 \quad-$

$10^{\text {h }} 06^{\prime}$ bis $10^{\text {h }} 36^{\prime}$ '.

$10^{\text {h }} 36^{\prime}$ bis $11^{\text {h }} 06^{\prime}$

$11^{\text {h }} 15^{\prime}$

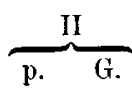

$9-$

$8-$

$9-$

$9-$

$10-$

$10-$

$9,5-$

$9-$

$8-$

- 0,28

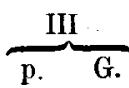

$16-$

$16-$

$14-$

15 -

$16-$

$16-$

$15-$

$15-$

$16-$

- 0,17

Resultat: In Ringer während > 14 Stunden keine Änderung. In $\mathrm{Na}_{2} \mathrm{HPO}_{4}$ etwas grösserer $\mathrm{O}_{\mathrm{g}}$-Verbrauch als in Ring er; während 12 Stunden keine Änderung. In $\mathrm{K}_{2} \mathrm{HPO}_{4}$ vielleicht etwas kleinerer $\mathrm{O}_{2}$-Verbrauch als in Ringer(?); während 12 Stunden keine Änderung; erhebliche Gewichtszunahme. RiugerLösung war etwas sauer (mit Phenolphthalein farblos, mit Neutralrot rot). $\mathrm{Na}_{2} \mathrm{HPO}_{4}$ eben alkalisch (mit Phenolphthalein rosa). Daher wohl der Unterschied im $\mathrm{O}_{2}$ verbrauch.

\section{v. In alkalischen Lösungen.}

Nr. 85. Grosser ungarischer Frosch.

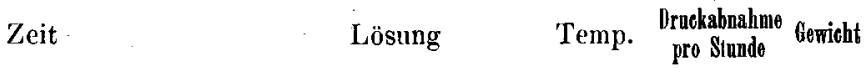

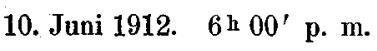

12. Juni 1912. $10^{\text {h }} 00^{\prime}$ a. $\mathrm{m}$.

$10^{\mathrm{h}} 30^{\prime}$ bis 12 h $30^{\prime}$

2 $555^{\prime}$

Ringer

Eis $\quad-\quad 0,27 \mathrm{~g}$

RingerII

$17,6^{\circ}$

- $\quad-$

Ringer II

$\rightarrow 34 \quad-$

3 h $20^{\prime}$ bis $4^{\text {h }} 20^{\prime}$

$4 \mathrm{~h}^{\prime} 20^{\prime}$ bis $5{\mathrm{~h} 20^{\prime}}^{\prime}$

Ringer II+1/1000 $\mathrm{NH}_{3}$

Eis

5 h $20^{\prime}$ bis $6^{\text {h }} 20^{\prime}$

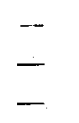

$17,6^{\circ}$

-

$-\quad-$

$40-$

38

34

Nr. 86. Grosser ungarischer Frosch.

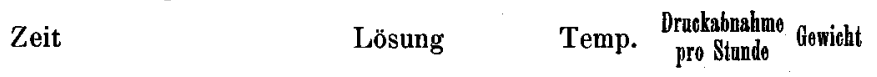

10. Juni 1912. $6 \mathrm{~h}^{0} 0^{\prime}$ p. $\mathrm{m}$.

12. Juni 1912. $10^{\mathrm{h}} 00^{\prime}$ a. $\mathrm{m}$.

$10^{\text {h }} 30^{\prime}$ bis $12^{\text {h }} 30^{\prime}$

Ringer

Eis

- $0,24 \mathrm{~g}$

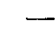

Ringer II

$17,6^{\circ}$

- $\quad-$

2 h $55^{\prime}$,

RingerII

Eis

$3^{\text {h }} 20^{\prime}$ bis $4^{\text {h }} 20^{\prime}$

Ringer II + 1/500 $\mathrm{NH}_{3} \quad 17,6^{0}$

4 h $20^{\prime}$ bis 5 h $20^{\prime}$

5 h $20^{\prime}$ bis 6 h $20^{\prime}$

Ringer II + 1/1000 $\mathrm{NH}_{3}$ sowie Ringer II $+1 / 500 \mathrm{NH}_{3}$ geben nach dem Versuche mit Phenolphthalein rote Farbe. 
Nr. 87. Grosser ungarischer Frosch.

$$
\text { Zeit }
$$

12. Juni 1912. 6 h $00^{\prime}$ p. m.

13. Juni 1912. $9 \mathrm{~h} 30^{\prime}$

$9 \mathrm{~h} 45^{\prime}$

$10^{\text {h }} 17^{\prime}$ bis $12^{\text {h }} 17^{\prime}$

12 h $30^{\prime}$

$3 \mathbf{b} 30^{\prime}$

3 h $33^{\prime}$

3 h $45^{\prime}$ bis 4 h $45^{\prime}$

$4^{\text {h }} 45^{\prime}$ bis $5^{\text {h }} 45^{\prime}$

$6^{\mathrm{h}} 00^{\prime}$

14. Juni 1912. 7 h $30^{\prime}$

$7 \mathrm{~h} 40^{\prime}$

$8^{\text {h }} 10^{\prime}$ bis $10^{\text {h }} 10^{\prime}$
Lösung

Ringer II

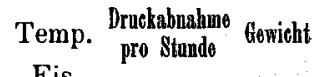

\section{Gefrorene Nieren.}

Nr. 88. Zwei grosse ungarische Frösche. 4 Nieren.

28. Mai 1912. $6^{\text {h }} 00^{\prime}$ p. m. Präparat in Ringer (Eis)

Druckabnahme pro Std.

29. Mai 1912. $7 \mathrm{~h} 30^{\prime}$ in "feuchter Kammer" ${ }^{1}$ ) bei $17,5^{\circ}$

$\begin{array}{lc}8 \mathrm{~h} 00^{\prime} \text { bis } 9 \mathrm{~h} 00^{\prime} & 37 \\ 9 \mathrm{~h} 00^{\prime} \text { bis } 10^{\mathrm{h}} 00^{\prime} & 38 \\ 10^{\mathrm{h}} 05^{\prime} \text { in Gefrierrohr, in } \mathrm{CO}_{2} \text {-Schnee und Äther. } & - \\ 10^{\mathrm{h}} 20^{\prime} \text { aufgetant bei } 37^{\circ} & - \\ 11^{\mathrm{h}} 00^{\prime} \text { bis } 12^{\mathrm{h}} 00^{\prime} & 17 \\ 12^{\mathrm{h}} 00^{\prime} \text { bis } 1 \mathrm{~h} 00^{\prime} & 14 \\ 1 \mathrm{~h} 00^{\prime} \text { bis } 2^{\mathrm{h}} 00^{\prime} & 12\end{array}$

1) In eines der Gefässchen wird $0,5 \mathrm{ccm}$ Ringer gegeben, Natronlauge wie sonst. Die Nieren werden an die Wand gebracht, kleben dort fest. Die Nieren werden dabei natürlich weniger gut mit Sauerstoff versorgt. Nach dem Versuche wird eine Niere zerzupft; im Zupfpräparat keine erhaltenen Zellen, Kerne, körniger Detritus, einige Glomeruli angedeutet. Eine Niere zerstampft. Im Brei keine Bakterien. Zwei Nieren zu osmotischen Versuchen:

29. Mai 1912, 2h $10^{\prime}$

$$
\begin{aligned}
& 3^{\text {h }} 10^{\prime} \\
& 4^{\text {h }} 10^{\prime} \\
& 5^{\text {h }} 20^{\prime} \\
& 6^{\text {h }} 50^{\prime} \\
& 7^{\text {h }} 00^{\prime} \\
& 9 \text { h } 00^{\prime}
\end{aligned}
$$

30. Mai 1912. $8 \mathrm{~h}^{\mathrm{h}} 30^{\prime}$

$$
11^{\text {h }} 30^{\prime}
$$

a) $111 \mathrm{mg}$

beide in Ringer auf Eis

$$
142 \mathrm{mg} \quad 136 \mathrm{mg}
$$

152

161

164 ,

in $1 / 2 \mathrm{Ringer}$

$167 \mathrm{mg}$

169

"beide in 1/1 Ringer

$173 \mathrm{mg}$
142 ,

$151 "$

156 "

in $\mathrm{KCl}$

$160 \mathrm{mg}$

166 "

$167 \mathrm{mg}$ 


\section{Aschènanalysen.}

Die Organe werden nach Neumann verascht, die Schwefelsäure wird abgeraucht; der gelöste Rückstand wird erst mit Bariumchlorid, dann mit Ammoniumkarbonat ausgefällt, Ammoniak wird abgeraucht (ganz leichte Rotglut). Es werden dann zuerst in der gewöhnlichen Weise die Chloride $(\mathrm{NaCl}+\mathrm{KCl})$ gewogen; danach wird Kalium als Kaliumplatinchlorid bestimmt ${ }^{1}$ ).

Nr. 89. 21. Nov. 1911. Zehn kräftige, frische Frösche werden getötet, die Nieren präpariert und in Ringer-Lösung auf Eis gebracht.

$10^{\mathrm{h}} 00^{\prime}$. 20 Nieren wiegen $1,33 \mathrm{~g}$.

$6 \mathrm{~b} 00^{\prime} . \begin{aligned} & 20 \% " \\ & \text { NaCl-Lösung. }\end{aligned}$

22. Nov. 1911. $10^{\text {h }} 00^{\prime}$ a. $m$. 20 Nieren wiegen $1,31 \mathrm{~g}$, dann in $7 \%$ ige Rohrzuckerlösung.

$4^{\text {h }} 00^{\prime}$ p. m. 20 Nieren wiegen $1,10 \mathrm{~g}$.

Verascht. Analyse: $\mathrm{KCl}$. . . . 0,0082 g, $\mathrm{NaCl}$. . 0,0016 g.

Wird die Flüssigkeit in den Harnkanälchen mit Rohrzuckerlösung ausgespült, so enthält $1 \mathrm{~g} \mathrm{Nierensubstanz} \mathrm{2,4} \mathrm{mg} \mathrm{KCl}$ und $1,2 \mathrm{mg} \mathrm{NaCl}$.

Nr. 90. 4. Dez. 1911. 30 Frösche getötet, Nieren präpariert. Je eine Niere eines Frosches zu $\mathrm{A}$ und $\mathrm{B}$, beide in Ringer auf Eis.
5. Dez, $1911.12^{\mathrm{h}} 00^{\prime}$
$6{ }^{\mathrm{h}} 00^{\prime}$
6 h $30^{\prime}$
A $1,62 \mathrm{~g}$
$1,64 \mathrm{~g}$
B $1,58 \mathrm{~g}$
$1,58 \mathrm{~g}$
in Ringer
in $\mathrm{KCl}$
6. Dez. 1911. 9h $30^{\prime}$
$1,65 \mathrm{~g}$
$2,48 \mathrm{~g}$.

Beide Portionen werden mit destilliertem Wasser ausgewaschen und verascht. Von $A$ und $B$ wird je eine Niere zurückbehalten, deren osmotisches Verhalten untersucht wird:

6. Dez. 1911. $10^{\text {h }} 00^{\prime}$. Die eine Niere von $A$ und $B$ :

$\begin{array}{rrrr} & \text { A } 69 \mathrm{mg} & \text { B } 103 \mathrm{mg} \\ \text { beide in Ringer (Eis) }\end{array}$

Beide Nieren behalten lange in Ringer konstantes Gewicht, sind also nicht geschädigt.

1) Ich habe mich genau nach den Vorschriften von Treadwell (Lehrb. d. analyt. Chemie 5. Aufl. 1911) gerichtet. 
Aschenanalyse von $A$ und $B$ :

$$
\begin{aligned}
& \text { A B } \\
& \mathrm{KCl} \ldots \ldots .00,0064 \mathrm{~g} \quad \cdots 0,0154 \mathrm{~g} \\
& \mathrm{NaCl} . \ldots, 0,0054 \mathrm{~g} \quad 0,0028 \mathrm{~g} \\
& \text { (in } 1,64-0,07=1,57 \mathrm{~g} \text { ) (in } 2,48-0,10=2,38 \mathrm{~g} \\
& \text { oder } 1,58-0,07=1,51 \mathrm{~g} \\
& \text { des ursprünglichen Gewichtes). }
\end{aligned}
$$

Nach A enthält $1 \mathrm{~g}$ Nierengewicht:

$$
\begin{aligned}
& \mathrm{KCl} \text {. . . . . . . . 4 4,1 mg } \\
& \mathrm{NaCl} \text {. . . . . . . 3,4 }
\end{aligned}
$$

B enthielt also ursprünglich:

$$
\begin{aligned}
& \mathrm{KCl} \text {. . . . . . . . . . } 6,2 \mathrm{mg} \\
& \mathrm{NaCl} \text {. . . . . . . . 5,2” }
\end{aligned}
$$

$\mathrm{B}$ hat zugenommen um: $2,38-1,51=0,87 \mathrm{~g}$.

B enthielt vor der $\mathrm{KCl}$-Wirkung: $\mathrm{KCl} 6,2 \mathrm{mg}$, $\mathrm{NaCl} 5,2 \mathrm{mg}$

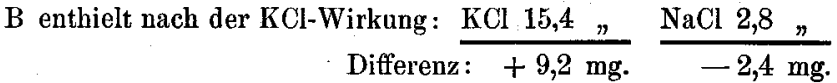

$0,87 \mathrm{~g}$ der $(0,89 \%$ igen) KCl-Lösung enthalten $7,7 \mathrm{mg} \mathrm{KCl}$.

Nun ist aber zu bedenken, dass die NaCl-haltige Flüssigkeit in den Kanälchen durch $\mathrm{KCl}$-Löung ersetzt ist, was sich an der Abnahme des NaCl-Gehaltes zeigt. Der Gehalt an $\mathrm{KCl}$ in dieser "Zwischenflüssigkeit" muss von der gefundenen Menge $\mathrm{KCl}$ abgezogen werden, wenn man die von den Zellen aufgenommene Menge $\mathrm{KCl}$ berechnen will. $2,4 \mathrm{mg} \mathrm{NaCl}$ entsprechen etwa $3 \mathrm{mg} \mathrm{KCl}$. Danach hätten die Zellen etwa $6,2 \mathrm{mg} \mathrm{KCl}$ aufgenommen, während die der Gewichtszunahme der Organe entsprechenden Menge $\mathrm{KCl}$ Lösung 7,7 mg KCl enthält. Danach hätten die Zellen etwas weniger $\mathrm{KCl}$ aufgenommen, als der Aufnahme von KCl-Lösung entspräche. Der Unterschied ist aber unerheblich (zumal ja verschiedene Organe verascht werden!).

Nr. 91. 14. Dez. 1911. 30 kräftige, frische Frösche. Je eine Niere zu A und B (wie Nr. 89). Beide in Ring er auf Eis.
15. Dez. 1911. 10h $00^{\prime}$
$6^{\text {h }} 15^{\prime}$
A $1,54 \mathrm{~g}$
$1,53 \mathrm{~g}$
B $1,58 \mathrm{~g}$
$6 \mathrm{~h} 30^{\prime}$
in Ringer
$1,54 \mathrm{~g}$
$1,61 \mathrm{~g}$
in $\mathrm{KCl}$
16. Dez. 1911. $10^{\text {h }} 00^{\prime}$ a. m.

$1,61 \mathrm{~g} \quad 2,45 \mathrm{~g}$
Je eine Niere aus A und B weiter gewogen, der Rest verascht.

Die einzelnen Nieren wiegen :
16. Dez. 1911. $10^{\mathrm{h}} 00^{\prime}$
A ?
B 67
18. Dez. 1911. $11^{\text {h }} 00^{\prime}$
19. Dez. 1911. $11^{\text {h }} 00^{\prime}$ 
20. Dez 1911 $11 \mathrm{~h} 00^{\prime}$

21. Dez. 1911. $10^{\mathrm{h}} 00^{\prime} \quad 66 \quad 46$

22. Dez. 1911. $10^{\text {h }} 00^{\prime} \quad 66 \quad 46$

Beide zeigen also in Ringer lange Zeit Gewichtskonstanz.

Resultat der Aschenanalysen :

$$
\begin{aligned}
& \text { A B } \\
& \mathrm{KCl} . \ldots . . .0,0045 \mathrm{~g} \quad 0,0116 \mathrm{~g} \\
& \mathrm{NaCl} . . . . .0,0048 \mathrm{~g} \quad 0,0029 \mathrm{~g}
\end{aligned}
$$

Bei B geringer Verlust beim Abrauchen des Ammoniaks.

Auch hier enthalten die Nieren in KCl-Lösung viel mehr $\mathrm{KCl}$, etwas weniger, als der Aufnahme von KCl-Lösung entspräche.

\section{Resultat dieser Versuche.}

In KCl-Lösung nehmen die Nieren - reversibelWasser und Kaliumchlorid auf, und zwar ungefähr (innerhalb der Versuchsfehler) im Verhältnisse der umgebenden, is ot onischen Lösung.

Über die Menge der Flüssigkeit, die in den Harnkanälchen enthalten ist und in offener Verbindung mit der Aussenflüssigkeit steht, lässt sich folgendes sagen :

1. wenn die Flüssigkeit kochsalzfrei (Robrzucker) ist, enthält $1 \mathrm{~g}$ Niere $1,2 \mathrm{mg} \mathrm{NaCl}$;

2. wenn die Flüssigkeit $0,7 \% \mathrm{NaCl}$ enthält, enthält $1 \mathrm{~g}$ Niere 3,4 bzw. $3,1 \mathrm{mg} \mathrm{NaCl}$ (Vers. 89 u. 90), also etwa $2 \mathrm{mg} \mathrm{NaCl}$ mehr. $1 \mathrm{~g}$ Niere enthält also in den offenen Kanälchen etwa $2 \mathrm{mg} \mathrm{NaCl}$ dem entspricht $0,29 \mathrm{~g} \quad 0,7 \%$ ige NaCl-Lösung. Die Flüssigkeit in den Harnkanälchen kann also etwa $30 \%$ des Nierengewichtes ausmachen. Dem entspricht auch ungefäbr die Abnahme des $\mathrm{NaCl}$ in KCl-Lösung. Diese Berechnung soll natürlich nur eine ungefähre Schätzung ermöglichen. Die Werte in den einzelnen Versuchen (verschiedene Tiere) weichen ja nicht unerheblich voneinander ab. 